\title{
AMBIGUITY IN SECURITIZATION MARKETS
}

\author{
A Dissertation \\ Presented to the Faculty of the Graduate School \\ of Cornell University \\ In Partial Fulfillment of the Requirements for the Degree of \\ Doctor of Philosophy
}

by

Alyssa Gray Anderson

August 2013 
(C) 2013 Alyssa Gray Anderson 


\title{
AMBIGUITY IN SECURITIZATION MARKETS
}

\author{
Alyssa Gray Anderson, Ph.D.
}

Cornell University 2013

During the financial crisis of 2008, origination and trading in asset-backed securities markets dropped dramatically. This dissertation considers the role that ambiguity can play in such a market freeze both theoretically and empirically.

I first present a theoretical model with ambiguity averse investors to explain how such a market freeze could occur and to investigate how ambiguity affects both origination and securitization decisions. The model captures many features of the crisis, including market freezes and fire sales, as well as the timing and duration of the crisis. In addition to impacting financial markets, the presence of ambiguity also reduces real economic activity, both when ambiguity is expected and, even more so, once it has been realized. Lastly, I consider the differing implications of ambiguity and risk, as well as the role of policies that help reduce ambiguity during market freezes.

The empirical section of this dissertation analyzes the interdependent roles of risk, ambiguity, and leverage in determining both the structure of securitization tranches and the effectiveness of the Term Asset-Backed Securities Loan Facility (TALF) during the 2008 financial crisis. During the crisis, securitization deals have larger safe tranches and fewer tranches per deal, suggesting a need to reduce the complexity and ambiguity of these securities. I test differences between tranches funded by TALF and those not to examine the interplay between securitization structure and the benefits of TALF in terms of reducing risk, reducing 
ambiguity, and increasing participation through the provision of leverage. I find that, while there is support of all three of these channels, the roles of reducing ambiguity and increasing leverage are most significant. 


\section{BIOGRAPHICAL SKETCH}

Alyssa Gray Anderson obtained her B.A. from Dartmouth College in 2007. She graduated cum laude with a double major in economics and engineering sciences with honors. In addition to her dissertation work on securitization and banking, Alyssa has also conducted research in market microstructure, experimental finance, and behavioral finance. Beginning in August 2013, she will be an economist at the Federal Reserve Board of Governors in Washington, D.C. 


\section{ACKNOWLEDGMENTS}

First and foremost, I would like to thank my advisor, Maureen O'Hara. I really appreciate you helping me see the big picture and ask the important questions. I would also like to thank Andrew Karolyi and David Easley for serving on my committee and giving me valuable feedback on many aspects of this dissertation.

Two other faculty members have been very influential in shaping my time at Cornell. Gideon Saar and Robert Bloomfield have taught me much about research, problem solving, and innovative thinking.

I would also like to thank my fellow Ph.D. students for their guidance and support: David De Angelis, Janet Gao, Yelena Larkin, Hao Li, Christopher Vincent, and Mao Ye.

Finally, I owe a huge debt to my family. I'd like to thank Dad, Gram, and Grandpop for all your support over the years. Gina, I am so grateful for having you to lean on throughout this process. James, you give me much-needed perspective, even when you don't realize it. Amy, I can't say it's been a pleasure going through this experience with you, but having your emotional and mental support and commiseration throughout has been invaluable. Mom, as always, I can't thank you enough for opening all those doors for me and instilling me with the motivation to walk through them. 


\section{TABLE OF CONTENTS}

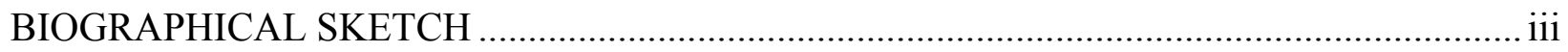

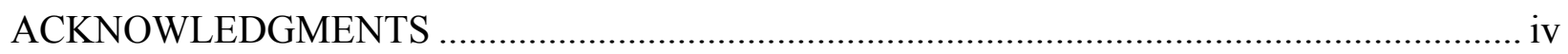

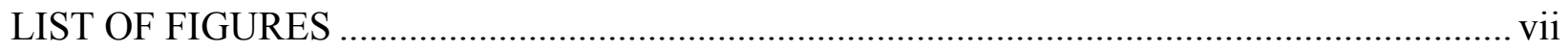

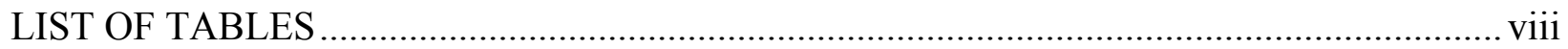

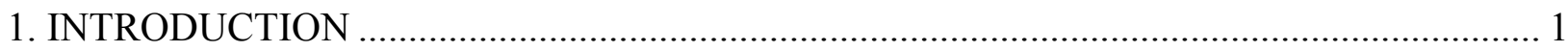

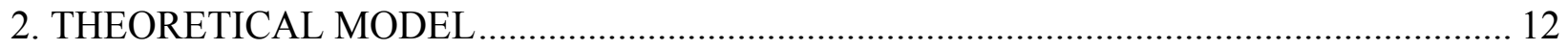

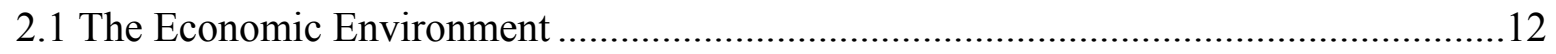

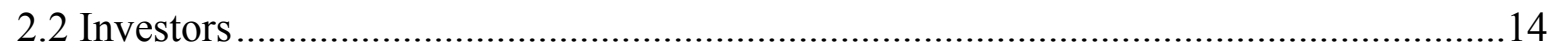

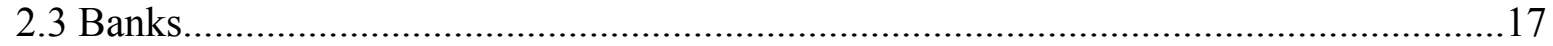

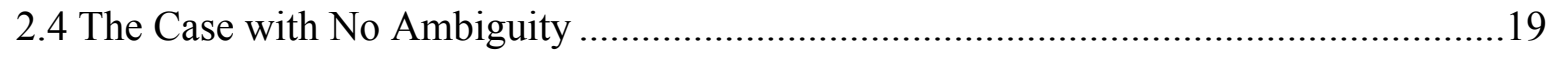

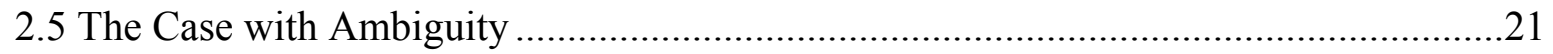

3. CHARACTERIZATION OF THE BANK'S OPTIMAL DECISION .................................. 24

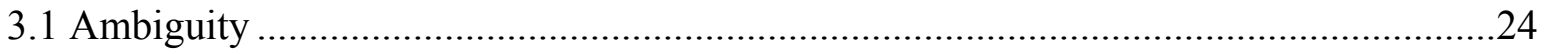

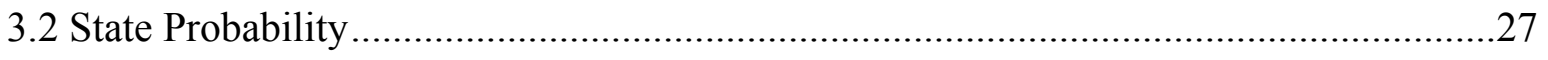

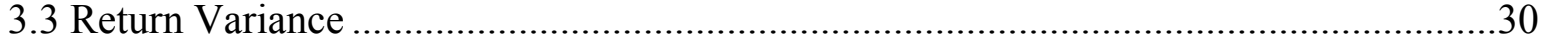

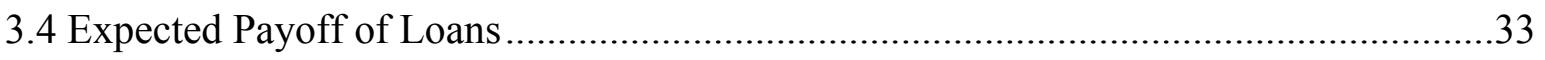

3.5 Expected Payoff of Additional Investment Opportunities.........................................36

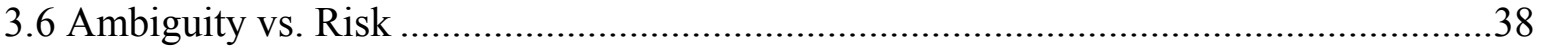

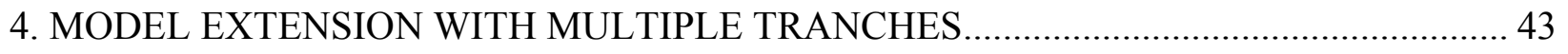

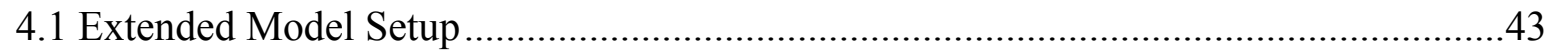

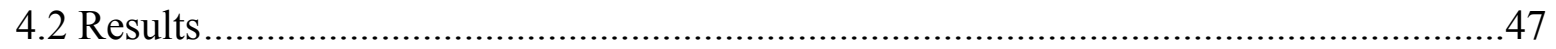

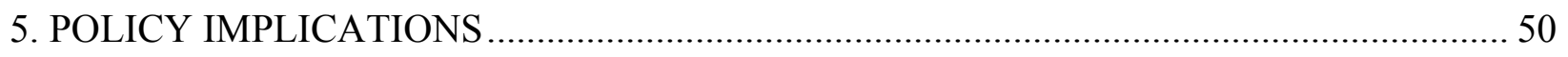

6. DISCUSSION OF MODEL IMPLICATIONS .............................................................. 54

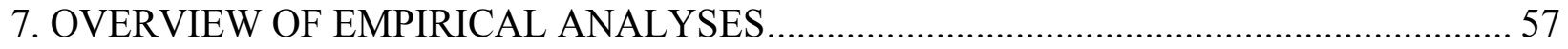

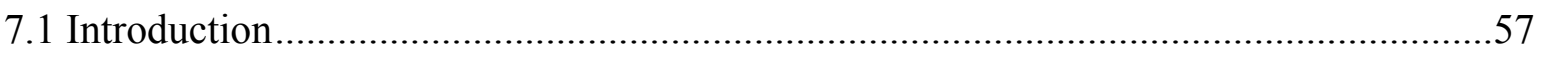

7.2 Institutional Background on TALF ..................................................................61

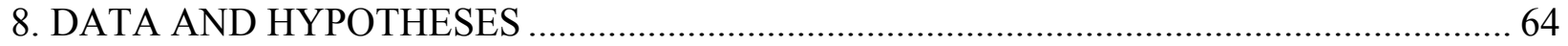

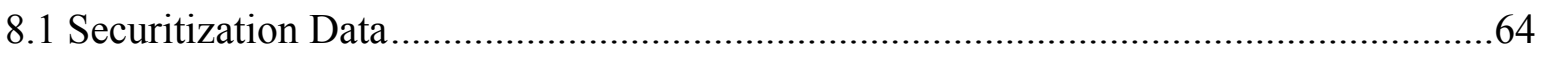

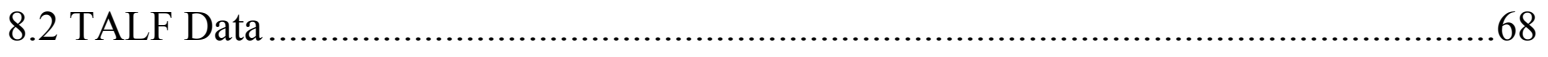

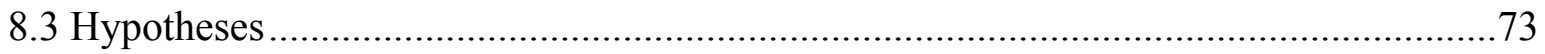




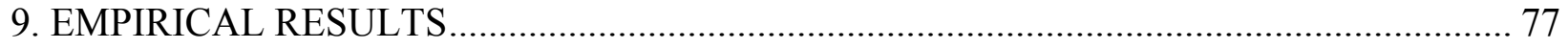

9.1 Tranche Structure during the Crisis ............................................................................ 77

9.2 Assessing the Channels through which TALF Operates ...........................................84

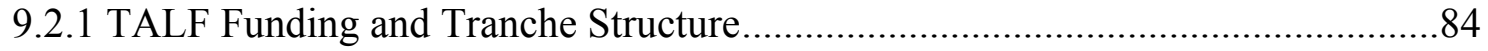

9.2.2 TALF Participation, Tranche Structure, and Loan Performance..........................89

9.3 Security-Level vs. Market-Level Effects .............................................................92

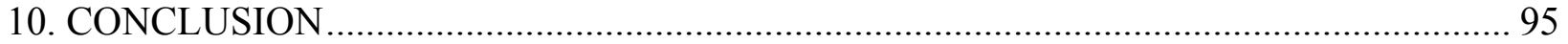

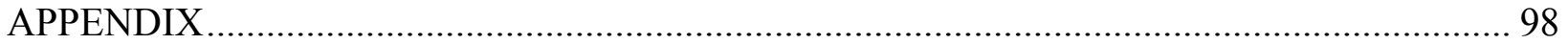

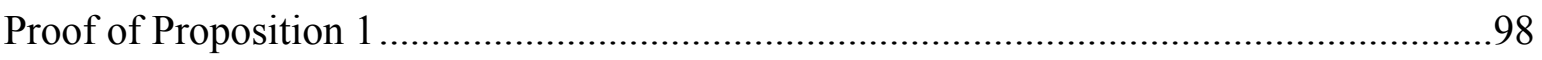

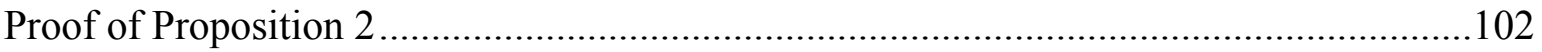

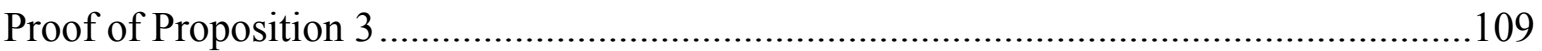

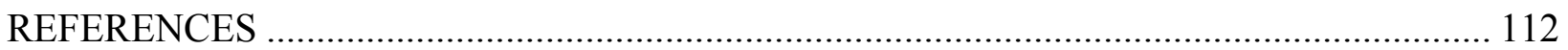




\section{LIST OF FIGURES}

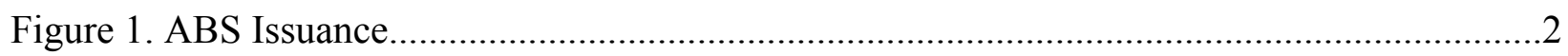

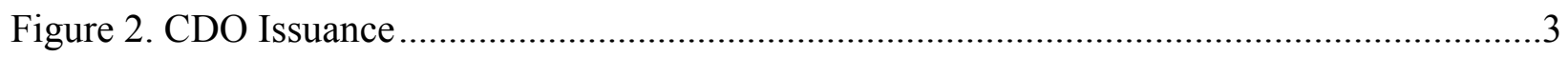

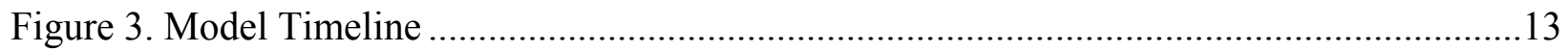

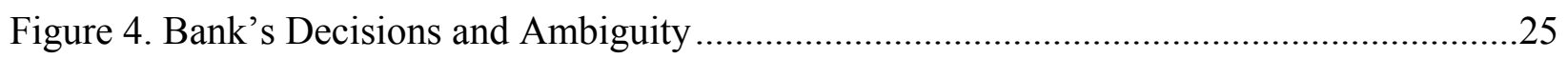

Figure 5. Bank's Decisions and the State Probability ........................................................29

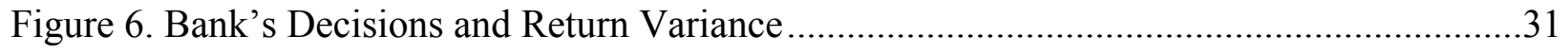

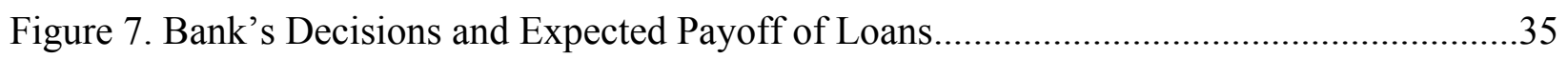

Figure 8. Bank's Decisions and the Expected Payoff of Additional Investments .......................37

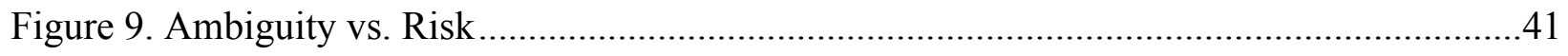

Figure 10. Bank's Decisions with Two Tranches .....................................................................48

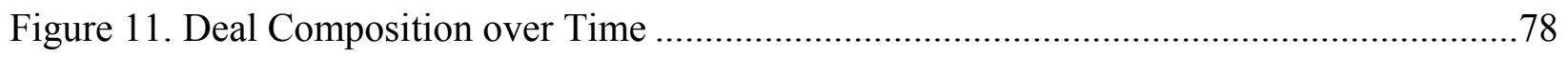

Figure 12. Deal Composition and TALF Funding ....................................................... 85 


\section{LIST OF TABLES}

Table 1. Summary Statistics of Securitization Tranches ........................................................65

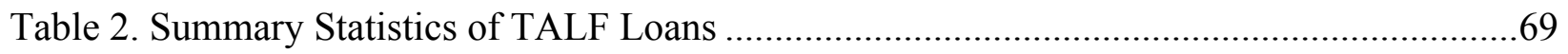

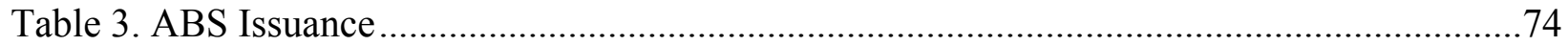

Table 4. Univariate Analysis of Tranche Structure across Time .............................................80

Table 5. Multivariate Analysis of TALF Funding and Tranche Structure ...............................87

Table 6. Multivariate Analysis of TALF Participation, Tranche Structure, and Loan

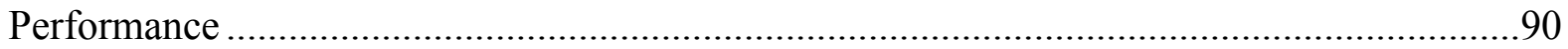




\section{CHAPTER 1}

\section{INTRODUCTION}

Financial intermediation has traditionally involved banks taking deposits and making loans to firms and consumers. Recently, however, the intermediation process has become market based, in that banks also borrow money, securitize loans, and buy and sell securities in the open market. This has been enabled by the development of significant markets in asset-backed securities (ABS) and collateralized debt obligations (CDOs). ABS markets facilitate trade in securities whose values are based on the cash flows of underlying assets such as mortgages (MBS), car loans, student loans, or credit card receivables. The value of CDOs depends on underlying collateral including high yield corporate loans (CLOs), high yield and investment grade corporate bonds (CBOs), and other securitized products such as ABS, MBS, or other CDOs. This securitization process has created securities that, prior to the financial crisis of 2008, were in high demand by investors.

However, during the recent financial crisis, many markets, including those of assetbacked securities and CDOs, suffered from a lack of origination. In October 2008, the volume in these markets essentially went to zero, as investors were unwilling to participate at any offered price. Additionally, issuance of new securities ceased in many asset classes of ABS, as shown in Figure 1. Contrary to standard economic theories, which suggest that the market should be able to find an equilibrium price, trade halted in these markets. ABS markets did not begin to recover until early 2009 when the Federal Reserve offered support programs to encourage investor 


\section{Figure 1. ABS Issuance}

This figure shows the quarterly US issuance of asset-backed securities by class from 2008 to 2012 . Source: SIFMA

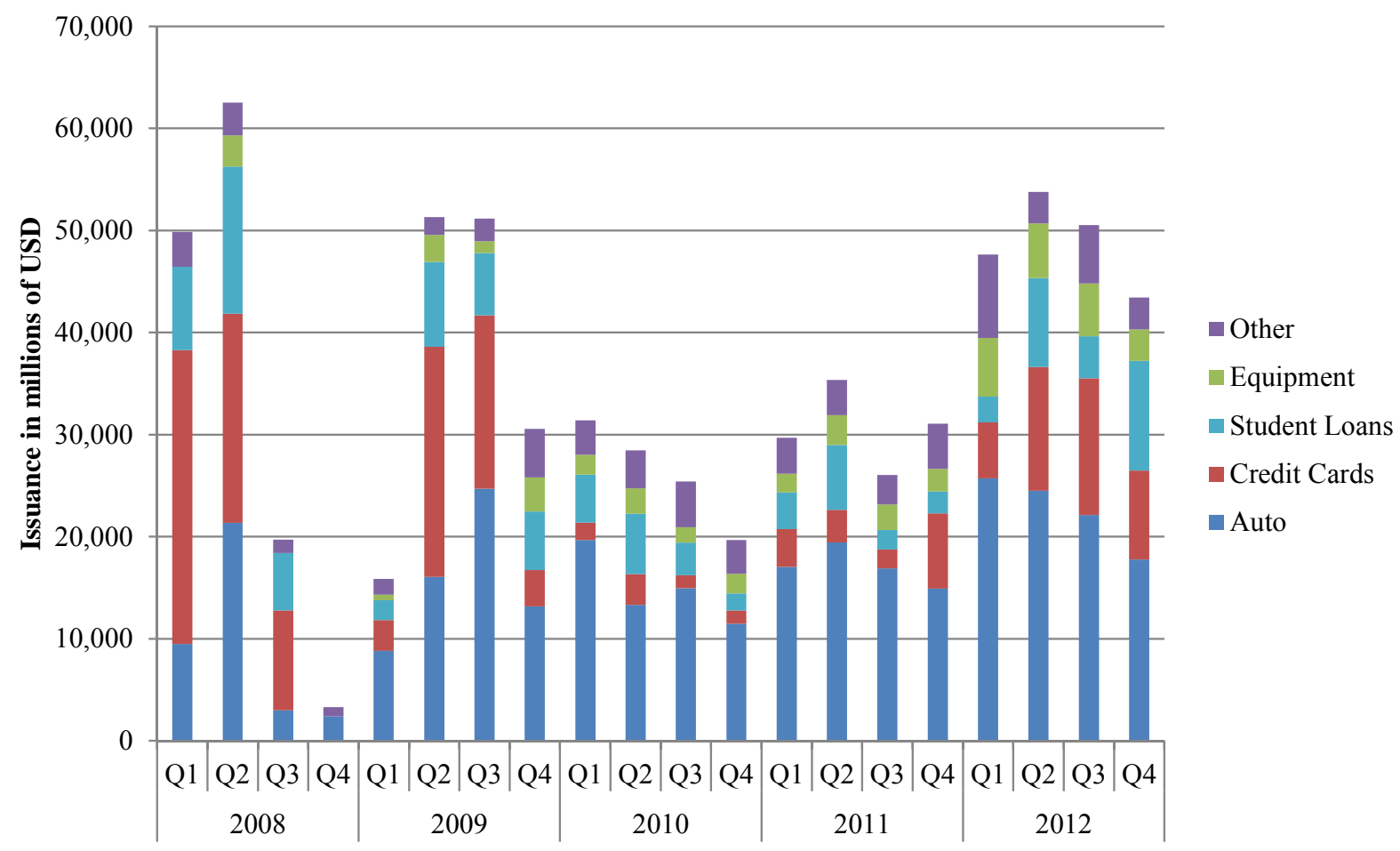




\section{Figure 2. CDO Issuance}

This figure shows the annual global issuance of collateralized debt obligations by collateral type from 2000 to 2012. CLOs are securities with corporate loans as collateral. CBOs are securities with high yield or investment grade corporate bonds as collateral. Structured Finance CDOs are securities with assets such as RMBS, CMBS, ABS, or other CDOs as collateral.

Source: SIFMA

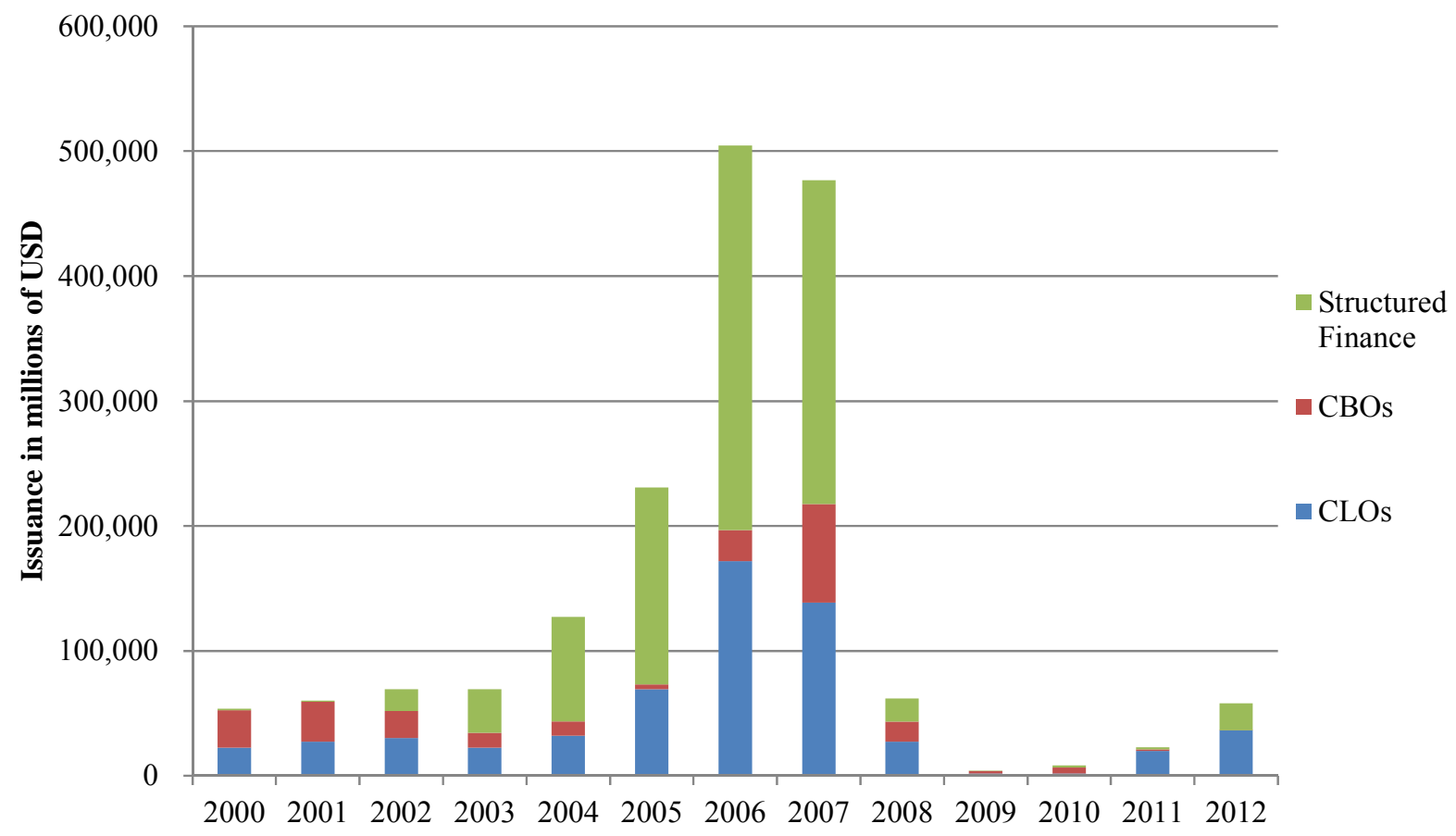


participation. However other markets, such as those of CDOs, which were not supported by any government programs during the crisis, have still not recovered, as seen in Figure 2.

This dissertation develops a model of financial intermediation to explain the market freeze seen in securitization markets during the crisis using ambiguity aversion. The first goal of the model is to analyze how ambiguity aversion among investors influences both their participation decision and the banks' securitization decision. While previous work has shown how ambiguity can lead to limited participation by investors, this model looks more specifically at the context of securitization markets. Securitization markets may be more susceptible to ambiguity given the complexity of the structure of these securities. Asset-backed securities are comprised of many underlying assets with complicated default probabilities and correlations, which make assessing the value of these securities difficult for some investors. This is potentially why markets trading ABS and CDOs completely collapsed during the crisis, while other markets were more resilient. Further, the additional complexity of CDOs may contribute to their continued stagnation. The second goal of the model is to understand how real investment, in the form of the number of loans undertaken, is influenced by the possibility of facing ambiguity averse investors.

The role of ambiguity aversion is illustrated by the Ellsberg paradox. ${ }^{1}$ Ellsberg (1961) shows that when individuals face uncertainty, they do not act as if they have a single prior, thus violating the independence axiom of Expected Utility Theory discussed by von Neumann and Morgenstern (1947) and Savage (1954). The distinction between risk and ambiguity was first

\footnotetext{
${ }^{1}$ In Ellsberg's experiment, an individual is presented with two urns. Urn one has 50 black balls and 50 red balls. Urn 2 has 100 balls in some unknown proportion of black and red. When given the choice between $\$ 100$ if a black ball is drawn from urn 1 and $\$ 0$ otherwise, and $\$ 100$ if a black ball is drawn from urn 2 and $\$ 0$ otherwise, most individuals choose the former gamble. This implies that the expected probability of black balls in urn 2 is less than 0.5 . When given the same choices except with a payoff if a red ball is drawn, most individuals will again choose the gamble with urn 1. This implies that the expected probability of red balls in urn 2 is less than 0.5 . However, the probability of both black and red cannot be less than 0.5, suggesting that the individual has multiple priors due to the uncertainty of the distribution.
} 
discussed by Knight (1921) and was formally developed by Schmeidler (1989) and Gilboa and Schmeidler (1989). They suggest that an individual facing uncertainty will use their minimum expected utility when making a decision. That is, from among his set of priors, the individual will consider the one that yields the worst-case outcome. This max-min utility will characterize ambiguity averse investors in my model.

The economy considered consists of banks, investors, and depositors. Banks can originate risky loans with normally distributed returns. They can then either retain or securitize these loans and sell them to risk averse and ambiguity averse investors. There are two states of the world one in which investors face ambiguity and one in which they do not. Given the possibility of facing ambiguity averse investors, who may choose not to participate if ambiguity is severe enough, banks originate fewer loans than they would otherwise.

The model captures a significant feature of the crisis, namely that it was not just the financial markets that froze. In addition, origination of new loans declined in the real economy. Banks did not invest in new loans, as they could not find buyers for their newly-created securities and had limited funding due to being stuck holding older loans that they could not sell. An important aspect of this model is the delay between when banks can originate loans and when they can sell them to investors. As discussed by Jiang, Nelson, and Vytlacil (2012), there is often a several month gap between when a loan is originated and when it is sold, given the time it takes to acquire and tranche a pool of securities. This delay is longer for non-conforming, higher risk, and other non-standard loans. The information revealed to investors during this time will influence the amount they are willing to purchase and the price they are willing to pay. In this model, the level of ambiguity is unknown during origination but is revealed prior to securitization. This can result in banks being left holding their loans if markets dry up, which is 
consistent with what happened during the crisis (Erel, Nadauld, \& Stulz, 2011). As the model shows, ambiguity can have significant real effects on the supply of loans, both when ambiguity is expected and, even more so, once ambiguity is realized.

In addition to its impact on origination, the model shows how the presence of ambiguity can affect the level of securitization. In many cases, banks securitize more of their loans when investors do not face ambiguity. Securitization in the state with ambiguity is significantly reduced in cases where ambiguity is high, additional investment opportunities are less profitable, or expected payoffs are low. However, there are also cases in which securitization is high when investors face ambiguity. In these situations, the potential ambiguity faced by investors is relatively low or the payoffs to securitization are relatively high. Therefore, banks originate a large number of loans by using deposits. In order to repay their debt, banks may be forced to sell securities at fire sale prices if the state with ambiguity is realized. Therefore, the model can create both market freezes and fire sales, depending on the banks' debt constraint, which is in turn determined by the prevalence of ambiguity and the attractiveness of securitization.

The model also lends itself to a comparison of the differing impacts of risk and ambiguity. Both increased risk, as measured by the variance of the distribution of returns, and increased ambiguity will reduce the price investors are willing to pay for securities. However, the bank can counteract the negative affect of risk by selling fewer securities because price is a function of both risk and quantity. The price impact of higher ambiguity, on the other hand, is strictly negative. Therefore, while the impact of risk on securitization is gradual, the impact of ambiguity is more blunt. Because of this, in certain regions, a small change in the level of ambiguity can have a large effect on the origination and securitization decisions of the bank. As 
a result, market characteristics or policies that are able to reduce ambiguity can be very effective in improving market conditions.

Given the adverse effects of ambiguity on investor participation, securitization market liquidity, and the availability of credit in the real economy through bank lending, the model can be used to address the role of policy decisions in ameliorating these issues. In particular, I consider policies that reduce ambiguity for investors. A prime example of such a policy is the Term Asset-Backed Securities Loan Facility (TALF), which offered loans to investors in the ABS market during the financial crisis from early 2009 through mid-2010. Since these loans were nonrecourse, the program essentially put a floor on the amount of losses an investor could face. This improved the worst-case outcome considered by investors, thereby reducing the amount of ambiguity present. Given the distinct equilibria that can arise as a result of ambiguity, policies that reduce ambiguity can have a positive impact on both origination in the real economy and participation in the financial markets, provided they shift ambiguity enough to change the market equilibrium.

This dissertation is related to several areas of the existing literature. First, it adds to the literature on limited market participation. Several explanations have been proposed to explain limited participation. Numerous studies, beginning with Allen and Gale (1994), have shown that a fixed participation cost can prevent full participation and can lead to a magnified impact of a small liquidity shock. However, models that are based on costs that are constant over time cannot explain the sudden change in market participation seen during the financial crisis. Alternatively, recent studies, including, among others, Cao, Wang, and Zhang (2005), Garlappi, Uppal, and Wang (2007), Epstein and Schneider (2007), Easley and O'Hara (2009, 2010), and Guidolin and Rinaldi $(2009,2010)$, have shown that ambiguity aversion can cause limited participation. The 
current model adds to this group of papers by allowing the degree of ambiguity to vary across states, which helps explain the sudden shift in participation seen in the securitization markets during the recent crisis.

Second, the model contributes to the literature on market freezes, specifically in the context of securitization markets. ${ }^{2}$ There are several existing explanations of why market freezes can occur, including adverse selection, regulatory arbitrage, and neglected risks. These theories are examined in detail by Tirole (2011) and Leitner (2011) and will be discussed further in Chapter 6. Briefly, the theory of adverse selection suggests that intermediaries have better information about loans than investors do, so securitization can be used to create informationally insensitive securities. However, when investors become uncertain of the value of these securities, the market can break down. ${ }^{3}$ Regulatory arbitrage suggests that banks hold securities as opposed to the underlying loans to take advantage of lower capital requirements. This allows them to increase their leverage, but when prices decline, they may be unable to sell their securities while still meeting their capital requirements, resulting in a market freeze. ${ }^{4}$ Lastly, the theory of neglected risks, developed by Gennaioli, Shleifer, and Vishny $(2011,2012)$, proposes that market participants ignore certain tail risks, thereby overinvesting in securities that are thought to be safe. When it is revealed that this is not the case, these markets can cease to function. Coval, Jurek, and Stafford (2009) also show that market freezes in securitization can result from imprecise models that underestimate or neglect certain risks.

An alternative explanation that is presented herein is ambiguity aversion, which is not mutually exclusive of these preceding theories, but serves to capture some features of the crisis

\footnotetext{
${ }^{2}$ This is also closely related to the literature on fire sales. See, among others, Coval and Stafford (2007), Diamond and Rajan (2010), and Shleifer and Vishny (2010a).

${ }^{3}$ See, among others, DeMarzo and Duffie (1990), Riddiough (1997), DeMarzo (2005), Pagano and Volpin (2010), and Dang, Gorton, and Holmström (2010).

${ }^{4}$ See, among others, Calomiris and Mason (2004), Leitner (2011), and Acharya, Schnabl, and Suarez (2011).
} 
that were not previously addressed. To the best of my knowledge, Uhlig (2010) is the only other paper that looks at ambiguity aversion in the context of securitization. Uhlig also argues that ambiguity aversion can capture features of the crisis that adverse selection cannot. In particular, under ambiguity aversion, a larger market share of distressed institutions can lead to a systemic bank run, as was seen during the crisis, while adverse selection predicts the opposite.

Similarly, my model explains other features of the crisis that the alternative theories do not. Specifically, my model explains the freeze both in the financial markets and in lending in the real economy. Additionally, it examines the securitization decision of the bank more specifically to understand how the bank's retention decision is made. Lastly, the model can explain both the timing and duration of the market freeze seen during the crisis. Despite bad news beginning to leak into the market as early as mid-2007, securitization markets did not crash until late 2008. This crash was largely unanticipated by investors, as indicated by the spreads on these securities, which suggests that it was not just news about increased risks that froze markets. The neglected risks hypothesis is the only one of these prior theories that can account for this delay in the crash by suggesting that there were risks that investors were unaware of until late 2008. However, it is unclear why, once these neglected risks are realized, the market should continue to falter. My model suggests that, given the presence of ambiguity, the market freeze can persist as long as investors remain uncertain about the expected outcome. This feature is particularly relevant for the CDO markets, where issuance continues to stagnate.

Lastly, the model contributes to understanding the link between financial intermediation (banks' securitization decisions) and the real economy (banks' loan origination decisions). Of particular interest is how limited market participation of investors due to ambiguity can influence the number of loans intermediaries are willing to finance. The prevailing literature suggests that 
securitization will increase investment both by providing a source of funding and by allowing intermediaries to initiate loans but then securitize and sell them, reducing their own risk exposure. ${ }^{5}$ However, this dissertation demonstrates that the origination benefits of securitization may be reduced if there is uncertainty over whether the securities can in fact be sold.

To the best of my knowledge, the only paper aside from this one that relates changes in investor outlook in securitization markets to the real economy is that of Shleifer and Vishny (2010b), who develop a model of market based financial intermediation with investor sentiment. They show that the ability of banks to securitize loans increases real investment, but also increases the cyclicality of lending. Banks securitize as much as possible initially; they do not retain any cash to buy securities in the case of a downturn. They also hold securities in downturns in order to realize future expected gains, rather than sell them to initiate new loans. Additionally, the authors find that capital injections during bad times do not help create new investments, but can help stabilize prices, as banks use new capital to buy distressed assets. My model is distinct from Shleifer and Vishny (2010b) in three important ways. First, it has securities with fundamental risk; second, it endogenizes prices that are not known to any market participants until after origination decisions have been made; and third, it allows for limited participation with risk and ambiguity averse investors.

The remainder of the dissertation is organized as follows. Chapter 2 presents a model of loan origination and securitization by banks in an economy with risk and ambiguity averse investors. I solve for the optimal demand functions of investors, which are then used to solve for the banks' optimal origination and retention decisions. Chapter 3 characterizes the equilibrium and discusses the impacts of key parameters, including the level of ambiguity, the probability of the state in which investors face ambiguity, return variance, the expected payoff of loans, and the

\footnotetext{
${ }^{5}$ See, among others, Shin (2009), Nadauld and Sherlund (2009), and Shleifer and Vishny (2010b).
} 
expected payoff of additional investment opportunities, on the banks' optimal decisions. Chapter 4 proposes an extension to the model incorporating both a safe tranche and a risky tranche. Chapter 5 considers the policy implications of the model, including a discussion of the impact of TALF. Chapter 6 discusses this model in relation to other existing theories, as well as the model's empirical implications. Chapter 7 introduces the empirical analysis and discusses some institutional background on TALF. Chapter 8 describes the data used and outlines the hypotheses tested. Chapter 9 presents the empirical results. Chapter 10 concludes. 


\section{CHAPTER 2}

\section{THEORETICAL MODEL}

\subsection{The Economic Environment}

I consider a model of financial intermediation with securitization. In the model, banks can originate risky loans for a cost of $\$ 1$. These loans have a final payoff of $V$ which is normally distributed with mean $\widehat{V}>1$ and variance $\sigma^{2}$. All loans are homogeneous. There is an infinite supply of loans that can be undertaken so banks are only limited in the number of loans they can originate by their funding. In order to differentiate between these positive NPV loans and those with $\widehat{V}<1$, an informed intermediary is necessary to screen and monitor the loans. Therefore, only banks can originate new loans.

There are three types of participants in the model - banks, depositors, and investors. Banks can either hold cash or originate loans using their equity and money borrowed from depositors. Depositors receive a riskless return of $r \geq 0$ after loan payoffs are realized. After a bank has originated new loans, it can either hold them itself or securitize and sell them. If the bank chooses to securitize its loans, it also chooses the fraction of the loans it retains. The remainder is sold to risk and ambiguity averse investors. With the cash on hand after securitizing, the bank can invest in new additional loans. These loans are essentially the same as the loans available initially in that they represent loans to individuals or firms. However, these loans will be modeled much more simply for the purpose of tractability. Specifically, banks can

invest $Y$ in loans that have an expected return of $i \in\left[0, i_{\text {max }}\right]$. Additionally, these loans cannot be securitized and pay off at the same time as the initial loans. The presence of these additional 
investment opportunities is the primary driver of securitization in the model. ${ }^{6}$ The bank chooses to either retain or securitize loans strictly contingent on the relative payoffs of the two options, given the price impact of selling more securities and the benefits of additional investments. The role of adverse selection and the "skin in the game" benefits of retention, as discussed by Demiroglu and James (2012), and the use of securitization for regulatory arbitrage of capital requirements are not modeled here.

In this model, there are three time periods. At time 0 , banks borrow money from depositors and originate loans. There are two possible states of the world and uncertainty over the state is resolved at the beginning of time 1. Banks then choose to retain the loans on their books or securitize and sell them to investors. With the cash on hand at time 1, banks can invest in another round of loans. All loan payoffs are realized and depositors are repaid at time 2. The timing of the model is shown in Figure 3 below.

Figure 3. Model Timeline

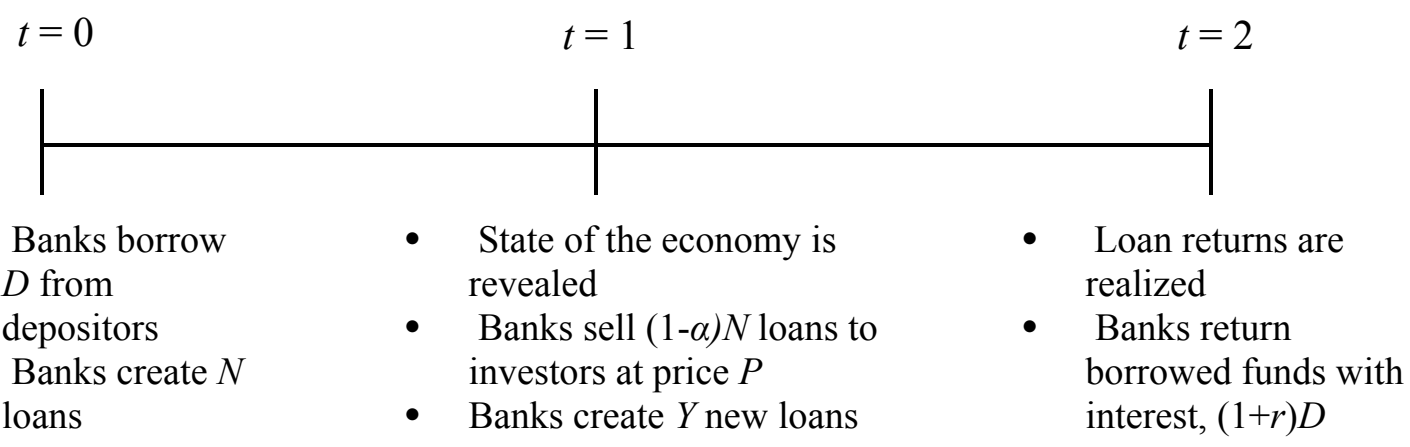

\footnotetext{
${ }^{6}$ Previous research suggests that funding is a primary driver of securitization, especially in nonmortgage ABS. See, among others, Ashcraft, Malz, and Pozsar (2009) and Loutskina (2011).
} 


\subsection{Investors}

There are two possible states of the world. The only difference between these states is the degree of ambiguity that investors face. I develop the model with two states to capture the sudden shift in participation seen during the financial crisis. Intuitively, it is likely easier for investors to assess the potential payoffs of assets during normal times. However, in bad times, there is increased uncertainty, both idiosyncratically about the tail risks of securities themselves and systematically about the potential length and depth of the downturn. This increased ambiguity makes valuing assets more difficult for investors. The two-state design of the model captures the shift in uncertainty when a market downturn is severe.

In the model, there exists a pool of risk and ambiguity averse investors who can opt to buy the securities that the banks have originated. ${ }^{7}$ Depending on the state of the world, the investors have certain information about the payoff of the securities. The state is either high or low, denoted by $S \in\{H, L\}$, and the probability of the high state is $\operatorname{Pr}[S=H]=\theta$. In state $H$, there is no information asymmetry between banks and investors, and investors know that the expected value of a security is $\widehat{V}$. In state $L$, they face ambiguity about the expected value of the final payoff, $V$. Specifically, they know $\mathrm{E}[V] \in[\underline{V}, \bar{V}]$, with $\underline{V}<\hat{V}^{8}{ }^{8}$ Although banks know the true expected payoff, $\hat{V}$, they cannot credibly convey this information to investors in state $L .{ }^{9}$

All investors have constant absolute risk aversion (CARA) utility of their final wealth, $u(w)=-\exp (-w)$. Given the assumptions of CARA utility and normally distributed returns, each investor maximizes the utility function

\footnotetext{
${ }^{7}$ All investors are assumed to be both risk and ambiguity averse. The assumption that all investors are ambiguity averse is relaxed in the extended model discussed in Chapter 4.

${ }^{8}$ There is no restriction on the ranking of $\bar{V}$ and $\hat{V}$.

${ }^{9}$ This may be because investors have full information, yet they are unable to fully interpret it given limitations in skill or time. Additionally, investors may rely on ratings to help them assess the potential value of securities, but given the decreased reliability of ratings during the crisis, may no longer be willing to do so.
} 


$$
(V-P) x-\frac{\gamma}{2} \sigma^{2} x^{2}
$$

where $P$ is the price at which investors can buy securities, $x$ is the investor's demand for securities, and $\gamma$ is the risk aversion coefficient. To account for investors' uncertainty over the value of the expected payoff, investor preferences can be modeled according to Gilboa and Schmeidler (1989), in which case investors maximize utility given the worst-case scenario. In this representation, investors have a set of priors, rather than a single prior, and use a max-min decision rule in determining their optimal solution. Therefore, the investor's maximization problem can be represented as

$$
\max _{x} \min _{V \in[\underline{V}, \bar{V}]}(V-P) x-\frac{\gamma}{2} \sigma^{2} x^{2}
$$

Solving the inner minimization reduces the problem to

$$
\max _{x_{H}}(\widehat{V}-P) x_{H}-\frac{\gamma}{2} \sigma^{2} x_{H}{ }^{2}
$$

in state $H$ and, in state $L$,

$$
\max _{x_{L}}(\underline{V}-P) x_{L}-\frac{\gamma}{2} \sigma^{2} x_{L}{ }^{2}
$$

This maximization problem gives the optimal demand for securities in states $H$ and $L$, respectively, as

$$
x_{H}=\left\{\begin{array}{cc}
\frac{\widehat{V}-P}{\gamma \sigma^{2}} & \text { if } \hat{V}-P \geq 0 \\
0 & \text { if } \hat{V}-P<0
\end{array}\right.
$$

and

$$
x_{L}=\left\{\begin{array}{cc}
\frac{\underline{V}-P}{\gamma \sigma^{2}} & \text { if } \underline{V}-P \geq 0 \\
0 & \text { if } \underline{V}-P<0
\end{array}\right.
$$


Since investors can buy but not sell securities in this setting, their demand is bounded at zero. Therefore, if the difference between their belief of expected value and price is less than zero, investors will opt not to participate. Given their ambiguity over expected value, investors will only purchase securities if their expected return is positive in the worst-case scenario.

There are several possible reasons that limited investor participation could be detrimental for banks. First, securitization serves as a funding source and enables banks to originate more loans than they would otherwise. By securitizing and selling their loans, they can then use their proceeds to originate new loans. If they cannot sell their securities due to limited participation, they will have to forego these other opportunities. Ambiguity among investors can reduce the ability for banks to securitize their loans, thereby reducing their profit as well as real economic activity. Banks must also have enough cash to repay their debt. Securitizing loans provides income that can be used to do so. If investors are unwilling to participate due to ambiguity, banks may be unable to repay their debts to depositors. These two issues are the primary focus of the model.

However, there are other explanations that are not modeled here. For instance, the loans that banks originate may be risky and they may want to sell them to avoid holding that risk. If securities cannot be sold due to limited participation, banks will be forced to hold more risk than they prefer. This issue is not at play in this model since it is assumed that banks are risk neutral. Another concern is that banks may need to sell a certain amount of their loans in order to meet capital requirements. Ambiguity aversion on the part of investors may force them to sell their assets at fire sale prices to make sure they meet these requirements. Although the current model does not have a capital constraint, the impact of a capital constraint is qualitatively very similar 
to the impact of the debt constraint modeled here. These other factors would increase the role that ambiguity plays in affecting both the banks' origination and securitization decisions, suggesting that the actual impact of ambiguity is even greater than that shown here.

\subsection{Banks}

Banks are risk neutral and know the true value of $\widehat{V}$. They are endowed with some initial equity, $E_{0}$. Additionally, banks can raise cash, $D$, from depositors, paying a riskless return of $r \geq$ 0 at time 2. Banks can either hold cash or originate loans. Let $N$ be the number of loans the bank undertakes. If a bank has originated new loans, it can either hold them itself or securitize and sell them. The bank chooses the fraction $\alpha$ of the loans to retain; the remaining $1-\alpha$ is sold to investors. Using the cash on hand after securitizing, the bank can invest $Y$ in new loans at time 1.

I model a single non-competitive bank. Given that each bank in the real world issues unique securitization tranches that are not perfect substitutes, this seems like a valid assumption. The bank's objective is to maximize profit, as specified by

$$
\max _{N, \alpha, D}(1-\alpha) N P+\alpha N V-N-r D+i Y
$$

Here, the first term is the profit from the portion of loans that is securitized and sold to investors; the second term is the profit from the portion that is retained; the third term is the cost of originating the loans; the fourth term is the cost of repaying depositors; and the final term is the profit from additional loans originated at time 1.

Price is derived from the investors' inverse demand function from equation (5) as $P=V-x \gamma \sigma^{2}$. Since investor demand must equal the supply of securities offered by the bank, $x=(1-\alpha) N$. Therefore, in equation (7), $P=V-(1-\alpha) N \gamma \sigma^{2}$. 
While maximizing its expected profit in equation (7), the bank is subject to several constraints. The first constraint is a budget constraint at time 0 . It requires the cost of initiating loans to be less than or equal to the funds available to the bank, which come from its equity and deposits. Specifically:

$$
N \leq E_{0}+D
$$

The bank is also subject to a budget constraint when creating loans at time 1 . Specifically, the amount invested in new loans, $Y$, cannot be more than the cash available from selling securities.

$$
Y \leq(1-\alpha) N\left(V-(1-\alpha) N \gamma \sigma^{2}\right)
$$

The second constraint imposes that the bank must be able to repay depositors with cash available at time 2. To ensure that depositors will always be repaid in full, banks cannot use the risky payoff from loans made at either time 0 or time 1 to repay depositors. Only their equity and profit from selling securities at time 1 can be used. While profit from selling securities at time 1 is, at that point, used to invest in new loans $(Y)$, these loans will return at least $Y$ at time 2, given that their return $i \in\left[0, i_{\max }\right]$. This implies that:

$$
(1+r) D \leq E_{0}+D-N+(1-\alpha) N\left(V-(1-\alpha) N \gamma \sigma^{2}\right)
$$

Next, the bank is subject to some minimum retention requirement. That is, the bank must retain at least $\underline{\alpha}$ of the loans it has originated. ${ }^{10}$ Additionally, $\alpha$ is constrained from above by 1 since it is a fraction. Therefore:

$$
\alpha \in[\underline{\alpha}, 1], 0 \leq \underline{\alpha}<1
$$

Lastly, the price of the security must be non-negative ${ }^{11}$, namely:

\footnotetext{
${ }^{10}$ This minimum threshold on $\alpha$ captures regulatory constraints that require banks to retain a minimum amount of the securities they create. For example, Section 941 of the Dodd-Frank Wall Street Reform and Consumer Protection Act, which was signed into law on July 21, 2010, requires securitizers to retain at least $5 \%$ of the credit risk of their securitized assets. While this requirement is meant to align the incentives of banks and investors, which is not a factor in this model, I include this constraint to show how such a regulation does not address the issues caused by ambiguity, as will be seen below.
} 


$$
P=V-(1-\alpha) N \gamma \sigma^{2} \geq 0
$$

Before proceeding, it is useful to make two observations. First, the bank will always choose to originate as many new loans as possible at time 1. That is, equation (9) is always binding. Given that loans have a non-negative return $\left(i \in\left[0, i_{\max }\right]\right)$ while holding cash has a zero return, the bank will invest any available cash in new loans.

Second, the bank's budget constraint at time 0 (equation (8)) will always bind before the riskless debt constraint (equation (10)). If the budget constraint does not bind, the bank will choose $D=0$, given that there is no need to take on potentially costly deposits if the bank is not even using all of its equity, $E_{0}$. Therefore, the debt constraint becomes

$$
0=E_{0}-N+(1-\alpha) N\left(V-(1-\alpha) N \gamma \sigma^{2}\right)
$$

Since $E_{0}-N>0$ when $(8)$ is not binding, $(1-\alpha) N\left(V-(1-\alpha) N \gamma \sigma^{2}\right)$ must be less than zero for (13) to hold. This would require $\alpha>1$, which is a violation of (11). Therefore, (8) binds before (10). By extension, provided $\widehat{V}>1$, (8) is always binding since, if creating loans is profitable, the bank will originate as many as possible subject to its funding.

\subsection{The Case with No Ambiguity}

As a reference point, I first look at the case in which there is no ambiguity. That is, investors know the true value of the expected payoff, $\widehat{V}$, in all states. The bank's maximization problem in this case is given by

$$
\max _{N, \alpha, D}(1+i)(1-\alpha) N\left(\widehat{V}-(1-\alpha) N \gamma \sigma^{2}\right)+\alpha N V-N-r D
$$

\footnotetext{
${ }^{11}$ The price at which securities are sold can be less than 1, the cost of originating the underlying loans, if the bank must sell securities to meet its debt constraint or if the benefit of additional investment opportunities $(i)$ outweighs the loss on the securities sold.
} 
The bank is subject to the constraints in equations (8) - (12). Proposition 1 characterizes the bank's optimal decision in the case when $\widehat{V}>1+r$. This condition requires that the return of a loan is greater than the cost of deposits. This simplification seems intuitive since it is likely that riskless deposits will have a lower return than risky loans. However, for completeness, the case in which $\widehat{V} \leq 1+r$ is discussed in the appendix.

Proposition 1. If $\widehat{V}>1+r$, the bank's optimal decision without ambiguity, $\left\{N_{N A}, \alpha_{N A}, D_{N A}\right\}$, is defined as follows. The bank will borrow as much as possible, subject to its binding debt constraint. The bank retains $\alpha_{N A}=\max \left\{1-\frac{\widehat{V}-\sqrt{\widehat{V}^{2}-4 \gamma \sigma^{2}(1+r)\left(N-E_{0}\right)}}{2 N \gamma \sigma^{2}}, \underline{\alpha}\right\}$. The optimal origination decision is given by $N_{N A}=\min \left\{E_{0}+\frac{(\widehat{V}+i(1+r))^{2} \widehat{V}^{2}-(\widehat{V}(1+r))^{2}}{4 \gamma \sigma^{2}(1+r)(\widehat{V}+i(1+r))^{2}}, N(\underline{\alpha})\right\}$. The bank's budget constraint is binding so $D_{N A}=N_{N A}-E_{0}$.

Proof. See the Appendix.

As the return to originating a new loan, $\widehat{V}$, increases, the number of loans originated will increase. This increase in origination is made possible by the accompanying increase in the amount of loans that are sold to investors as securities. Given that the return on loans is greater than the cost of deposits, the bank will originate as many loans as its debt constraint (equation (10)) will allow. This constraint is always binding when $\widehat{V}>1+r$, as indicated in Proposition 1 , given that the bank is borrowing more to take advantage of the higher profitability of loans. 


\subsection{The Case with Ambiguity}

When ambiguity is present, investors make their decision based on the worst-case outcome, as described above. There are now two states, one in which investors know the true expected value and the other in which they only know a range of possible expected values. Therefore, the originator must determine a securitization strategy for both potential states. The origination decision, however, is made at time 0 before the state is known, so will take both states into account. The bank is again constrained to have its retained assets be less than or equal to its equity in both states, its costs less than its funds, its fraction of retained assets above the minimum threshold $(\alpha)$ and less than or equal to 1 , and non-negative prices in both states. Therefore, the bank's maximization problem is

$$
\begin{aligned}
& \max _{N, \alpha_{H}, \alpha_{L}, D} \theta\left[(1+i)\left(1-\alpha_{H}\right) N P_{H}+\alpha_{H} N \hat{V}\right] \\
&+(1-\theta)\left[(1+i)\left(1-\alpha_{L}\right) N P_{L}+\alpha_{L} N \hat{V}\right]-N-r D
\end{aligned}
$$

$$
\begin{array}{ll}
\text { subject to } & N \leq E_{0}+D \\
& (1+r) D \leq E_{0}+D-N+\left(1-\alpha_{H}\right) N P_{H} \\
& (1+r) D \leq E_{0}+D-N+\left(1-\alpha_{L}\right) N P_{L} \\
& \alpha_{S} \in[\underline{\alpha}, 1] \forall S \in\{H, L\}, 0 \leq \underline{\alpha}<1 \\
& P_{H}=\widehat{V}-\left(1-\alpha_{H}\right) N \gamma \sigma^{2} \geq 0 \\
& P_{L}=\underline{V}-\left(1-\alpha_{L}\right) N \gamma \sigma^{2} \geq 0
\end{array}
$$

The following proposition characterizes the bank's optimal decision under ambiguity. Again I focus on the case in which $\widehat{V}>1+r$. 
Proposition 2. If $\widehat{V}>1+r$, the bank's optimal decision under ambiguity, $\left\{N, \alpha_{H}, \alpha_{L}, D\right\}$, is defined as follows. The bank's optimal origination decision is $N \leq N_{N A}$. The bank's budget constraint is binding so the bank borrows $D=N-E_{0}$. The bank's debt constraint is always binding in state L. Therefore, the bank retains:

$$
\alpha_{L}=\max \left\{1-\frac{\underline{V}-\sqrt{\underline{V}^{2}-4 \gamma \sigma^{2}(1+r)\left(N-E_{0}\right)}}{2 N \gamma \sigma^{2}}, \underline{\alpha}\right\}
$$

There exists a threshold $\underline{V}^{*}$ such that the bank's optimal retention decision in state $H$ is given by:

(a) If $\underline{V}<\underline{V}^{*}$, the bank's debt constraint is slack in state $H$ and the bank retains:

$$
\alpha_{H}=\max \left\{1-\frac{i \widehat{V}}{2(1+i) N \gamma \sigma^{2}}, \underline{\alpha}\right\}
$$

(b) If $\underline{V} \geq \underline{V^{*}}$, the bank's debt constraint is binding in state $H$ and the bank retains:

$$
\alpha_{H}=\max \left\{1-\frac{\hat{V}-\sqrt{\hat{V}^{2}-4 \gamma \sigma^{2}(1+r)\left(N-E_{0}\right)}}{2 N \gamma \sigma^{2}}, \underline{\alpha}\right\}
$$

$\underline{V}^{*}$ is defined as

$$
\underline{V}^{*}=\widehat{V} \sqrt{\frac{((1-\theta)(1+r)(1+i))^{2}+\left(2 i+i^{2}\right)(\hat{V}+i(1+r))^{2}}{(1+i)^{2}(\hat{V}+i(1+r))^{2}}}
$$

Proof. See the Appendix.

The threshold $\underline{V}^{*}$ determines whether or not the bank's debt constraint binds in state $H$. If $\underline{V}<\underline{V}^{*}$, ambiguity is high. Therefore, the bank opts to originate fewer loans given its exposure to ambiguity averse investors in state $L$. Fewer deposits are required to fund these loans so the debt constraint in state $H$ does not bind. However, when $\underline{V} \geq \underline{V}^{*}$, ambiguity is not as severe and the bank will originate more loans. This requires more deposits and the bank's debt constraint will therefore bind in both states. When this constraint is binding, the bank will have to sell more 
securities in order to repay depositors. Therefore, $\alpha_{H}$ is always lower when the debt constraint binds than it would be otherwise.

As the return to originating a new loan increases, the number of loans originated will increase. However, the effect on the bank's retention decision will depend on model parameters. The bank faces several tradeoffs when choosing between securitization and retention. First, the bank must consider the relative payoff from keeping loans, which depends on $\widehat{V}$, versus the payoff from selling securities, which depends on $i$ and price. Additionally, securitization can allow the bank to originate more loans initially. The bank must weigh the benefit of having a larger volume of loans against the decrease in price encountered when trying to sell more securities. Finally, the bank faces a tradeoff between creating more loans and being constrained by its funding, potentially leading to selling at fire sale prices if the state with ambiguity is realized, and creating fewer loans in order to be able to retain them all if the state with ambiguity is realized. Creating more loans may lead to more profits in the good state, but also increases exposure to the ambiguity averse investors in the bad state. These tradeoffs will be discussed in more depth in the following chapter. 


\section{CHAPTER 3}

\section{CHARACTERIZATION OF THE BANK'S OPTIMAL DECISION}

To understand the role of ambiguity in determining the bank's optimal strategy, the origination and securitization decisions can be compared in the case with ambiguity versus the case without ambiguity. I consider the impact of several key model parameters, including the level of ambiguity, the state probability, the return variance, the expected payoff of loans, and the expected payoff of additional investment opportunities, on the bank's optimal decisions in equilibrium in turn. Each section is summarized by three results on origination, retention, and prices, respectively.

\subsection{Ambiguity}

The bank's decision to originate and securitize is dependent on the level of ambiguity in the market, as measured by $\underline{V}$. The lower $\underline{V}$ is relative to $\widehat{V}$, the expected payoff of the security, the more ambiguity there is in the market. When $\underline{V}$ is very low and there is consequently a significant amount of ambiguity facing investors, the bank will choose to originate fewer loans so it will be able to retain them all in state $L$. Given that investors' demand is based on the worstcase estimation of value, the price will be very low in this state. Therefore, the bank will be better off holding the securities itself relative to selling at a price significantly below the true

expected value. On the other hand, when $\underline{V}$ is very close to $\widehat{V}$ and there is, therefore, very little ambiguity in the market, the bank's optimal origination and securitization decisions will approach the equilibrium values under no ambiguity. 


\section{Figure 4. Bank's Decisions and Ambiguity}

This figure shows how the bank's optimal origination and securitization decisions are affected by the level of ambiguity, as measured by $\underline{V}$. $\underline{V}$ ranges from 0 (extreme ambiguity) to $\hat{V}$ (no ambiguity). The solid line is the case with no ambiguity and the dashed line is the case with ambiguity. In the plots for retention and additional investment, the dashed line is state $H$ and the dotted line is state $L$. Model parameters are fixed as follows: $E_{0}=10 ; \widehat{V}=1.2 ; i=0.2 ; r=0.05 ; \theta=0.9 ; \sigma^{2}=0.1 ; \gamma=1 ; \underline{\alpha}=$ 0.05 .
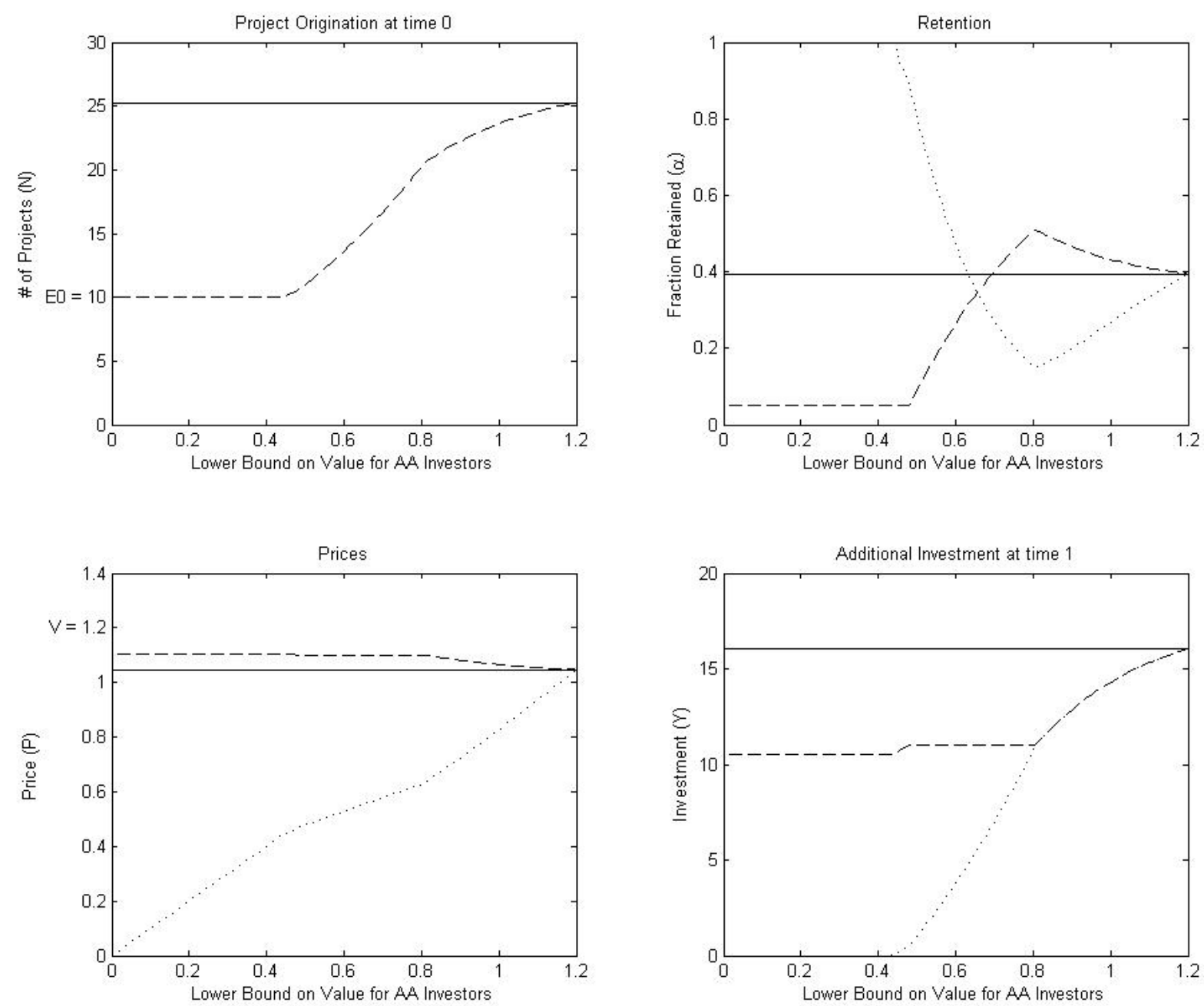
Figure 4 shows the effect of changing $\underline{V}$ on the bank's optimal decision for certain model parameters. Specifically, the parameters are fixed as follows: $E_{0}=10 ; \hat{V}=1.2 ; i=0.2 ; r=$ $0.05 ; \theta=0.9 ; \sigma^{2}=0.1 ; \gamma=1 ; \underline{\alpha}=0.05 .^{12,13,14} \underline{V}$ ranges from 0 (extreme ambiguity) to $\widehat{V}$ (no ambiguity). For small values of $\underline{V}$, the bank originates few loans to be able to retain all of them in state $L$. The price in this state is too low to justify selling any securities, given the high level of ambiguity. However, the bank will sell as many securities as possible in state $H$. This is because the lower quantity of loans originated will result in a higher price, given investors' downward slopping demand curve.

As $\underline{V}$ increases, the number of loans the bank originates increases and the fraction that it retains in state $L$ decreases. The bank's debt constraint is binding in state $L$, but as the price in $L$ increases due to ambiguity decreasing, the bank can take on more deposits to originate more loans. In state $H$, decreasing ambiguity leads the bank to retain a higher fraction of its securities. However, as the bank is also increasing its origination, the total amount sold, $\left(\left(1-\alpha_{H}\right) N\right)$, remains constant and, correspondingly, so does the price in $H$. The fraction retained in state $L$ eventually becomes lower than the fraction retained in state $H$, despite the lower price available in state $L$. This is because, as $\underline{V}$ increases, the bank can originate more loans given the improving conditions in state $L$, but the bank must sell more of them in state $L$ to meet its debt constraint.

As $\underline{V}$ gets even larger, the bank's debt constraint is now binding in both states $H$ and $L$. This leads the bank to slow its increasing origination and begin selling more securities in state $H$

\footnotetext{
${ }^{12}$ The return on loans originated at time 0 and additional investments originated at time 1 are assumed to be the same since they both represent loans to firms or consumers.

${ }^{13}$ I assume the return on deposits, $r$, is 0.05 in my characterization of the equilibrium. However, the results would be qualitatively similar if $r=0$ and banks therefore had unlimited funding.

${ }^{14}$ I assume the minimum retention requirement, $\underline{\alpha}$, is 0.05 in accordance with the Dodd-Frank requirement that securitizers retain at least $5 \%$ of the credit risk of their securitized assets. However, this does not qualitatively affect the results; the minimum retention requirement could be removed entirely and similar results would be obtained. It is important to note that, while such a requirement may help with adverse selection, it does not alleviate the negative implications of ambiguity.
} 
to meet its constraint. The bank can now retain more securities in state $L$, decreasing its exposure to the ambiguity averse investors. As a result, the price falls in state $H$ and rises in state $L$. As ambiguity continues to decrease, the equilibrium decisions of the bank approach those in the case with no ambiguity.

As with ex ante origination, the presence of ambiguity leads to lower investment at time 1. However, while this impact is relatively small in state $H$, it is very large in state $L$. This is because, even as the bank begins to sell more of its securities in state $L$, it is selling these securities at very low prices and so still has little cash with which to invest in new loans. As a result, policies that reduce ambiguity could have a particularly significant impact on investment in high ambiguity states, provided ambiguity can be reduced enough to change the equilibrium outcome.

Result 1a: For all levels of ambiguity, origination at times 0 and 1 are nondecreasing.

Result 1b: When ambiguity is high, the bank sells as much as possible in state $H$ and retains everything in state $L$. As ambiguity decreases, retention in state $H$ increases and retention in state $L$ decreases. As ambiguity decreases further, the bank's debt constraint in state $H$ becomes binding and these trends reverse.

Result 1c: For all levels of ambiguity, price in state $H$ is nonincreasing and price in state $L$ is nondecreasing.

\subsection{State Probability}

The degree of ambiguity in the market is also influenced by $\theta$, the probability of state $H$, since, in state $H$, investors do not face ambiguity over the expected payoff of securities. When $\theta$ 
is small, the probability of facing ambiguity averse investors is relatively high, so the bank originates fewer loans. Given the lower price that the bank faces in state $L$ due to ambiguity, it opts to originate fewer loans so it is able to retain them all in this state. As $\theta$ increases, the number of loans the bank is willing to undertake increases. This also leads to selling more securities in state $L$, as the bank becomes constrained by its debt. The lower probability of facing ambiguity averse investors leads the benefits of higher loan volume to outweigh the lower price faced if state $L$ occurs.

Figure 5 shows the effect of changing $\theta$ on the bank's optimal decision for certain model parameters. Specifically, the parameters are fixed as follows: $E_{0}=10 ; \widehat{V}=1.2 ; \underline{V}=0.7 ; i=$ $0.2 ; r=0.05 ; \sigma^{2}=0.1 ; \gamma=1 ; \underline{\alpha}=0.05$. For small values of $\theta$, the bank retains all of the loans it originates in state $L$. As $\theta$ increases, the number of loans that the bank originates increases, given the lower probability of facing ambiguity averse investors, and the fraction of securities that it retains in state $L$ decreases.

As in the case of increasing $\underline{V}$, as $\theta$ gets larger, the fraction retained in state $L$ becomes lower than the fraction retained in state $H$, despite the lower price available in state $L$. This is again because the bank can originate more loans and correspondingly increase the fraction of securities it retains in state $H$ to keep the total amount of securities it sells, $\left(\left(1-\alpha_{H}\right) N\right)$, and correspondingly the price, constant. At the same time, the bank must sell an increasing amount of securities in state $L$ to meet its debt constraint.

Note that, in this case, as $\theta$ approaches 1, the bank's optimal decision does not converge to its optimal decision under no ambiguity. This is because there is still ambiguity when $\theta=1$ in this example, given the specification that $\underline{V}=0.7$. As $\theta$ approaches 1 , the fraction of securities retained in state $L$ is actually less than the fraction retained when there is no ambiguity, given the 


\section{Figure 5. Bank’s Decisions and the State Probability}

This figure shows how the bank's optimal origination and securitization decisions are affected by the probability of the high state $(H)$ occurring $(\theta) . \theta$ ranges from 0 (state $L$, with ambiguity, always occurs) to 1 (state $H$, with no ambiguity, always occurs). The solid line is the case with no ambiguity and the dashed line is the case with ambiguity. In the plots for retention and additional investment, the dashed line is state $H$ and the dotted line is state $L$. Model parameters are fixed as follows: $E_{0}=10 ; \hat{V}=1.2 ; \underline{V}=0.7 ; i=$ $0.2 ; r=0.05 ; \sigma^{2}=0.1 ; \gamma=1 ; \underline{\alpha}=0.05$.
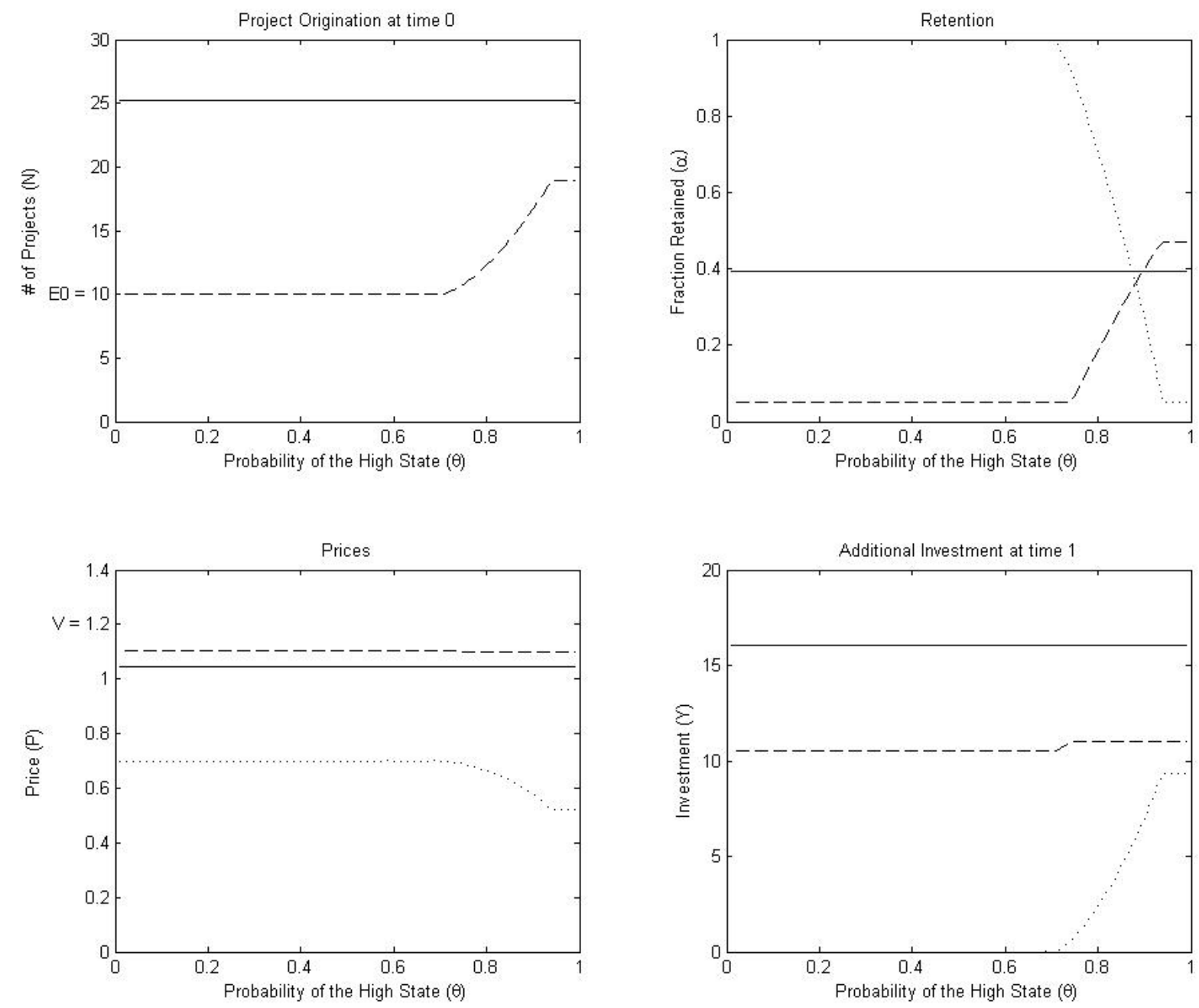
bank's binding debt constraint. In other words, when the bank is constrained due to its heightened volume of origination, it is forced to sell more of its securities at fire sale prices under ambiguity.

Result 2a: For all state probabilities, origination at times 0 and 1 are nondecreasing.

Result 2b: When the probability of the good state (state $H$ ) occurring is low, the bank sells as much as possible in state $H$ and retains everything in state $L$. As the probability of the good state occurring increases, retention in state $H$ increases and retention in state $L$ decreases.

Result 2c: For all state probabilities, prices in both states $H$ and $L$ are nonincreasing given that value is constant and origination is nondecreasing.

\subsection{Return Variance}

Given that investors are risk averse, their price function is inversely related to the variance of returns $\left(\sigma^{2}\right)$. Therefore, the bank's profits for selling securities are higher when variance is lower. As a result, the number of loans the bank originates increases as $\sigma^{2}$ decreases. In addition, the fraction of loans that the bank retains will decrease as $\sigma^{2}$ decreases since the bank wants to take advantage of higher prices by selling more securities.

Figure 6 shows the effect of changing $\sigma^{2}$ on the bank's optimal decision for certain model parameters. Specifically, the parameters are fixed as follows: $E_{0}=10 ; \hat{V}=1.2 ; \underline{V}=$ $0.7 ; i=0.2 ; r=0.05 ; \theta=0.9 ; \gamma=1 ; \underline{\alpha}=0.05$. The presence of ambiguity decreases the number of loans originated for all values of $\sigma^{2}$ and increases the fraction of those loans retained for high values of $\sigma^{2}$. In this example, the bank's debt constraint is always binding in state $L$, so the bank will sell more securities to meet this requirement for low values of $\sigma^{2}$. However, for 


\section{Figure 6. Bank’s Decisions and Return Variance}

This figure shows how the bank's optimal origination and securitization decisions are affected by the variance of returns $\left(\sigma^{2}\right)$. The solid line is the case with no ambiguity and the dashed line is the case with ambiguity. In the plots for retention and additional investment, the dashed line is state $H$ and the dotted line is state $L$. Model parameters are fixed as follows: $E_{0}=10 ; \widehat{V}=1.2 ; \underline{V}=0.7 ; i=0.2 ; r=$ $0.05 ; \theta=0.9 ; \gamma=1 ; \underline{\alpha}=0.05$.
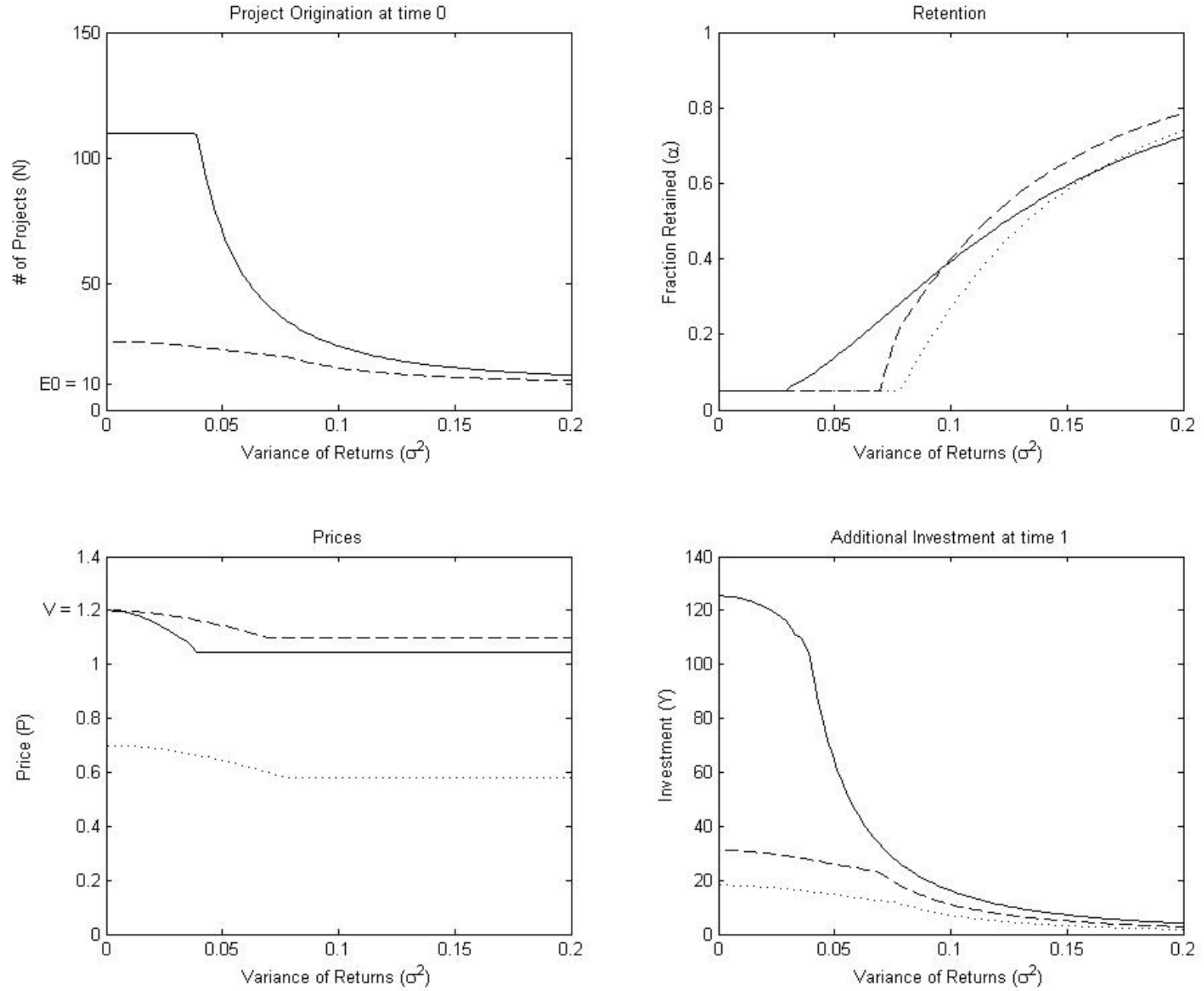
higher values of $\sigma^{2}$, in order to satisfy its debt constraint, the bank will also reduce origination. The bank consistently sells more securities in state $L$ than in state $H$, despite the presence of ambiguity, due to its binding debt constraint.

The fraction retained is generally increasing in $\sigma^{2}$, while the amount of origination is decreasing. Since $\sigma^{2}$ directly influences the price investors are willing to pay, a higher $\sigma^{2}$ leads to lower prices, which means the bank will opt to retain more and will need to originate less in order to do so, given its debt constraint.

When the variance of returns is high, the fraction of securities retained approaches 1 in all cases. ${ }^{15}$ This is due to the negative relationship between variance and prices. In these cases, since the bank is not selling much to investors, the impact of ambiguity on retention is relatively low. However, for small values of $\sigma^{2}$, the difference in retention between the state with ambiguity and the state without ambiguity becomes more significant. Notably though, the primary effect of ambiguity is on origination, especially when variance is low. The bank can originate many more loans without ambiguity. It is limited in its origination under ambiguity due to the debt constraint in state $L$. Therefore, decreasing ambiguity for securities with low variance can have a significant impact on origination in the real economy.

Result 3a: For all levels of variance, origination at times 0 and 1 are nonincreasing.

Result 3b: When variance is low, the bank sells as much as possible in both states $H$ and $L$. As variance increases, retention in both states increases, with retention in state $L$ always less than retention in state $H$ given the bank's debt constraint.

Result 3c: For all levels of variance, prices in both states $H$ and $L$ are nonincreasing.

\footnotetext{
${ }^{15}$ This is a direct result of the assumption that banks are risk neutral and investors are risk averse. Therefore, as the risk of the loans increases, the banks are better able to bear this risk so they retain more of their loans.
} 


\subsection{Expected Payoff of Loans}

Both the return to retaining loans and the return to selling securities are directly tied to the expected payoff $(\widehat{V})$ of the loans originated. Therefore, as the expected payoff increases, the bank chooses to originate more loans. The number of loans originated is nondecreasing in $\widehat{V}$. However, the relationship between $\widehat{V}$ and the fraction retained is not as direct. In both the case of no ambiguity and state $H$ under ambiguity, an increase in $\widehat{V}$ increases the profit to both retention and securitization. If the bank securitizes more, the increased supply of securities in the market will result in a lower price, which suggests the bank should retain more. However, by retaining more, the bank foregoes additional investment opportunities. Therefore, the impact of a higher $\widehat{V}$ on retention depends on its impact on price relative to the return on additional investments $(i)$. On the other hand, in state $L$, only the profit to retention is increased with an increase in $\widehat{V}$. Changes in $\widehat{V}$ do not affect the price ambiguity averse investors will pay since they are only concerned with the worst-case outcome, $\underline{V}$. As a result, when not bound by its debt constraint, the bank has the incentive to retain as much as possible in state $L$.

Figure 7 shows the effect of changing $\widehat{V}$ on the bank's optimal decision for certain model parameters. Specifically, the parameters are fixed as follows: $E_{0}=10 ; \underline{V}=0.7 ; i=0.2 ; r=$ $0.05 ; \theta=0.9 ; \sigma^{2}=0.1 ; \gamma=1 ; \underline{\alpha}=0.05$. When $\widehat{V}<1$, the bank has no incentive to originate loans since the payoff $(\widehat{V})$ does not exceed the cost $(\$ 1)$. Therefore, the figure only includes results for $\widehat{V} \geq 1$. As expected, the number of loans originated is nondecreasing in $\widehat{V}$ in cases both with and without ambiguity, and the number of loans originated with ambiguity is significantly less than the number originated without ambiguity. Under ambiguity, the number of loans the bank can originate is limited due to the bank's debt constraint. This constraint is 
binding in state $L$, so the bank sells more securities to meet it. However, once the bank reaches its minimal amount of retention $(\underline{\alpha})$, it cannot originate any more loans since it cannot sell more securities to meet its debt constraint. For lower values of $\widehat{V}$, the bank opts to retain all of its loans in state $L$. However, as $\widehat{V}$ increases, the bank retains a smaller fraction in state $L$ because its debt constraint has become binding, so for higher values of $\widehat{V}$, the amount retained in state $L$ can again be less than the amount retained in state $H$. The bank trades off receiving a lower price due to selling more securities in state $L$ for creating more loans and retaining more of them in state $H$. In the case with no ambiguity, the large increase in retention for low values of $\widehat{V}$ is due to the bank's debt constraint becoming binding. This occurs when $\widehat{V}$ becomes larger than $1+r$ and it therefore becomes profitable to take on deposits. Subsequently, as $\widehat{V}$ increases, the bank sells enough securities to meet its debt constraint.

Result 4a: For all levels of expected payoff, origination at times 0 and 1 are nondecreasing. Result 4b: When expected payoff is low, the bank sells most of its securities in state $H$ and retains everything in state $L$. As expected payoff increases, the bank's debt constraint binds in state $L$ so retention decreases. Meanwhile, retention in state $H$ increases until $\alpha_{L}=\underline{\alpha}$. At this point, origination reaches its maximum so the bank can sell a larger fraction in state $H$.

Result 4c: For all levels of expected payoff, price in state $H$ is nondecreasing due to the increase in value, while price in state $L$ is nonincreasing since the bank must sell more accommodate higher origination. 


\section{Figure 7. Bank's Decisions and Expected Payoff of Loans}

This figure shows how the bank's optimal origination and securitization decisions are affected by the expected payoff of loans $(\widehat{V})$. The solid line is the case with no ambiguity and the dashed line is the case with ambiguity. In the plots for retention and additional investment, the dashed line is state $H$ and the dotted line is state $L$. Model parameters are fixed as follows: $E_{0}=10 ; \underline{V}=0.7 ; i=0.2 ; r=0.05 ; \theta=$ $0.9 ; \sigma^{2}=0.1 ; \gamma=1 ; \underline{\alpha}=0.05$.
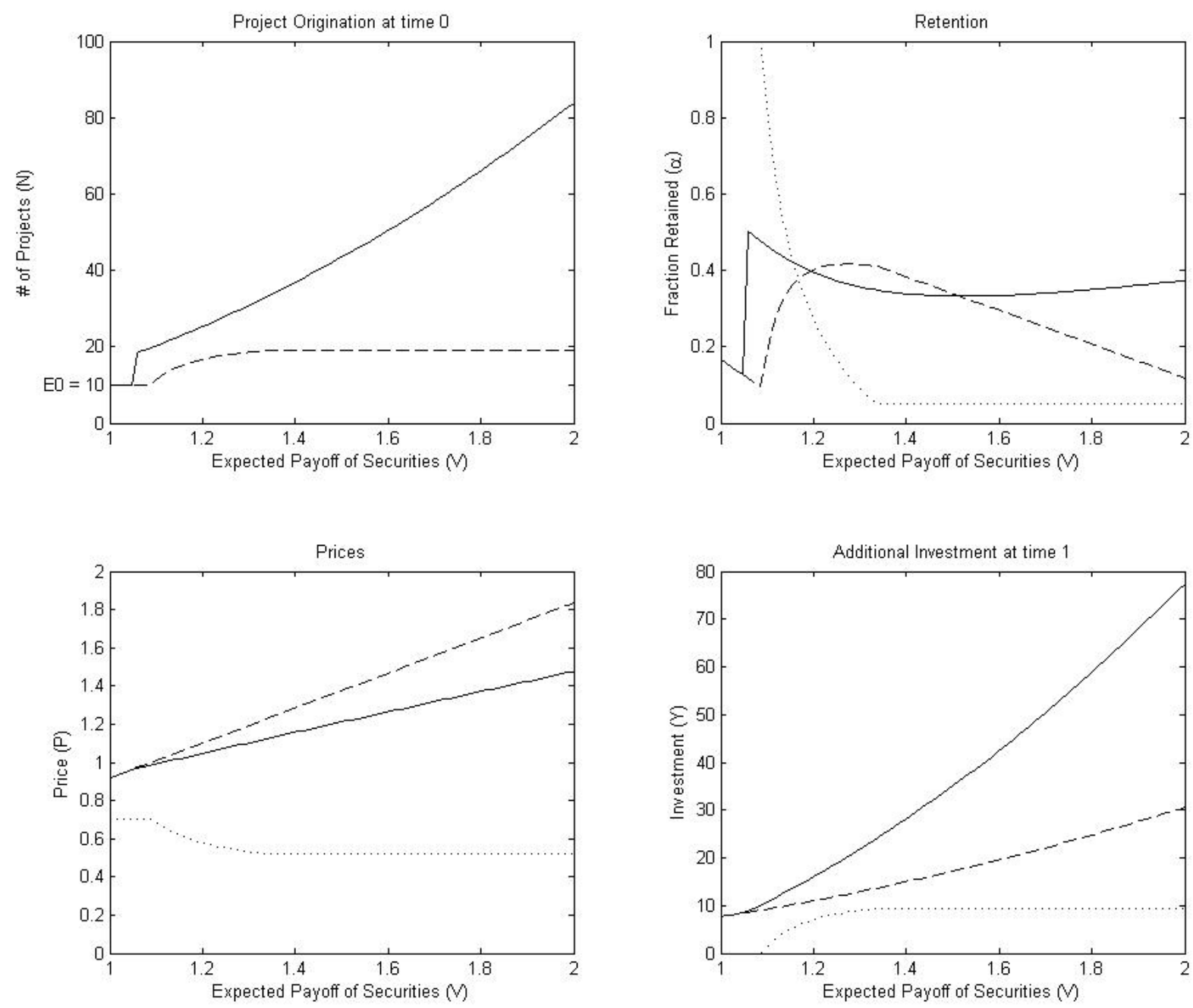


\subsection{Expected Payoff of Additional Investment Opportunities}

The primary motivation for securitization in this model is funding. In particular, the bank chooses to sell securities at time 1 so it can invest that cash in new loans and increase its return. When these additional loans are more profitable (higher $i$ ), the bank will securitize more of its initial loans.

Figure 8 shows the effect of the return on additional investment opportunities on the bank's optimal decision for certain model parameters. Specifically, the parameters are fixed as follows: $E_{0}=10 ; \widehat{V}=1.2 ; \underline{V}=0.7 ; r=0.05 ; \theta=0.9 ; \sigma^{2}=0.1 ; \gamma=1 ; \underline{\alpha}=0.05$. In both the state with and without ambiguity, loan origination is nondecreasing in $i$. Additionally, the fraction retained decreases with $i$ as the bank has a higher incentive to securitize in order to fund new loans. As a result of higher origination and lower retention, prices decrease as $i$ increases in all cases. The presence of ambiguity decreases the number of loans originated for all values of $i$.

For lower values of $i$, the bank's debt constraint is binding in both states. Therefore, as $i$ increases and, as a result, origination increases, the bank will need to sell more in both states to meet its constraint. However, for higher values of $i$, the debt constraint becomes slack in state $H$. As $i$ increases, the bank sells a larger fraction of its loans in both states relative to the case with no ambiguity. This is because it has originated significantly fewer loans due to its binding debt constraint in state $L$. The presence of ambiguity causes the debt constraint to bind in state $L$ since the price received for securities in this state is low.

As seen before with return variance in Section 3.3, the presence of ambiguity can have a particularly large impact on origination, especially when securitization is very attractive (i.e. low variance, high returns to additional investments). While retention both with and without ambiguity approaches $\underline{\alpha}$ as $i$ increases, origination with ambiguity is much lower than it is 


\section{Figure 8. Bank's Decisions and the Expected Payoff of Additional Investments}

This figure shows how the bank's optimal origination and securitization decisions are affected by the expected payoff of additional investments made at time $1(i)$. The solid line is the case with no ambiguity and the dashed line is the case with ambiguity. In the plots for retention and additional investment, the dashed line is state $H$ and the dotted line is state $L$. Model parameters are fixed as follows: $E_{0}=10 ; \widehat{V}=$ $1.2 ; \underline{V}=0.7 ; r=0.05 ; \theta=0.9 ; \sigma^{2}=0.1 ; \gamma=1 ; \underline{\alpha}=0.05$.
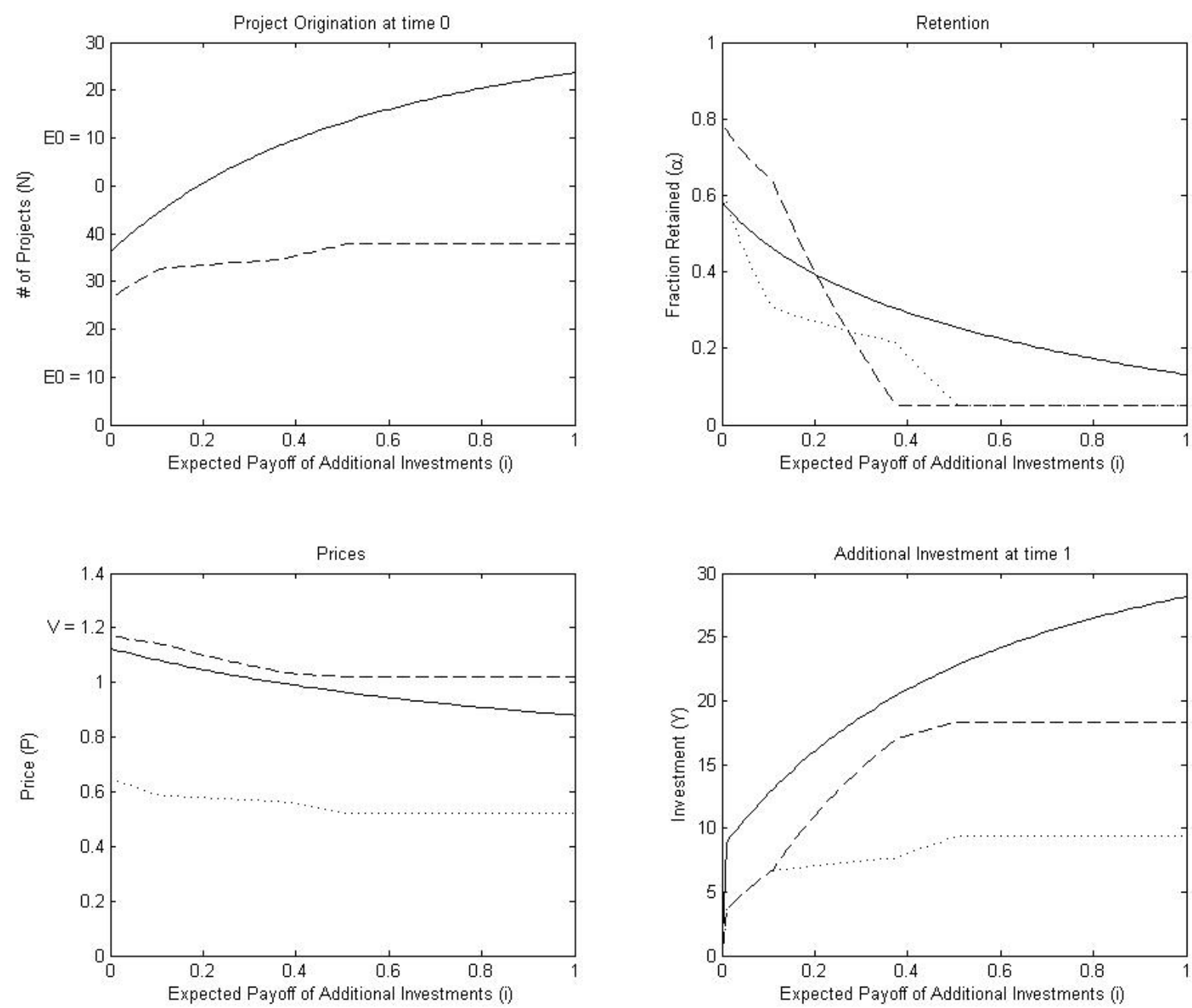
without due to the bank's debt constraint. Ambiguity decreases the price received for securities that the bank sells, which reduces its capacity to take on deposits, thereby reducing origination.

Result 5a: For all levels of expected payoff of additional investment opportunities, origination at times 0 and 1 are nondecreasing.

Result 5b: For all levels of expected payoff of additional investment opportunities, retention in both states $H$ and $L$ are nonincreasing.

Result 5c: For all levels of expected payoff of additional investment opportunities, prices in both states $H$ and $L$ are nonincreasing.

\subsection{Ambiguity vs. Risk}

I now turn to a comparison of the impact of risk versus the impact of ambiguity by removing both ambiguity and risk from the model in turn. I start with a model with only risk and no ambiguity. In this case, investors know the true expected value of loans, $\widehat{V}$, in both states. In other words, $\underline{V}=\widehat{V}$. Therefore, the bank's optimization problem reduces to

$$
\max _{N, \alpha, D}(1+i)(1-\alpha) N\left(\widehat{V}-(1-\alpha) N \gamma \sigma^{2}\right)+\alpha N \widehat{V}-N-r D
$$

Alternatively, a setting with ambiguity and no risk is equivalent to $\sigma^{2}=0$. Therefore, the bank's optimization problem is

$$
\begin{gathered}
\max _{N, \alpha_{H}, \alpha_{L}, D} \theta\left[(1+i)\left(1-\alpha_{H}\right) N \hat{V}+\alpha_{H} N \hat{V}\right]+(1-\theta)\left[(1+i)\left(1-\alpha_{L}\right) N \underline{V}+\alpha_{L} N \hat{V}\right] \\
-N-r D
\end{gathered}
$$

An increase in either risk or ambiguity serves to decrease the price that investors are willing to pay for securities. However, the impact of ambiguity is more direct. Specifically, ambiguity affects price directly proportional to the change in ambiguity, as measured by a lower 
$\underline{V}$, since price is simply $\underline{V}$ in this case. On the other hand, when there is risk, price is $\widehat{V}-$ $(1-\alpha) N \gamma \sigma^{2}$. Therefore, increasing risk, as measured by a higher $\sigma^{2}$, not only impacts price directly through $\sigma^{2}$, but also proportional to $(1-\alpha) N$. As risk increases, the negative impact on price can be counteracted with a simultaneous decrease in origination and/or securitization. As a result, the impact of ambiguity is more absolute than the impact of risk. Specifically, there is a threshold on $\underline{V}$, as defined in the following proposition, above which the bank retains as little as possible and below which the bank retains as much as possible.

Proposition 3. When there is ambiguity but no risk in the market, the bank will always choose $\alpha_{H}=\underline{\alpha}$. There exists a threshold $V^{*}$ such that:

a) If $\underline{V}>V^{*}$, ambiguity is low and the bank chooses $\alpha_{L}=\underline{\alpha}$ and $N=\frac{(1+r) E_{0}}{1+r-\left(1-\alpha_{L}\right) \underline{V}}$.

b) If $\underline{V} \leq V^{*}$, ambiguity is high and the bank chooses $\alpha_{L}=1$ and $N=E_{0}$. $V^{*}$ is defined as

$$
V^{*}=\frac{(1-\theta)(1+r) \hat{V}}{(i \theta(1-\underline{\alpha})+1) \hat{V}+(1+r)(i-\theta-i \theta)}
$$

Proof. See the Appendix.

Intuitively, this threshold $V^{*}$ is the maximum amount of ambiguity the market can bear while remaining operational. If ambiguity is too large, the bank chooses not to sell any securities in the state with ambiguity given the depressed price it will face. A lower threshold is preferable since it will require more ambiguity to cause a market freeze. Considering the partial derivatives of $V^{*}$ reveals that the threshold decreases when $\widehat{V}, \theta$, or $i$ increase and when $\underline{\alpha}$ or $r$ decrease. All 
of these changes in model parameters make securitization more profitable and the bank will therefore be willing and able to securitize their loans under higher values of ambiguity.

The difference between risk and ambiguity can be seen in Figure 9, where the bank's origination and retention decisions are plotted under risk with no ambiguity and under ambiguity with no risk for certain model parameters. Specifically, the parameters are fixed as follows: $E_{0}=10 ; \widehat{V}=1.2 ; i=0.2 ; r=0.05 ; \theta=0.5 ; \gamma=1 ; \underline{\alpha}=0.05$. In the first case with just risk, I set $\underline{V}=\widehat{V}$ and consider $\sigma^{2} \in[0,0.2]$. In the second case with just ambiguity, I set $\sigma^{2}=0$ and consider $\underline{V} \in[0, \widehat{V}]$. I also impose a maximum on the amount of available deposits, $D_{\max }$, to prevent origination from going to infinity as risk and ambiguity go to zero. I set $D_{\max }=100$. This is why origination is capped at $110=E_{0}+D_{\max }$ in both the case of low risk and low ambiguity.

Under both very low risk and very low ambiguity, the bank will originate as many loans as possible and securitize them all. Conversely, under both very high risk and very high ambiguity, the bank will originate fewer loans and retain them all. However, ambiguity and risk differ significantly in the intermediate ranges. As discussed above, the negative impact of increased risk can be mitigated by lower origination or higher retention. Therefore, as shown in Figure 9, both outcome variables change gradually as risk increases.

On the other hand, in the case of ambiguity, the optimal decisions behave differently, especially for retention. Specifically, there are two distinct regions in the plot of retention under ambiguity. There is not a gradual change between the extremes of full retention and full securitization, as there is in the case of risk. Once the level of ambiguity increases above the threshold, $V^{*}$, as defined in Proposition 3, retention immediately increases from $\underline{\alpha}$ to 1 . Crossing this threshold also causes a drop in origination but under the current model parameters, this drop 


\section{Figure 9. Ambiguity vs. Risk}

This figure shows how the bank's optimal origination and securitization decisions are affected when there is risk but no ambiguity (top) versus when there is ambiguity and no risk (bottom). The plot of retention with ambiguity displays the retention in state $L$; retention in state $H$ is always $\underline{\alpha}$. In the case with only risk, model parameters are fixed as follows: $E_{0}=10 ; \widehat{V}=1.2 ; \underline{V}=\widehat{V} ; i=0.2 ; \bar{r}=0.05 ; \theta=0.5 ; \gamma=$ $1 ; \underline{\alpha}=0.05$; and $\sigma^{2} \in[0,0.2]$. In the case with only ambiguity, model parameters are fixed as follows: $E_{0}=10 ; \hat{V}=1.2 ; i=0.2 ; r=0.05 ; \theta=0.5 ; \sigma^{2}=0.1 ; \gamma=1 ; \underline{\alpha}=0.05 ;$ and $\underline{V} \in[0, \hat{V}]$.
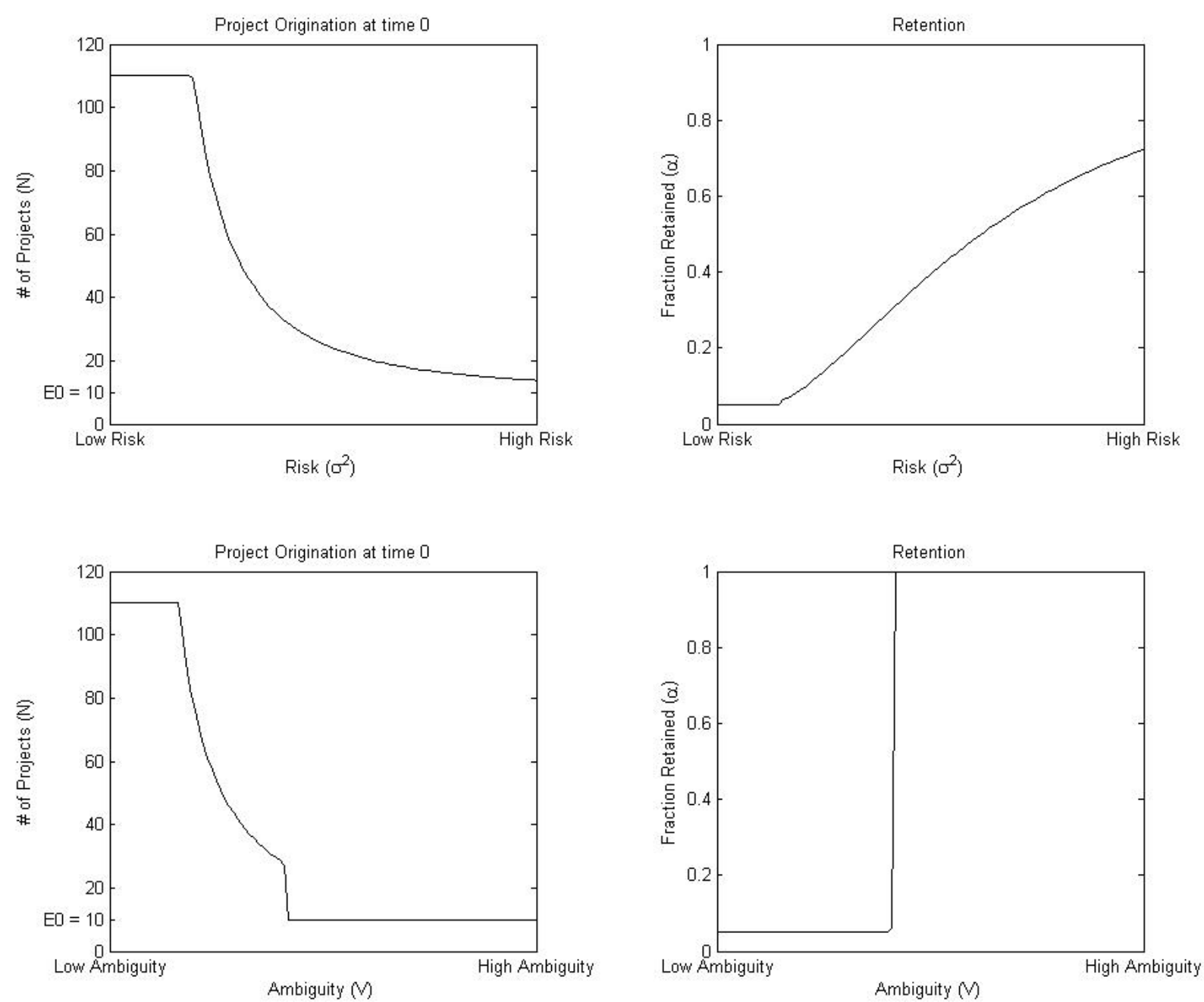
is not very severe. However, when either $E_{0}$ or $V^{*}$ is higher, the extremity of this fall in origination increases since origination is higher in this case.

The shift between these equilibria under ambiguity is very dramatic. Because of this, a small change in the level of ambiguity, especially around $V^{*}$, can have a large effect on both the origination and, in particular, the securitization decisions of the bank. Therefore, market characteristics or policies that are able to reduce ambiguity can be very effective in improving market conditions. 


\section{CHAPTER 4}

\section{MODEL EXTENSION WITH MULTIPLE TRANCHES}

\subsection{Extended Model Setup}

A pivotal assumption of the current model is that securities' returns are distributed normally and that the bank can only create one type of security. However, this is not necessarily the case in reality, especially given the tranche structure of most ABS. In particular, securities are often created such that the most senior tranches are low risk, debt-like securities, while the more subordinated tranches resemble equity. I aim to capture this characteristic with an extension of the initial model present in Chapter 2. Incorporating multiple tranches into the model not only provides a better approximation of reality, but also provides insight into the effect of ambiguity on the structure of securitization. Ambiguity may affect not only the fraction of loans the bank chooses to securitize, but also the degree of subordination the bank chooses.

Relative to the initial model, there are two fundamental differences in this extension. First, the securitization options available to banks are different. In particular, banks can now create two tranches with their loans - a safe tranche and a risky tranche. This securitization decision is still made at time 1 , after the state is revealed. Therefore, the size of the safe tranche can differ depending on whether the economy is in a state with ambiguity or not. The safe tranche is denoted $B$ and the risky tranche is therefore $N-B$. The bank sells the entire safe tranche and, as before, chooses a fraction, $1-\alpha$, of the risky tranche to sell. Investors in the safe tranche get a return $b \geq 0$ when payoffs are realized at time 2 . Payoffs of the risky tranche are 
assumed to be normally disturbed, as in the initial model. ${ }^{16}$ However, the mean of these securities depends on the size of the safe tranche. Since the risky tranche is subordinate, investors in the risky tranche are entitled to the return on loans less the amount promised to the safe tranche holders. Specifically,

$$
\tilde{V}=\frac{N \widehat{V}-(1+b) B}{N-B}
$$

In state $H$, investors will use $\tilde{V}$ as their expected value when determining the price they are willing to pay. However, in state $L$, investors face ambiguity so they will use $\underline{V}$ instead of $\widehat{V}$, which yields an expected payoff for the risky tranche of

$$
\underline{\tilde{V}}=\frac{N \underline{V}-(1+b) B}{N-B}
$$

The second primary difference between this extended model and the initial model is that there are now two types of investors. There are again risk and ambiguity averse investors (AA) who are identical to those described in Section 2.2. In addition, this model will have investors who are only risk averse (non-AA) who know $\widehat{V}$ in both states. However, to prevent the bank from simply circumventing the AA investors and selling strictly to the non-AA investors, the wealth of these investors will be capped at $W$.

In this extended model, the bank's optimization problem is defined as

$$
\begin{aligned}
\max _{N, \alpha_{H}, \alpha_{L}, D, B_{H}, B_{L}} & \theta\left[(1+i)\left(\left(1-\alpha_{H}\right)\left(N-B_{H}\right) P_{1, H}+B_{H} P_{2, H}\right)+\alpha_{H}\left(N-B_{H}\right) \hat{V}\right] \\
+ & (1-\theta)\left[(1+i)\left(\left(1-\alpha_{L}\right)\left(N-B_{L}\right) P_{1, L}+B_{L} P_{2, L}\right)+\alpha_{L}\left(N-B_{L}\right) \hat{V}\right] \\
& -N-r D
\end{aligned}
$$

\footnotetext{
${ }^{16}$ The assumption of normality for the risky tranche is a strong assumption, especially when the size of the safe tranche is large. This assumption is made primarily for the purpose of tractability. A more accurate assumption would be that the payoff of the risky tranche follows a truncated normal distribution where the payoff is bounded from below at $B$. Further work will consider this alternative distribution.
} 


$$
\begin{array}{ll}
\text { subject to } & N \leq E_{0}+D \\
& B_{S} \leq N, \forall S \in\{H, L\} \\
& (1+r) D+(1+b) B_{H} \leq E_{0}+D-N+\left(1-\alpha_{H}\right)\left(N-B_{H}\right) P_{1, H}+B_{H} P_{2, H} \\
& (1+r) D+(1+b) B_{L} \leq E_{0}+D-N+\left(1-\alpha_{L}\right)\left(N-B_{L}\right) P_{1, L}+B_{L} P_{2, L} \\
& \frac{\alpha_{S}\left(N-B_{S}\right)}{N} \in[\underline{\alpha}, 1], \forall S \in\{H, L\} ; 0 \leq \underline{\alpha}<1 \\
& P_{1, S} \geq 0, \forall S \in\{H, L\} \\
& P_{2, S}=\frac{1+b}{1+r}, \forall S \in\{H, L\}
\end{array}
$$

The three terms in the profit function for each state are the profit from selling a fraction of the risky tranche, the profit from selling the safe tranche, and the payoff of the retained risky tranche, respectively. The first constraint is a simple budget constraint, identical to (8), and the third and fourth constraints are debt constraints equivalent to (10) in the initial model. The second constraint, $B_{S} \leq N$, is a new constraint that requires that the safe tranche be smaller than or equal to the total amount of loans originated. The fifth constraint is a modification of (11). Since the bank must retain a minimal holding, $\underline{\alpha}$, of all of its initial loans, the amount retained, $\alpha_{S}\left(N-B_{S}\right)$, is scaled by the total number of loans, $N$.

The final constraint on the price of the safe tranche is new to this extension. The yield of a deposit and the yield of the safe tranche must be equivalent since they are both riskless investments. ${ }^{17}$ That is,

\footnotetext{
${ }^{17}$ Deposits and the safe tranche are not completely identical since investors must invest in deposits at time 0 and get their payoff at time 2, while investors invest in the safe tranche at time 1 and get their payoff at time 2 . However, for the sake of tractability, I assume investors only value consumption at time 2 and have no other options available to them. They are, therefore, indifferent between investing in a riskless asset at time 0 or time 1 , given that they both payoff at time 2 .
} 


$$
\frac{1+b}{P_{2, S}}=1+r, \forall S \in\{H, L\}
$$

If this constraint is violated, investors will want to hold exclusively deposits or exclusively the safe tranche, while the bank's preference of what to issue will be the opposite.

Lastly, I consider the pricing of the risky tranche. This model results in either a separating equilibrium, in which only the non-AA investors participate in the market for the risky tranche, or a pooling equilibrium, in which both investor types buy the risky tranche. Both types of investors are willing to buy the safe tranche in either state of the world since there is no ambiguity about its payoff. In the separating equilibrium, states $H$ and $L$ will be identical since only the non-AA investors are buying the risky asset. In particular, the price in both states will be the same since ambiguity is not relevant when AA investors are not participating in the market. Therefore,

$$
P_{1, H}=P_{1, L}=\tilde{V}-(1-\alpha)(N-B) \gamma \sigma^{2}
$$

$\tilde{V}$ is defined in (18). However, since only the non-AA investors are participating in this case, there is additional constraint requiring that the investors' budget constraint be met, given that the non-AA investors only have wealth $W$. That is,

$$
(1-\alpha)(N-B) P_{1} \leq W
$$

On the other hand, in the pooling equilibrium, the price of the risky tranche will depend on the level of ambiguity in state $L$. Therefore, the prices are given by

$$
\begin{aligned}
P_{1, H} & =\tilde{V}-\left(1-\alpha_{H}\right)\left(N-B_{H}\right) \gamma \sigma^{2} \\
P_{1, L} & =\underline{\tilde{V}}-\left(1-\alpha_{L}\right)\left(N-B_{L}\right) \gamma \sigma^{2}
\end{aligned}
$$

$\tilde{V}$ and $\underline{V}$ are defined in (18) and (19), respectively. Investors do not face a budget constraint in this case because the AA investors are assumed to have unlimited wealth. 


\subsection{Results}

Initial results of this model are shown in Figure 10. Model parameters are fixed as follows: $\quad E_{0}=10 ; W=0.01 ; \widehat{V}=1.2 ; i=0.2 ; r=0.05 ; b=0.05 ; \theta=0.5 ; \sigma^{2}=1 ; \gamma=$ $1 ; \underline{\alpha}=0.05$. When ambiguity is high (low $\underline{V}$ ), there will be a separating equilibrium in which risky securities are only sold to non-AA investors. AA investors will only buy the safe tranche. In this case, the bank originates fewer loans than they would under no ambiguity, even though they are not selling anything to the AA investors. This is due to the fact that the non-AA investors have limited wealth. The bank also creates a larger safe tranche in this case, given the limited buying capacity of the non-AA investors.

When ambiguity is sufficiently decreased, the economy enters a pooling equilibrium in which both types of investors are willing to buy the risky securities. However, investors are still unwilling to participate in the risky security market in state $L$, so the bank retains the full risky tranche in this state. Given this, the bank creates a larger safe tranche in state $L$ than it does in state $H$, since investors are always willing to buy the safe tranche. As ambiguity decreases even further, the bank originates more loans to take advantage of the increasing prices of the risky tranche in state $L$. However, this results in the debt constraint binding in both states. Therefore, the bank must sell more of its securities to meet this constraint, which accounts for the drop in retention in both states for very high values of $\underline{V}$. 


\section{Figure 10. Bank’s Decisions with Two Tranches}

This figure shows how the bank's optimal origination and securitization decisions are affected by the level of ambiguity, as measured by $\underline{V}$, when the bank can create both a safe and a risky tranche. $\underline{V}$ ranges from 0 (extreme ambiguity) to $\widehat{V}$ (no ambiguity). The solid line is the case with no ambiguity and the dashed line is the case with ambiguity. In all plots except that of origination, the dashed line is state $H$ and the dotted line is state $L$. Model parameters are fixed as follows: $E_{0}=10 ; \widehat{V}=1.2 ; i=0.2 ; r=$ $0.05 ; b=0.05 ; \theta=0.5 ; \sigma^{2}=1 ; \gamma=1 ; \underline{\alpha}=0.05 ; W=0.01$.
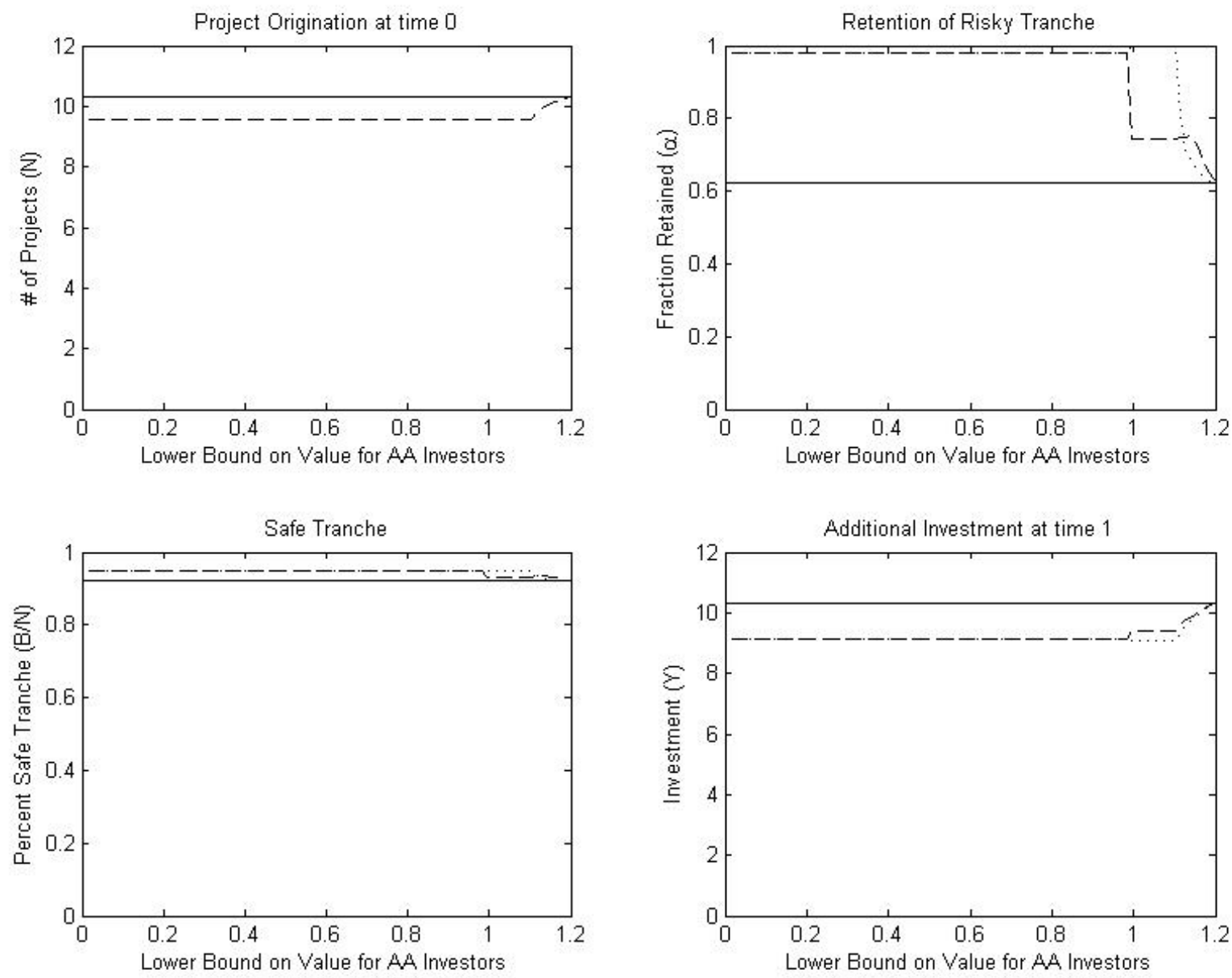
Result 6a: For all levels of ambiguity, origination at times 0 and 1 are nondecreasing.

Result 6b: When ambiguity is high, there is a separating equilibrium and only non-AA investors buy the risky tranche. When ambiguity is moderate, there is a pooling equilibrium in which the bank sells part of the risky tranche in state $H$ to both types of investors and retains the full risky tranche in state $L$. When ambiguity is low, there is a pooling equilibrium in which both types of investors will buy part of the risky tranche in both states.

Result 6c: For all levels of ambiguity, the size of the safe tranche is nonincreasing in both states. The safe tranche in state $L$ is always larger than or equal to the safe tranche in state $H$. 


\section{CHAPTER 5}

\section{POLICY IMPLICATIONS}

As discussed in Section 3.6, the presence of ambiguity leads to two very distinct equilibria and small changes in ambiguity can have large changes in the outcome. This model lends itself to consideration of policies that help alleviate the negative implications of ambiguity, including origination of fewer loans and limited participation in the market. I have shown that increasing the minimum expected payoff considered by investors can increase the price at which these investors are willing to participate. One way to implement such an increase would be to have an insurance-like contract, either from the private market or the government, which would protect investors from losses.

Consider the decision making process of an ambiguity averse investor choosing whether or not to participate in the ABS market. Given the complexity of these securities, the investor may not be able to determine their true expected payoffs. First, the investor may only have coarse information available given the opacity of these markets. Second, even if the information is revealed by the issuer, the investor may not have the ability, resources, or time to correctly interpret this information. Therefore, the investor will consider a range of outcomes, for some of which the payoff of the securities may be very low. Even if these outcomes are unlikely, an ambiguity averse investor is highly influenced by the worst-case scenario. Therefore, these investors are only willing to participate in the market at unrealistically low prices that account for these potential bad outcomes. 
Now consider the case in which there exists some contract that can put a lower threshold on the expected payoffs considered by investors. A prime example of such a program is the Term Asset-Backed Securities Loan Facility (TALF). The Federal Reserve announced TALF in November 2008 to make loans to investors in eligible ABS in response to the drastic reductions in origination and trading in ABS markets during the financial crisis. TALF provided investors with nonrecourse loans with which to buy securities. ${ }^{18}$ Therefore, if the value of the securities purchased turned out to be very low, the investor did not have to repay the loan and could simply pass the security, and its resulting losses, on to the government instead. This effectively put a limit on how much investors could lose on their investments in asset-backed securities, which is equivalent to increasing $\underline{V}$ in the model.

In this case, the ambiguity averse investors are willing to participate in the market at a higher price closer to the securities' true expected value. Not only does this approach increase trading in the securitization market, it also increases origination among banks ex post by providing more access to the funding benefits of securitization. Once a program such as TALF is implemented, banks are able to sell their securities and can then use those proceeds to originate new loans. Empirical analyses of the impact of TALF and the importance of ambiguity reduction in its effectiveness are discussed in Chapters 7 to 9 .

However, a government program like TALF is mainly beneficial in unfreezing markets that have already broken down; an alternative solution that could reduce ambiguity ex ante would be even more beneficial. An insurance-like contract that would pay investors when the value of the underlying collateral fell below a certain point would encourage ambiguity averse investors to participate in the market even in high ambiguity environments. Such a contract would be similar to a credit default swap except that the "default" event would be a decline in the

\footnotetext{
${ }^{18}$ For further details on the TALF program, see Section 7.2.
} 
asset value by some predetermined amount. This would not only have the ex post benefits of a government guarantee program, but it would also increase origination ex ante since banks would not have to prepare for the case when investors flee the market if ambiguity gets too high.

A program that reduces ambiguity for investors, whether through the government or through the private market, is analogous to a program like deposit insurance. Deposit insurance prevents depositors from running on a bank by insuring the full repayment of their deposits up to a certain value. Without such insurance, it may be rational for depositors to run if they suspect other depositors will run. Therefore, an illiquid bank can become insolvent due to the inherent mismatch in the durations of their assets and liabilities. Implementing deposit insurance averts this negative equilibrium by removing the reason for depositors to run.

Likewise, in the case of ambiguity aversion, investors rationally opt not to participate in a market unless the price of the security is lower than their worst-case expectation of its payoff. A program like TALF reduces ambiguity, thereby inducing investors to participate in the market. If non-participation is driven by ambiguity, as opposed to risk, then such a program should be costless to implement, similar to deposit insurance. In the case of deposit insurance, the program itself prevents bank runs, making it costless to insure illiquid banks. Likewise, a program like TALF encourages investors to purchase securities, which are not excessively risky securities but rather securities about which the investors are not sure they have full information. Therefore, it should be rare that a security will turn out to be low value and the investor will not repay their loan. This was in fact the case with TALF. As of March 2011, TALF had earned nearly $\$ 600$ million in interest and there were not yet any losses on the funded securities (Nelson (2011)).

While such programs may have the benefits of increasing participation and origination at a negligible cost, they may also have the threat of increased moral hazard. Given the presence of 
an insurance-like contract, banks may be less diligent about the quality of loans they make since investors are more willing to participate even when the underlying securities are highly ambiguous or risky. Increasing moral hazard may be acceptable if ambiguity can be reduced enough to induce participation. However, this tradeoff must be considered before implementing such a program, especially since there are some regions in which a change in ambiguity will not affect the outcome at all and others in which a small change in ambiguity can have a large impact on the resulting equilibrium. However, my model cannot currently speak to this tradeoff. Moral hazard would increase the origination of negative NPV loans, but my model, as it stands, does not have heterogeneous loans. 


\section{CHAPTER 6}

\section{DISCUSSION OF MODEL IMPLICATIONS}

There are several other existing theories of market freezes in securitization markets, which can be compared to the model presented here. These include theories of adverse selection, regulatory arbitrage, and neglected risks. First, many papers discuss the role of adverse selection in securitization. Financial intermediaries can pool and tranche assets to create informationally insensitive securities. Since all investors are symmetrically informed about these securities, the result is a highly liquid, low risk market. However, as bad news comes into the market, investors realize they may in fact be at an informational disadvantage and choose not to trade, resulting in a market freeze. Work in this area includes, among others, DeMarzo and Duffie (1990), Riddiough (1997), DeMarzo (2005), Pagano and Volpin (2010), and Dang, Gorton, and Holmström (2010).

The theory of regulatory arbitrage is described by, among others, Calomiris and Mason (2004), Leitner (2011), and Acharya, Schnabl, and Suarez (2011). It suggests that banks can use securitization as a means to reduce capital requirements. By holding highly-rated securitization tranches instead of the underlying assets or by holding securities in an off-balance sheet conduit, banks can increase leverage while still adhering to their capital requirements. However, when there is bad news and the prices of these assets decline, banks may not be able to sell these assets while still meeting their capital requirements. Thus, a market freeze can occur.

Recent work by Gennaioli, Shleifer, and Vishny $(2011,2012)$ develops another theory of shadow banking involving neglected risks. Investors ignore certain tail risks, leading to increased 
securitization and creation of debt that is perceived as risk free. However, when it is revealed that this debt is riskier than anticipated, intermediaries default on their obligations and a liquidity crisis can occur given the increased leverage allowed by securitization. This theory reconciles the fact that, during the recent financial crisis, markets did not seem to fully understand the risks in securitization markets, even as bad news started to be revealed. Despite negative information on the housing market beginning to come to light in mid-2007, securitization markets did not crash until late 2008 .

However, the existing theories face some limitations in explaining the recent crisis. While my model is not mutually exclusive of these other theories, it does address some of these limitations. In particular, my model explains both the freeze in the financial markets and in the real economy in terms of origination of new loans, while the other theories focus solely on the financial markets.

Additionally, while these theories can explain how a liquidity crisis can occur, they do not explain how one can persist. Although the neglected risks hypothesis can explain the timing of the securitization market crash, it does not explain why the market took time to recover. My model can explain both the timing and duration of the market freeze seen during the crisis. It suggests that, given the presence of ambiguity, the market freeze can persist as long as investors remain uncertain about the expected outcome. This helps explain why, even several years after the initial crisis, CDO markets are still weak despite limited losses on these securities. ${ }^{19}$

The model provides several empirical implications. First, banks will hold more securities during crises because they face prices much lower than the true value of their securities. It becomes more difficult to sell these securities but, since there is a lag between origination and

\footnotetext{
${ }^{19}$ For example, only 32 tranches in 14 CLOs of all of the 4118 tranches in 719 US broadly syndicated arbitrage cash flow CLOs that Moody's has rated since 1996 have suffered principal losses at maturity (Xu 2012).
} 
securitization, banks will be forced to retain a greater portion of the loans they have already originated. This is particularly true when ambiguity is severe or when the returns to securitization are low. This prediction is supported by Erel, Nadauld, and Stulz (2011), who show that the aggregate holdings of highly-rated tranches increased between the end of 2006 and the end of 2007. More specifically, the model suggests that, during times of heightened ambiguity, firms without binding funding constraints will choose to retain their securities and markets will freeze, while constrained firms will be forced to sell their securities at fire sale prices. The model also suggests that prices will be lower when ambiguity is high. However, the amount of securitization may be higher or lower, depending on whether or not the firm is constrained by its debt. Lastly, during times of heightened ambiguity, origination of new loans will be severely restricted, even when ambiguity is relatively mild.

The model's implications about ambiguity and risk also yield a number of empirical predictions. While the impact of risk on securitization is continuous, the impact of ambiguity is more disjointed. There are several distinct equilibria with respect to ambiguity so a small change in the level of ambiguity can create a large change in the bank's origination and securitization decisions, as the economy shifts to a different equilibrium. This implies that, under ambiguity, market freezes can both start and end abruptly as the amount of ambiguity changes. Additionally, as discussed in Chapter 5, in the presence of ambiguity, a program like TALF aimed at inducing participation will be costless. If the program were simply reducing the risk to investors, this would not be the case since the government would bear the remaining risk and would suffer losses on the poorly performing securities. 


\section{CHAPTER 7}

\section{OVERVIEW OF EMPIRICAL ANALYSES}

\subsection{Introduction}

In the years leading up to the 2008 financial crisis, securitization became an increasingly important aspect of lending to both businesses and individuals. However, in late 2008 in the face of increased uncertainty about future payoffs, investors fled securitization markets and issuance in asset-backed securities (ABS) and commercial mortgage-backed securities (CMBS) dropped to near zero. Reliance on securitization to fund loans makes access to credit in the primary market dependent on the functioning of the secondary market for securities backed by these loans. Therefore, market freezes like the ones seen during the recent financial crisis have significant implications for the real economy. As a result, in an effort to increase credit availability to consumers and businesses, the Federal Reserve created the Term Asset-Backed Securities Loan Facility (TALF) to provide loans to investors in AAA-rated ABS securities during the crisis. $^{20}$

After the creation of TALF, issuance in ABS markets rose and spreads decreased. TALF helped the market recover quickly, such that only $\$ 71$ billion of the available $\$ 200$ billion was lent through TALF (Ashcraft, Malz, and Pozsar (2009)). However, it is debatable how much of this recovery was due directly to TALF and how much was simply the result of conditions improving in the broader market. Several papers have attempted to determine the role of TALF in the recovery by looking at yields around TALF announcements and the acceptance/rejection of individual securities in the program (Agarwal, Barrett, Cun, and De Nardi (2010), Ashcraft,

\footnotetext{
${ }^{20}$ Institutional details of TALF are discussed in Section 7.2.
} 
Garleanu, and Pedersen (2010), and Campbell, Covitz, Nelson, and Pence (2011)). This dissertation continues this line of research by assessing the impact of both TALF and the crisis more broadly on the structure of securitization tranches to determine what made TALF so effective. I consider three channels through which TALF aided the recovery of ABS markets. In particular, TALF could benefit the market by reducing risk, reducing ambiguity, and inducing investor participation through the provision of leverage.

There are two key features of the TALF program that may contribute to the functioning of these three channels. First, TALF loans were designed such that investors bore the first loss. This was done through the use of a haircut, meaning that the loan amount was less than the value of the collateral being purchased. Second, TALF loans were nonrecourse, meaning that, when the loan comes due, if the value of the ABS collateral is less than the loan amount, the investor can surrender the collateral to the Fed rather than repay the loan. This ensures that the most the investor can lose is the haircut.

The first potential benefit of TALF is a reduction of risk for investors in ABS. Investors may have been unwilling to participate in securitization markets during the crisis because of increased risk. There exists information asymmetry between investors in ABS and the originators of those securities about the quality of the underlying assets. Securitization is designed to circumvent this potential for adverse selection by creating low-risk, informationally insensitive senior tranches. However, during the crisis, investors became uncertain of the true risk involved in these securities, leading them to withdraw from the market. ${ }^{21}$ Additionally, it has been suggested that there were neglected tail risks that came to light during the crisis, also causing investors to be unwilling to participate (Gennaioli, Shleifer, and Vishny $(2011,2012))$. TALF

\footnotetext{
${ }^{21}$ See, among others, DeMarzo and Duffie (1990), Riddiough (1997), DeMarzo (2005), Pagano and Volpin (2010), Dang, Gorton, and Holmström (2010), and Anderson (2012).
} 
benefited the market by reducing the risk that investors were exposed to given its nonrecourse feature, which put a cap on how much investors could lose on their investment.

In a similar way, TALF also served to reduce the ambiguity of asset-backed securities. Given the complexity of securitization tranches and the correlations between underlying collateral, ABS tranches are difficult to value. Investors rely on credit ratings to help evaluate these securities, but during the crisis, even highly-rated tranches experienced losses. Therefore, the payoff of these securities became more ambiguous (Agarwal, Barrett, Cun, and De Nardi (2010)). As a result, investors could not determine a single prior for the value. Instead, they consider a range of possible values and, if investors are ambiguity averse, they give particular weight to the worst-case outcomes (Schmeidler (1989) and Gilboa and Schmeidler (1989)). However, TALF ensures that the most an investor can lose is the haircut. Therefore, if the haircut results in a maximum loss that is less than the worst-case outcome the investor was previously considering, TALF will reduce the ambiguity that the investor faces (Anderson (2012)).

Lastly, TALF could benefit the market by providing leverage to investors through the haircut. While the haircut offered by TALF was higher than haircuts during normal times, it was less than those available in the private market at the time. Reducing the haircut reduces investors' funding constraints, which in turn reduces their required return (Ashcraft, Garleanu, and Pedersen (2010)). The higher leverage provided by the low haircuts of TALF also induced new investors, such as hedge funds, to participate in the market (Ashcraft, Malz, and Pozsar (2009)). This brought liquidity to the market, making other investors more willing to participate as well.

Each of these three channels has certain empirical implications for both how the structure of securitization changes in the crisis and which securities are funded by TALF. First, risk and 
ambiguity have different implications for the structure of securitization deals. In the CMBS market, I find a large reduction in the volume of highly-rated tranches, suggesting that there is increased risk among these securities such that they cannot support as many highly-rated tranches. However, deals do become simpler as there is a large reduction in the number of tranches per deal. This implies both risk and ambiguity are at play in the CMBS market. On the other hand, in the ABS market, there is an increase in the volume of highly-rated tranches, as well as a shift toward simpler deal structures. These results both suggest that ambiguity is the dominant factor in the ABS market. It seems reasonable that risk would be a more important issue among CMBS given that the roots of the financial crisis were in the real estate sector.

To examine the specific role of TALF, I look at the difference in the structure of TALFfunded tranches and those that were eligible for the program but did not participate. I find that TALF-funded CMBS tranches have higher losses, but the differences in all other delinquency variables are insignificant, which suggests that TALF helps reduce risk at least to a small degree. I also find that these tranches are larger in dollar value and percent of the total deal. They also pay higher coupons to investors but have lower weighted-average coupons on the underlying collateral, suggesting that these tranches are more subordinated. These results support the theory that TALF provides a reduction in ambiguity. However, the funded tranches are also more likely to have a fixed rate and less likely to be private placements, which does not support a reduction in ambiguity. Among ABS, the funded tranches are also larger in dollar value. In addition, they have fewer total tranches, more variable rate coupons, and more private placements. However, they are smaller as a percent of the total deal and less likely to be callable. Therefore, there is mixed evidence among both asset types on TALF reducing ambiguity. Lastly, if TALF encourages new investors to enter the market given the higher returns that leverage provides, 
TALF-funded securities should also have higher coupons than non-funded securities. I find evidence of this among legacy CMBS, but not ABS.

In addition to the structural differences suggested by these three channels, they also have different implications on whether TALF will have security-level benefits on just the securities taking part in the program or market-level benefits for the securitization market as a whole. If TALF reduces risk, it will directly benefit the securities funded through the program since it puts a cap on how much the investor can lose. However, there is no spillover benefit to other securities in the market that are not funded by TALF. Likewise, if TALF is reducing ambiguity, it will directly benefit the funded security for the same reason. However, reducing ambiguity does have a spillover effect. The fact that the Federal Reserve is willing to offer these loans gives investors a signal about the value of the securities, which reduces their ambiguity. Therefore, even if a security is not funded by the program, the mere fact that it is eligible decreases its ambiguity and makes investors more willing to purchase this security. Lastly, increasing participation through leverage has market-level benefits since a larger pool of investors will make the market for all securities more liquid. While there are both security- and market-level impacts of TALF, the market-level impacts appear to be more significant, suggesting that the reduction of ambiguity and provision of leverage are more important than the reduction of risk.

\subsection{Institutional Background on TALF}

During the financial crisis of 2008, the asset-backed securities markets suffered drastic reductions in origination and increases in interest rate spreads. As illiquidity was priced into these securities, the cost of issuing new securities and, correspondingly, originating new loans increased significantly. Concerned that continued disruptions in the ABS markets would limit the 
availability of credit to individuals and small businesses, the Federal Reserve initiated TALF. ${ }^{22}$ The program, which was announced on November 25, 2008, allowed the Federal Reserve to make up to $\$ 200$ billion in loans to investors in eligible ABS.

The eligibility of securities was determined by several factors. First, eligible ABS had to be in certain asset classes, including those backed by auto loans, commercial mortgages (CMBS), credit card loans, equipment loans, dealer floor plan loans, small business loans, and student loans. The program applied to both newly issued and legacy CMBS, while collateral in all other asset classes had to be newly issued. In addition, eligible securities had to have a AAA credit rating and pass a Federal Reserve risk assessment.

TALF loans were structured such that the private investors would bear the initial loss and the government would bear the rest. Each loan was extended for some amount less than the full value of the underlying collateral. This difference, called the haircut, was meant to ensure that the investor was liable for the first loss. The value of the haircut was fixed for the life of the loan and was determined by asset class.

Any US company that owned eligible collateral was eligible to borrow from TALF. Acceptance into the program, interest rates, and haircuts were conditional solely on the collateral, not the borrower.

TALF loans were nonrecourse, with maturities of three to five years. If the investor did not repay the loan, the Federal Reserve would keep the collateral. However, if the value of the collateral was not sufficient to cover the full amount of the loan, the nonrecourse feature prevented the Federal Reserve from having any claim on any other assets of the investor. These features - nonrecourse loans and long maturities - are thought to be critical to the success of the program by isolating investors from short-term market volatility (Sack (2010)).

\footnotetext{
${ }^{22}$ I provide a brief overview of TALF here. For a more detailed description, see Ashcraft, Malz, and Pozsar (2009).
} 
The first TALF loan subscription was on March 17, 2009. The program was closed by March 2010 for all collateral types except newly issued CMBS, which remained operational until June 2010. Despite the Fed's willingness to expand the program to lend up to $\$ 1$ trillion if necessary, only about $\$ 71$ billion was lent through TALF. By the end of 2010, only about $\$ 25$ billion in TALF loans were outstanding. As of March 2011, TALF had earned nearly $\$ 600$ billion in interest and there were not yet any losses on the funded securities (Nelson (2011)). This is consistent with the explanations that TALF served to decrease ambiguity or to induce participation by new investors through leverage. However, it suggests that TALF was not used to reduce risk for investors. If the securities funded by TALF were in fact more risky, the Federal Reserve would likely have suffered losses on these loans. 


\section{CHAPTER 8}

\section{DATA AND HYPOTHESES}

\subsection{Securitization Data}

Tranche-level data on securitization is obtained from Bloomberg. My sample includes all commercial mortgage-backed securities issued between 2003 and 2011 and all asset-backed securities issued between 2008 and 2011. Since the focus of this study is the structure of securitization deals during the financial crisis, the time window is limited to shortly before the freezing of the ABS market in late 2008 to shortly after TALF was terminated and the market had mostly recovered. The window is longer for CMBS since TALF funds were also provided to investors in legacy CMBS that were issued prior to January 1, 2009. Observations with a nonpositive tranche value or deal value are removed. This yields a final sample of 16,338 tranches.

Summary statistics for the full sample are shown in Panel A of Table 1. With the exception of \# of Tranches in Deal, which is deal-level, all variables are tranche-level. Original Tranche Value is the dollar value of the tranche at origination, while Amount Outstanding is the dollar value of the tranche outstanding in June 2012. Original Deal Value is the total dollar value of the entire deal to which the tranche belongs. Original WAL is the weighted-average life of the underlying collateral, while Duration is the initial time to maturity of the tranche, both in years. Fixed Coupon and Floating Spread give the interest rate paid to holders of the tranche, whereas Original $W A C$ is the weighted-average coupon of the underlying collateral. \% Rated is the percent of tranches that have a credit rating from either Standard \& Poor's, Fitch, Moody's, or DBRS. $\% A B S$ is the percent of all tranches (both rated and unrated) that are rated AAA by any of the 4 rating agencies, and \% Investment Grade is the percent of all tranches that are rated BBB- or higher by S\&P or Fitch, Baa3 or higher by Moody's, or BBB or higher by DBRS. 


\section{Table 1. Summary Statistics of Securitization Tranches}

This table reports the summary statistics for all securitization tranches in the final sample of tranche-level data. Panel A reports statistics for the full sample. The full sample period for CMBS is 2003 to 2011. The full sample period for all other asset classes is 2008 to 2011. Panel B splits results for CMBS and ABS. Additionally, the sample in Panel B is restricted to those tranches issued during TALF-eligible time periods. Specifically, the sample includes CMBS issued from January 2003 to March 2010, Small Business ABS issued from January 2008 to March 2010, and all other ABS issued from January 2009 to March 2010. With the exception of \# of Tranches in Deal, which is deal-level, all variables are tranchelevel. Therefore, note that the smaller number of observations for \# of Tranches in Deal is due to the variable being deal-level, not missing observations. Original Tranche Value is the dollar value of the tranche at origination. Original Deal Value is the total dollar value of the entire deal to which the tranche belongs. Amount Outstanding is the dollar value of the tranche outstanding in June 2012. Original WAL is the weighted-average life of the underlying collateral in years. Duration is the expected life of the tranche in years. Fixed Coupon is the coupon rate paid to holders of fixed rate tranches. Floating Spread is the spread over the reference rate (typically LIBOR) in basis points paid to investors in variable rate tranches. Original WAC is the weighted-average coupon of the underlying collateral. Tranche as \% of Entire Deal is Original Tranche Value divided by Original Deal Value. \% Rated is the percent of tranches that have a credit rating from either Standard \& Poor's, Fitch, Moody's, or DBRS. $\% A A A$ is the percent of all tranches (both rated and unrated) that are rated AAA by any of the 4 rating agencies. \% Investment Grade is the percent of all tranches that are rated BBB- or higher by Standard \& Poor's or Fitch, Baa3 or higher by Moody's, or BBB or higher by DBRS. \% TALFFunded is the percent of tranches that have any portion funded by TALF loans. 
Table 1 (cont.)

\begin{tabular}{|c|c|c|c|c|c|c|c|c|}
\hline \multicolumn{9}{|c|}{ Panel A. Full Sample } \\
\hline & Mean & Std. Dev. & Minimum & 5th percentile & Median & 95th percentile & Maximum & No. of obs. \\
\hline \multicolumn{9}{|l|}{ Characteristics } \\
\hline Original Tranche Value (\$) & $183,225,783$ & $471,058,044$ & 0.01 & $2,706,000$ & $34,563,500$ & $910,408,000$ & $13,091,079,300$ & 16,338 \\
\hline Original Deal Value (\$) & $1,430,561,336$ & $1,219,552,472$ & 30,000 & $125,050,000$ & $1,149,644,401$ & $3,713,176,835$ & $8,786,263,441$ & 16,338 \\
\hline Amount Outstanding (\$) & $111,264,714$ & $361,224,760$ & 0 & 0 & $14,306,056$ & $550,000,000$ & $10,068,518,939$ & 16,338 \\
\hline Original WAL & 7.12 & 4.42 & 0.03 & 1.10 & 7.17 & 14.50 & 30.10 & 13,709 \\
\hline Duration & 27.64 & 12.89 & 0 & 5 & 33 & 42 & 52 & 16,335 \\
\hline$\%$ with Fixed Rate & 30.44 & 46.02 & 0 & 0 & 0 & 100 & 100 & 16,338 \\
\hline Fixed Coupon $(\%)$ & 4.05 & 2.17 & 0 & 0 & 4.45 & 7.17 & 32.00 & 4,973 \\
\hline Floating Spread (bps) & 152 & 231 & -250 & 15 & 90 & 500 & 3350 & 3,152 \\
\hline Original WAC & 6.02 & 2.03 & 0 & 4.08 & 5.73 & 9.38 & 24.18 & 13,521 \\
\hline Tranche as $\%$ of Entire Deal & 13.46 & 32.95 & 0 & 0.25 & 3.17 & 71.56 & 2830.70 & 14,744 \\
\hline \# of Tranches in Deal & 8.19 & 9.09 & 1 & 1 & 5 & 27 & 84 & 1,994 \\
\hline$\%$ Callable & 88.51 & 31.89 & 0 & 0 & 100 & 100 & 100 & 16,338 \\
\hline$\%$ Private Placement & 55.29 & 49.72 & 0 & 0 & 100 & 100 & 100 & 16,338 \\
\hline \multicolumn{9}{|l|}{ Ratings } \\
\hline$\%$ Rated & 59.29 & 49.13 & 0 & 0 & 100 & 100 & 100 & 16,338 \\
\hline$\%$ AAA Rated & 47.17 & 49.92 & 0 & 0 & 0 & 100 & 100 & 16,338 \\
\hline$\%$ Investment Grade & 57.52 & 49.43 & 0 & 0 & 100 & 100 & 100 & 16,338 \\
\hline \multicolumn{9}{|l|}{ Type of Deal } \\
\hline \% Auto Loan ABS & 7.62 & 26.53 & 0 & 0 & 0 & 100 & 100 & 16,338 \\
\hline$\%$ Credit Card ABS & 1.95 & 13.84 & 0 & 0 & 0 & 0 & 100 & 16,338 \\
\hline$\%$ Student Loan ABS & 1.61 & 12.59 & 0 & 0 & 0 & 0 & 100 & 16,338 \\
\hline$\%$ Equipment Loan ABS & 1.54 & 12.32 & 0 & 0 & 0 & 0 & 100 & 16,338 \\
\hline$\% \mathrm{CMBS}$ & 69.38 & 46.09 & 0 & 0 & 100 & 100 & 100 & 16,338 \\
\hline$\% \mathrm{CDO}$ & 0.71 & 8.40 & 0 & 0 & 0 & 0 & 100 & 16,338 \\
\hline \multicolumn{9}{|l|}{ TALF } \\
\hline$\%$ TALF-Funded & 2.47 & 15.53 & 0 & 0 & 0 & 0 & 100 & 16,338 \\
\hline
\end{tabular}


Table 1 (cont.)

\begin{tabular}{|c|c|c|c|c|c|c|c|c|}
\hline \multicolumn{9}{|c|}{ Panel B. TALF-Eligible CMBS and ABS Tranches } \\
\hline & \multicolumn{4}{|c|}{$C M B S$} & \multicolumn{4}{|c|}{$A B S$} \\
\hline & Mean & Std. Dev. & Median & No. of obs. & Mean & Std. Dev. & Median & No. of obs. \\
\hline \multicolumn{9}{|l|}{ Characteristics } \\
\hline Original Tranche Value (\$) & $189,260,136$ & $518,304,380$ & $25,000,000$ & 10586 & $260,930,811$ & $424,498,032$ & $132,600,000$ & 727 \\
\hline Original Deal Value (\$) & $1,820,717,070$ & $1,239,867,152$ & $1,546,862,539$ & 10586 & $1,108,582,202$ & $1,088,323,935$ & $708,860,759$ & 727 \\
\hline Amount Outstanding (\$) & $111,143,659$ & $386,117,426$ & $9,686,064$ & 10586 & $122,607,983$ & $349,070,611$ & $11,150,000$ & 727 \\
\hline Original WAL & 7.78 & 3.87 & 9.61 & 8695 & 2.69 & 2.19 & 2.28 & 554 \\
\hline Duration & 31.71 & 10.15 & 35 & 10586 & 8.98 & 9.01 & 6 & 727 \\
\hline$\%$ with Fixed Rate & 18.65 & 38.95 & 0 & 10586 & 71.39 & 45.23 & 100 & 727 \\
\hline Fixed Coupon $(\%)$ & 4.86 & 1.38 & 5.05 & 1974 & 3.58 & 2.68 & 3.24 & 519 \\
\hline Floating Spread (bps) & 107 & 117 & 75 & 2151 & 470 & 446 & 218 & 202 \\
\hline Original WAC & 5.86 & 1.16 & 5.75 & 9583 & 7.59 & 4.43 & 6.04 & 278 \\
\hline Tranche as \% of Entire Deal & 6.55 & 31.72 & 1.37 & 9659 & 36.89 & 35.81 & 22.25 & 657 \\
\hline \# of Tranches in Deal & 16.44 & 10.62 & 15 & 644 & 2.83 & 4.24 & 1 & 256 \\
\hline$\%$ Callable & 89.23 & 31.00 & 100 & 10586 & 84.18 & 36.52 & 100 & 727 \\
\hline \% Private Placement & 62.81 & 48.33 & 100 & 10586 & 45.80 & 49.86 & 0 & 727 \\
\hline \multicolumn{9}{|l|}{ Ratings } \\
\hline$\%$ Rated & 64.27 & 47.92 & 100 & 10586 & 64.65 & 47.84 & 100 & 727 \\
\hline$\%$ AAA Rated & 54.25 & 49.82 & 100 & 10586 & 49.24 & 50.03 & 0 & 727 \\
\hline \% Investment Grade & 62.28 & 48.47 & 100 & 10586 & 64.51 & 47.88 & 100 & 727 \\
\hline \multicolumn{9}{|l|}{ Type of Deal } \\
\hline$\%$ Auto Loan ABS & & & & & 42.37 & 49.45 & 0 & 727 \\
\hline$\%$ Credit Card ABS & & & & & 17.06 & 37.64 & 0 & 727 \\
\hline$\%$ Student Loan ABS & & & & & 5.23 & 22.27 & 0 & 727 \\
\hline$\%$ Equipment Loan ABS & & & & & 11.00 & 31.32 & 0 & 727 \\
\hline$\%$ Small Business Loan ABS & & & & & 17.61 & 38.11 & 0 & 727 \\
\hline$\%$ Other ABS & & & & & 6.74 & 25.09 & 0 & 727 \\
\hline \multicolumn{9}{|l|}{ TALF } \\
\hline$\%$ TALF-Funded & 2.42 & 15.36 & 0 & 10586 & 20.36 & 40.29 & 0 & 727 \\
\hline
\end{tabular}


Given differences between CMBS and ABS both in structure and TALF-eligibility, Panel B of Table 1 reports summary statistics for these two asset classes separately. In addition, the sample shown in Panel B is restricted to tranches issued during TALF-eligible time periods. Specifically, the sample includes CMBS from January 2003 to March 2010, Small Business ABS from January 2008 to March 2010, and all other ABS from January 2009 to March 2010. The differences in sample periods are due to the differences in which securities were eligible for TALF among different asset classes. In general, ABS have shorter maturities, a higher percentage of fixed rate coupons, fewer tranches per deal, and fewer private placements than CMBS. Over $20 \%$ of ABS tranches were at least partially funded by TALF, compared to only about $2.4 \%$ of CMBS. Among ABS, over $40 \%$ are backed by auto loans and about $17 \%$ by credit card receivables.

\subsection{TALF Data}

The Federal Reserve Board provides data on all TALF transactions. ${ }^{23}$ In particular, their loan data gives the following information: the borrower, the loan amount at origination, the loan amount outstanding as of September 30,2010, the origination date, the maturity date, the interest rate, the market value of the underlying collateral, the issuer of the underlying collateral, the collateral asset class, and the haircut. Additionally, the Federal Reserve provides data on TALF borrowers, including the borrower name and the material investors. Material investors include any entity with a $10 \%$ or greater stake in the borrower's securities. In an effort to differentiate between informed investors, such as hedge funds, and less informed investors, such as pension funds or insurance companies, borrowers and investors are classified based on whether the words "insurance", "retirement", or "pension" are present in their names.

${ }^{23}$ TALF data can be found at http://www.federalreserve.gov/newsevents/reform talf.htm. 


\section{Table 2. Summary Statistics of TALF Loans}

This table provides a summary of all TALF loans, both for the full sample in Panel A and broken down by asset class in Panel B. Asset classes include Auto, Credit Card, Student Loan, Equipment, Asset, Floorplan, Small Business, and CMBS. These securities are backed by auto loans, credit card receivables, student loans, business equipment loans, either insurance premium finance loans or residential mortgage servicing advances, loans extended to automobile dealers to finance their inventory, loans guaranteed by the Small Business Administration, and commercial mortgages, respectively. Loan Amount is the average dollar amount of each loan. Loan Amount Outstanding is the average dollar amount of each loan outstanding as of September 30, 2010. Collateral Value is the dollar value of the securities being purchased. Fixed Rate is the average interest rate required on fixed rate TALF loans. Floating Rate Spread is the average spread in basis points over the variable rate benchmark (in most cases, LIBOR) on variable rate TALF loans. Haircut (\$) is defined as the difference in the value of the ABS collateral and the loan amount. Haircut (\%) is the haircut divided by the value of the collateral. \% Pension/Insurance Borrowers/Investors is the percent of borrowers/investors that are either pension funds or insurance companies. Number of Loans is the total number of loans provided. 
Table 2 (cont.)

\begin{tabular}{|c|c|c|c|c|c|c|c|c|}
\hline \multicolumn{9}{|c|}{ Panel A. Full Sample } \\
\hline & Mean & Std. Dev. & Minimum & 5th percentile & Median & 95th percentile & Maximum & No. of obs. \\
\hline \multicolumn{9}{|l|}{ Loan Characteristics } \\
\hline Loan Amount $(\$)$ & $32,488,894$ & $74,501,409$ & $1,200,000$ & $10,000,000$ & $14,700,000$ & $94,000,000$ & $1,565,100,000$ & 2,188 \\
\hline Loan Amount Outstanding (\$) & $12,804,479$ & $43,993,550$ & 0 & 0 & 0 & $52,200,000$ & $979,800,000$ & 2,188 \\
\hline Collateral Value (\$) & $36,146,618$ & $80,870,132$ & $1,200,000$ & $11,000,000$ & $17,000,000$ & $101,000,000$ & $1,665,000,000$ & 2,188 \\
\hline Fixed Rate $(\%)$ & 2.97 & 0.54 & 1.78 & 2.09 & 2.87 & 3.87 & 3.87 & 1,355 \\
\hline Floating Rate Spread (bps) & 106.90 & 27.44 & 75 & 75 & 100 & 175 & 175 & 833 \\
\hline Haircut (\$) & $3,657,724$ & $6,858,085$ & 0 & 700,000 & $2,100,000$ & $10,500,000$ & $101,500,000$ & 2,188 \\
\hline Haircut (\%) & 10.91 & 3.98 & 0 & 5.84 & 10.03 & 17.03 & 21.13 & 2,188 \\
\hline Duration of Loan & 3.521 & 0.878 & 3 & 3 & 3 & 5 & 5 & 2,188 \\
\hline \multicolumn{9}{|l|}{ Borrower Characteristics } \\
\hline$\%$ Pension/Insurance Borrowers & 5.76 & 23.30 & 0 & 0 & 0 & 100 & 100 & 2,188 \\
\hline \% Pension/Insurance Investors & 34.37 & 47.50 & 0 & 0 & 0 & 100 & 100 & 2,188 \\
\hline \multicolumn{9}{|l|}{ Asset Class } \\
\hline$\%$ Auto Loan ABS & 22.85 & 42.00 & 0 & 0 & 0 & 100 & 100 & 2,188 \\
\hline$\%$ Credit Card ABS & 18.88 & 39.14 & 0 & 0 & 0 & 100 & 100 & 2,188 \\
\hline \% Student Loan ABS & 7.77 & 26.78 & 0 & 0 & 0 & 100 & 100 & 2,188 \\
\hline$\%$ Equipment Loan ABS & 3.61 & 18.66 & 0 & 0 & 0 & 0 & 100 & 2,188 \\
\hline$\%$ Asset ABS & 5.12 & 22.04 & 0 & 0 & 0 & 100 & 100 & 2,188 \\
\hline$\%$ Floorplan ABS & 4.02 & 19.65 & 0 & 0 & 0 & 0 & 100 & 2,188 \\
\hline$\%$ Small Business ABS & 6.40 & 24.48 & 0 & 0 & 0 & 100 & 100 & 2,188 \\
\hline$\%$ CMBS & 31.35 & 46.40 & 0 & 0 & 0 & 100 & 100 & 2,188 \\
\hline
\end{tabular}


Table 2 (cont.)

\begin{tabular}{|c|c|c|c|c|c|c|c|c|}
\hline \multicolumn{9}{|c|}{ Panel B. Characteristics by Asset Class } \\
\hline & Auto & Credit Card & Student Loan & Equipment & Asset & Floorplan & Small Business & CMBS \\
\hline \multicolumn{9}{|l|}{ Loan Characteristics } \\
\hline Number of Loans & 500 & 413 & 170 & 79 & 112 & 88 & 140 & 686 \\
\hline Loan Amount (\$) & $25,571,200$ & $63,716,223$ & $52,762,941$ & $20,387,342$ & $29,386,607$ & $44,227,273$ & $15,378,571$ & $17,592,857$ \\
\hline Fixed Rate $(\%)$ & 2.57 & 2.83 & & 2.46 & 2.64 & 2.65 & 2.41 & 3.33 \\
\hline Floating Rate Spread (bps) & 100.00 & 100.00 & 147.65 & & 100.00 & 100.00 & 75.00 & \\
\hline Haircut $(\%)$ & 8.67 & 7.47 & 11.70 & 6.60 & 10.04 & 13.70 & 5.96 & 15.71 \\
\hline \multicolumn{9}{|l|}{ Borrower Characteristics } \\
\hline$\%$ Pension/Insurance Borrowers & 6.80 & 11.62 & 10.59 & 5.06 & 1.79 & 4.55 & 0.00 & 2.33 \\
\hline$\%$ Pension/Insurance Investors & 29.60 & 33.41 & 35.88 & 43.04 & 47.32 & 45.45 & 26.43 & 35.13 \\
\hline
\end{tabular}


Summary statistics on TALF loans are provided in Table 2, both for the full sample and by asset class. TALF loans were offer for several asset classes. Auto ABS are securities backed by consumer auto loans. Credit card ABS are backed by credit card receivables. Student loan ABS are backed by student loans. Equipment ABS are backed by leases for business equipment. Asset $\mathrm{ABS}$ are backed by either insurance premium finance loans or residential mortgage servicing advances. Floorplan ABS are backed by loans extended to automobile dealers to finance their inventory. Small business ABS are backed by loans guaranteed by the Small Business Administration. CMBS are backed by newly issued or legacy commercial mortgages.

TALF loans were for an average of \$32 million and overall \$71 billion were lent through TALF. Many of these loans were repaid before maturity. The haircuts on TALF loans averaged $10 \%$, which insured that investors took any initial loses on the ABS they purchased. Haircuts were highest on CMBS, floorplan ABS, and student loan ABS. The largest asset classes purchased with TALF loans were CMBS, auto ABS, and credit card ABS. Pension and insurance borrowers are most prevalent among auto, credit card, and student loan ABS. These are also the three largest classes of ABS, which may suggest that these investors prefer more common securities, as they may translate to more liquidity or less ambiguity. However, there does not appear to be an obvious correlation between investor type and risk, as measured by haircut or interest rate.

To show the usage of TALF relative to the entire securitization market, Table 3 shows the total volume of ABS issuance ${ }^{24}$ and the fraction that is TALF-funded. Auto ABS were initially highly funded by TALF. However, by the third quarter of 2008, this asset class was primarily funded in the private market. A significant portion of credit card ABS were funded by TALF throughout the duration of the program, but a significant portion was also funded in the private

\footnotetext{
${ }^{24}$ Data on net ABS issuance can be found at http://www.sifma.org/research/statistics.aspx.
} 
market. Equipment ABS relied very little on TALF, while ABS based on other asset classes, such as small business loans, floorplan loans, servicing advances, and premium finance, were funded predominantly by TALF.

\subsection{Hypotheses}

As discussed in the introduction, there are three primary channels through which TALF could operate - decreasing risk, decreasing ambiguity, and increasing participation via leverage. While these three channels are not mutually exclusive, each has certain empirical implications for both how the structure of securitization changes in the crisis and which securities are funded by TALF. First, risk and ambiguity have different effects on the structure of securitization deals. If the freeze in securitization markets is a result of increased risk, deals issued after the freeze should have smaller safe tranche. As the underlying collateral is riskier, it cannot support as large of a highly-rated tranche. On the other hand, if the freeze is due to increased ambiguity, Anderson (2012) suggests that deals should have a larger safe tranche. If investors have more ambiguity about the value of the underlying collateral, they are only willing to buy the safest tranches. Only investors who are not ambiguity averse will buy subordinate tranches. Therefore, issuers will structure their deals with larger safe tranches to increase participation. Additionally, if ambiguity is causing the market freeze, deals should become simpler by having fewer large tranches as opposed to many small tranches.

To examine the specific role of TALF, I look at the difference in the structure of TALFfunded tranches and those that were eligible for the program but did not participate. If TALF serves to reduce risk, the securities that are funded by TALF should be riskier than those that are not because investors may only be willing to buy these riskier securities if they have the support of a nonrecourse TALF loan. Campbell, Covitz, Nelson, and Pence (2011) find evidence of this, 


\section{Table 3. ABS Issuance}

This table provides summary statistics on asset-backed securities issuance during the time of TALF (March 2009 - March 2010). Values in Panel A and B represent the total dollar amount of ABS issued in each quarter by asset class in millions of dollars. Panel A shows only the portion of ABS that is funded by TALF, while Panel B shows all ABS issuance. The percent of total ABS issuance that is funded by TALF is shown in Panel C.

\begin{tabular}{|c|c|c|c|c|c|}
\hline \multirow[b]{2}{*}{ Class } & \multicolumn{5}{|c|}{ Total TALF-Funded ABS } \\
\hline & 2009 Q1 & $2009 \mathrm{Q} 2$ & $2009 \mathrm{Q} 3$ & 2009 Q4 & 2010 Q1 \\
\hline Auto & 1907 & 6051 & 4546 & 191 & 91 \\
\hline Credit Cards & 2803 & 12428 & 8411 & 1817 & 856 \\
\hline Equipment & 0 & 1035 & 111 & 295 & 170 \\
\hline Student Loans & 0 & 2508 & 3609 & 1038 & 1815 \\
\hline \multirow[t]{2}{*}{ Other } & 0 & 1018 & 2049 & 3063 & 3207 \\
\hline & \multicolumn{5}{|c|}{ Total ABS } \\
\hline Class & 2009 Q1 & $2009 \mathrm{Q} 2$ & $2009 \mathrm{Q} 3$ & $2009 \mathrm{Q} 4$ & 2010 Q1 \\
\hline Auto & 8819 & 16050 & 24706 & 13173 & 18828 \\
\hline Credit Cards & 3000 & 22556 & 16989 & 3550 & 1715 \\
\hline Equipment & 515 & 2629 & 1162 & 3349 & 1955 \\
\hline Student Loans & 1956 & 8310 & 6095 & 5736 & 4457 \\
\hline \multirow[t]{2}{*}{ Other } & 1571 & 1734 & 2206 & 4739 & 3991 \\
\hline & \multicolumn{5}{|c|}{ Percent of ABS that are TALF-Funded } \\
\hline Class & 2009 Q1 & $2009 \mathrm{Q} 2$ & 2009 Q3 & $2009 \mathrm{Q} 4$ & $2010 \mathrm{Q1}$ \\
\hline Auto & $21.63 \%$ & $37.70 \%$ & $18.40 \%$ & $1.45 \%$ & $0.48 \%$ \\
\hline Credit Cards & $93.44 \%$ & $55.10 \%$ & $49.51 \%$ & $51.17 \%$ & $49.93 \%$ \\
\hline Equipment & $0 \%$ & $39.36 \%$ & $9.51 \%$ & $8.81 \%$ & $8.72 \%$ \\
\hline Student Loans & $0 \%$ & $30.18 \%$ & $59.21 \%$ & $18.10 \%$ & $40.72 \%$ \\
\hline Other & $0 \%$ & $58.72 \%$ & $92.89 \%$ & $64.63 \%$ & $80.34 \%$ \\
\hline
\end{tabular}


given that both yields and yield spread volatilities are higher among TALF-funded securities. To further test this, I look at the delinquency characteristics of the underlying collateral of CMBS. If TALF is helping reduce risk, TALF-funded securities should have higher losses, loan-to-value ratios, and foreclosure rates.

Characterizing differences in ambiguity between tranches is more subjective since ambiguity can arise from a number of sources. The first attribute I consider is the structure of the deal in terms of the number of tranches and the size of each. As mentioned above, a structure with fewer large tranches is likely to be less ambiguous since it is less complicated. This implies TALF-funded tranches will be smaller and be part of deals with more total tranches. However, the alternative is also possible. For example, consider two deals - Deal A has one large AAArated tranche that is $50 \%$ of the total deal and Deal B has 5 AAA-rated tranches that are each $10 \%$ of the total deal. Although all of these tranches have similar risk levels, as evidenced by the fact that they are all AAA-rated, the single large tranche in Deal A will likely experience losses sooner than the senior tranches in Deal B and has a larger range of losses than any one tranche in Deal B, making it more ambiguous. Therefore, if TALF serves to reduce ambiguity, TALFfunded tranches may be larger, both in dollar value and percent of the total deal, and be part of deals with fewer total tranches. Additionally, in a security like Deal B, the more subordinate tranches are likely to have more ambiguity since, despite their high credit rating, they will experience losses sooner than the other highly-rated tranches. Lastly, tranches with variable rates, tranches that are callable, and tranches that are private placements may also be more likely to be TALF-funded since these features increase the uncertainty of the security.

The final channel which TALF could provide support to the market was through increased leverage, which would enable new investors to enter the market and increase liquidity. 
Levered investors were forced from securitization markets in late 2008 as rollover risk and rising spreads limited their funding. However, the introduction of TALF provided a new source of funding for levered investors. In particular, Ashcraft, Malz, and Pozsar (2009) show that the market share of hedge funds increased from $2-5 \%$ before the crisis to $32 \%$ in 2009 . If these new investors were willing to enter the market using TALF given the higher returns that leverage would provide them, TALF-funded securities should also have higher coupons than non-funded securities.

In addition to the structural differences suggested by these three channels, they also have different implications on whether TALF will have security-level benefits on just the securities taking part in the program or market-level benefits for the securitization market as a whole. If TALF reduces risk, it will directly benefit the securities funded through the program since it puts a cap on how much the investor can lose. However, there is no spillover benefit to other securities in the market that are not funded by TALF. Likewise, if TALF is reducing ambiguity, it will directly benefit the funded security for the same reason. However, reducing ambiguity does have a spillover effect. The fact that the Federal Reserve is willing to offer these loans gives investors a signal about the value of the securities, which reduces their ambiguity. Therefore, even if a security is not funded by the program, the mere fact that it is eligible decreases its ambiguity and makes investors more willing to purchase this security. Lastly, increasing participation through leverage has market-level benefits since a larger pool of investors will make the market for all securities more liquid. 


\section{CHAPTER 9}

\section{EMPIRICAL RESULTS}

\subsection{Tranche Structure during the Crisis}

To address the roles of risk and ambiguity in the financial crisis, I begin with a deal-level look at the composition of securities by ratings. If risk is high during the crisis, deals should have smaller highly-rated tranches due to poorer quality collateral. On the other hand, if ambiguity is high, deals should have larger highly-rated tranches since they are more attractive to ambiguity averse investors. Figure 11 shows the percentage of the total dollar value of securitization issuance by rating throughout the crisis period. The intervals are pre-crisis (before 9/2008), during the crisis but before TALF (9/2008 to 2/2009), during the crisis and TALF (3/2009 to 3/2010), and after TALF (after 3/2010). Note that each group is the percentage of the entire deal that is given that particular rating, but there may be multiple tranches within each rating. Within the CMBS market, the amount of AAA-rated tranches decreases by almost half during the crisis (interval 3). This likely reflects the increased risk in mortgage-related securities due to price declines in the real estate market and suggests that risk is more relevant than ambiguity in this market. Similarly, when the crisis first began (interval 2), there were very few securities issued, none of which were AAA-rated. However, after the crisis (interval 4), the structure of securitization deals is very similar to what it was before the crisis (interval 1).

Relative to CMBS, ABS issuances are more likely to be AAA-rated overall. Additionally,

during the crisis (interval 3), there is a small increase in AAA-rated tranches and an even larger increase in tranches rated A or better. This suggests that there was not a significant increase in 


\section{Figure 11. Deal Composition over Time}

This figure shows the percentage of the total dollar value of securitization issuance by rating over four time intervals. The intervals are pre-crisis (before 9/2008), during the crisis but before TALF (9/2008 to $2 / 2009$ ), during the crisis and TALF (3/2009 to 3/2010), and after TALF (after 3/2010). The sample is restricted to deals with ratings. NR refers to tranches that are not rated.

\section{Panel A. CMBS Deal Structure}

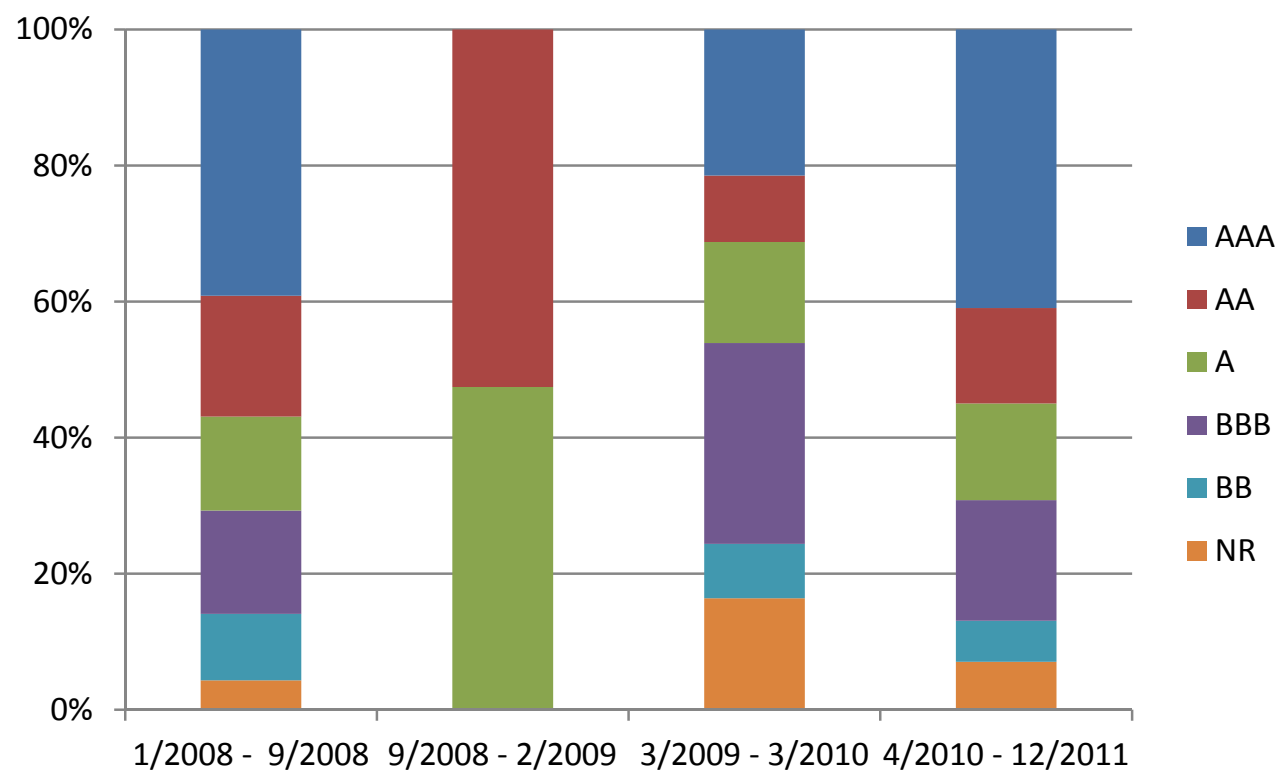

\section{Panel B. ABS Deal Structure}

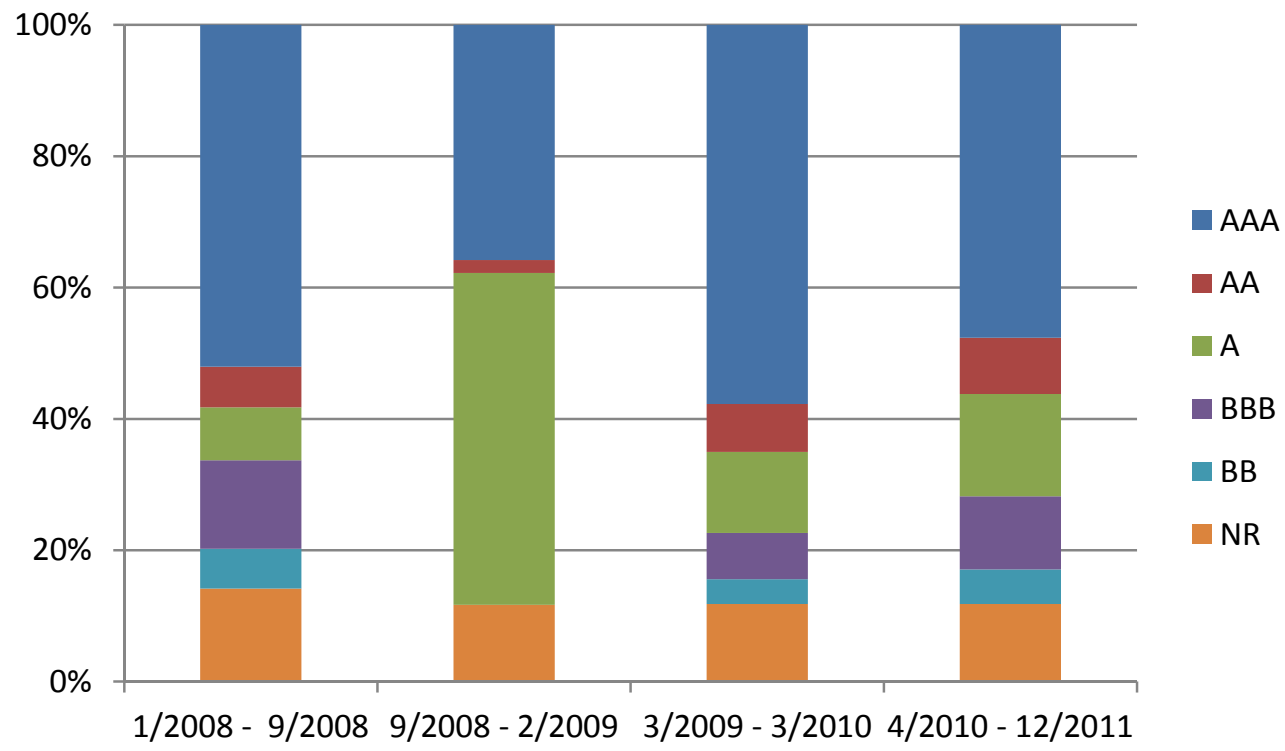


risk or losses in these markets, as the underlying collateral still received high ratings. This supports the idea that investors did not pull out of the ABS markets due to increased risk, but rather because of increased ambiguity. As with CMBS deals, the structure of deals is very similar in the last period after the crisis (interval 4) to what it was before the crisis (interval 1).

Next, I conduct a univariate analysis of the key tranche variables over time. The sample period is divided into four time intervals - pre-crisis (before 9/2008), during the crisis but before TALF (9/2008 to 2/2009), during the crisis and TALF (3/2009 to 3/2010), and after TALF (after 3/2010). The means and medians of all of the tranche-level variables discussed in Section 8.2 by interval can be seen in Table 4. I test for differences in means between intervals 1 and 2, 2 and 3, 3 and 4 , and 1 and 4 . Asterisks on the means of intervals 2, 3, and 4 denote the significance of the differences of these values from the corresponding means in intervals 1,2 , and 3 , respectively.

Panel A of Table 4 presents the univariate analysis for CMBS. First, the data show the decline in issuance of new tranches during the crisis, as the number of tranches issued per month drops from around 150 before the crisis to 2 when the crisis first begins. In the following periods, issuance increases but is still significantly less after the crisis than it was before. When the crisis first begins, tranches are more likely to have fixed rates, have much fewer tranches per deal, and are less likely to be private placements. Further into the crisis once TALF begins, there is an increase in coupons and fewer tranches per deal than before the crisis. Tranches are also less likely to be callable and more likely to be private placements, which is consistent with the freezing of the CMBS market in late 2008. I also find that more tranches have a credit rating and a larger portion of those that are rated have either a AAA or investment grade rating. The results on ratings and number of tranches per deal suggest a change in the structure of CMBS during the 


\section{Table 4. Univariate Analysis of Tranche Structure across Time}

This table presents the univariate analysis of tranche-level variables over four time intervals. The intervals are pre-crisis (before 9/2008), during the crisis but before TALF (9/2008 to 2/2009), during the crisis and TALF (3/2009 to 3/2010), and after TALF (after 3/2010). Original Tranche Value is the dollar value of the tranche at origination. Original Deal Value is the total dollar value of the entire deal to which the tranche belongs. Amount Outstanding is the dollar value of the tranche outstanding in June 2012. Original $W A L$ is the weighted-average life of the underlying collateral in years. Duration is the expected life of the tranche in years. Fixed Coupon is the coupon rate paid to holders of fixed rate tranches. Floating Spread is the spread over the reference rate (typically LIBOR) in basis points paid to investors in variable rate tranches. Original WAC is the weighted-average coupon of the underlying collateral. Tranche as \% of Entire Deal is Original Tranche Value divided by Original Deal Value. \% Rated is the percent of tranches that have a credit rating from either Standard \& Poor's, Fitch, Moody's, or DBRS. $\% A A A$ is the percent of all tranches (both rated and unrated) that are rated AAA by any of the 4 rating agencies. $\%$ Investment Grade is the percent of all tranches that are rated BBB- or higher by Standard \& Poor's or Fitch, Baa3 or higher by Moody's, or BBB or higher by DBRS. \% TALF-Funded is the percent of tranches that have any portion funded by TALF loans. T-tests are done on the difference in means between subsequent intervals. Asterisks on mean values for interval $t$ denote the significance of differences between the means of interval $t$ and the means of interval $t-1$. The last two columns report the differences between means and medians of interval 4 and interval $1 . * * *, * *$ and $*$ indicate $\mathrm{p}$-values of $1 \%, 5 \%$, and $10 \%$, respectively. 
Table 4 (cont.)

\begin{tabular}{|c|c|c|c|c|c|c|c|c|c|c|}
\hline \multirow{5}{*}{$\begin{array}{l}\text { Number of Tranches } \\
\text { Tranches per Month }\end{array}$} & \multicolumn{8}{|c|}{ Panel B. Comparison of CMBS Tranches over Time } & \multirow{2}{*}{\multicolumn{2}{|c|}{$\begin{array}{c}\text { Difference between } \\
\text { Interval } 4 \text { and Interval }\end{array}$}} \\
\hline & \multicolumn{2}{|c|}{$1 / 2003-8 / 2008$} & \multicolumn{2}{|c|}{$9 / 2008-2 / 2009$} & \multicolumn{2}{|c|}{$3 / 2009-3 / 2010$} & \multicolumn{2}{|c|}{$4 / 2010-12 / 2011$} & & \\
\hline & \multicolumn{2}{|c|}{10,329} & \multicolumn{2}{|c|}{13} & \multicolumn{2}{|c|}{244} & \multicolumn{2}{|c|}{750} & \multirow{2}{*}{\multicolumn{2}{|c|}{-116.18}} \\
\hline & & & 2. & & 18 & & 35 . & & & \\
\hline & Mean & Median & Mean & Median & Mean & Median & Mean & Median & Mean & Median \\
\hline \multicolumn{11}{|l|}{ Characteristics } \\
\hline Original Tranche Value (\$) & 192045 & 25000 & 376871 & 133515 & $61394 *$ & 24432 & $160374 * * *$ & 44760 & -31671 & 19760 \\
\hline Original Deal Value (\$) & 1854892 & 1597857 & 1448640 & 207703 & 393834 & 250994 & $912404 * * *$ & 856633 & $-942488^{* * *}$ & -741224 \\
\hline Amount Outstanding $(\$)$ & 112538 & 9173 & $44202 * * *$ & 25769 & 55687 & 23750 & $149410^{* * *}$ & 41555 & $36872 * *$ & 32382 \\
\hline Original WAL & 7.80 & 9.69 & 6.56 & 3.68 & 6.94 & 7.12 & $6.32 * * *$ & 6.61 & $-1.48 * * *$ & -3.09 \\
\hline Duration & 31.67 & 35 & 28.31 & 31 & $33.65^{*}$ & 36 & $29.96 * * *$ & 33 & $-1.71 * * *$ & -2 \\
\hline$\%$ with Fixed Rate & 18.51 & & $0.46^{*}$ & & $0.23 *$ & & $0.37 * * *$ & & $0.19^{* * *}$ & \\
\hline Fixed Coupon (\%) & 4.85 & 5.04 & 5.79 & 5.84 & 4.83 & 5.21 & $3.92 * * *$ & 4.19 & $-0.93 * * *$ & -0.85 \\
\hline Floating Spread (bps) & 106.66 & 75 & $100 * * *$ & 100 & 325 & 335 & 230.01 & 144.1 & $123.36 * * *$ & 69.1 \\
\hline Original WAC & 5.86 & 5.75 & $6.36^{* * *}$ & 6.36 & $5.48 * * *$ & 5.49 & 5.46 & 5.62 & $-0.4 * * *$ & -0.13 \\
\hline Tranche as $\%$ of Entire Deal & 6.20 & 1.32 & $42.73 * * *$ & 23.35 & $18.79 * *$ & 11.16 & $16.03 *$ & 6.50 & $9.84 * * *$ & 5.19 \\
\hline \# of Tranches in Deal & 23.48 & 24.00 & $4.85^{* * *}$ & 7.00 & $15.52 * * *$ & 12.00 & $19.75 * * *$ & 13.00 & $-3.73 * * *$ & -11 \\
\hline$\%$ Callable & 90.47 & & 76.92 & & $37.3 * * *$ & & $74.93 * * *$ & & $-15.54 * * *$ & \\
\hline \% Private Placement & 62.08 & & $23.08 * * *$ & & $95.9 * * *$ & & $91.87 * *$ & & $29.79 * * *$ & \\
\hline \multicolumn{11}{|l|}{ Ratings } \\
\hline$\%$ Rated & 63.56 & & $23.08 * * *$ & & $96.72 * * *$ & & $87.6^{* * *}$ & & $24.04 * * *$ & \\
\hline$\%$ AAA Rated & 53.61 & & $0 * * *$ & & $84.43 * * *$ & & $61.6^{* * *}$ & & $7.99 * * *$ & \\
\hline \% Investment Grade & 61.53 & & $23.08 * * *$ & & $96.31 * * *$ & & $82.93 * * *$ & & $21.41 * * *$ & \\
\hline \multicolumn{11}{|l|}{ TALF } \\
\hline$\%$ TALF-Funded & 2.47 & & 0 & & 0.41 & & 0 & & & \\
\hline
\end{tabular}


Table 4 (cont.)

\begin{tabular}{|c|c|c|c|c|c|c|c|c|c|c|}
\hline \multicolumn{11}{|c|}{ Panel B. Comparison of ABS Tranches over Time } \\
\hline \multirow{4}{*}{$\begin{array}{l}\text { Number of Tranches } \\
\text { Tranches per Month }\end{array}$} & \multicolumn{2}{|c|}{$1 / 2008-8 / 2008$} & \multicolumn{2}{|c|}{$9 / 2008-2 / 2009$} & \multicolumn{2}{|c|}{$3 / 2009-3 / 2010$} & \multicolumn{2}{|c|}{$4 / 2010-12 / 2011$} & \multicolumn{2}{|c|}{$\begin{array}{c}\text { Difference between } \\
\text { Interval } 4 \text { and Interval } 1\end{array}$} \\
\hline & \multicolumn{2}{|c|}{507} & \multicolumn{2}{|c|}{189} & \multicolumn{2}{|c|}{602} & \multicolumn{2}{|c|}{1,169} & \multirow{2}{*}{\multicolumn{2}{|c|}{-7.71}} \\
\hline & & & 31.5 & & 46. & & 55 & & & \\
\hline & Mean & Median & Mean & Median & Mean & Median & Mean & Median & Mean & Median \\
\hline \multicolumn{11}{|l|}{ Characteristics } \\
\hline Original Tranche Value $(\$)$ & 261191 & 120000 & $126491 * * *$ & 28279 & $291433 * * *$ & 163000 & $170651^{* * *}$ & 112790 & $-90540 * * *$ & -7210 \\
\hline Original Deal Value (\$) & 1008170 & 750000 & $1694376^{* * *}$ & 643920 & $921466 * * *$ & 690790 & $716733 * * *$ & 708189 & $-291438 * * *$ & -41811 \\
\hline Amount Outstanding (\$) & 97697 & 0 & $47562 * * *$ & 1552 & $133756 * * *$ & 12434 & 116954 & 50460 & 19258 & 50460 \\
\hline Original WAL & 3.29 & 2.54 & $2.45^{*}$ & 1.85 & 2.7 & 2.32 & $3.37 * * *$ & 2.92 & 0.08 & 0.38 \\
\hline Duration & 7.90 & 6 & $13.74 * * *$ & 7 & $7.23 * * *$ & 5 & $9.26 * * *$ & 6 & $1.36 * * *$ & 0 \\
\hline$\%$ with Fixed Rate & 56.41 & & $0.49 *$ & & $0.77 * * *$ & & 0.79 & & $0.22 * * *$ & \\
\hline Fixed Coupon (\%) & 5.21 & 5.05 & 5.65 & 5.57 & $3.4 * * *$ & 2.98 & $2.58 * * *$ & 1.99 & $-2.63 * * *$ & -3.06 \\
\hline Floating Spread (bps) & 160.40 & 120 & $825.08 * * *$ & 1,100 & $203.12 * * *$ & 155 & $118.21 * * *$ & 86 & $-42.19 * * *$ & -34 \\
\hline Original WAC & 7.59 & 6.93 & $8.76^{*}$ & 7.01 & 7.66 & 6.21 & $9.4 * * *$ & 5.90 & $1.8 * * *$ & -1.03 \\
\hline Tranche as $\%$ of Entire Deal & 31.56 & 17.86 & 30.66 & 14.02 & 35.54 & 21.39 & $29.62 * * *$ & 19.70 & -1.94 & 1.84 \\
\hline \# of Tranches in Deal & 5.32 & 5.00 & $23.95 * * *$ & 7.00 & $4.1 * * *$ & 4.00 & $4.44 * * *$ & 5.00 & $-0.88 * * *$ & 0 \\
\hline$\%$ Callable & 94.28 & & $45.5^{* * *}$ & & $95.18 * * *$ & & 94.7 & & 0.42 & \\
\hline$\%$ Private Placement & 21.70 & & $31.22 * *$ & & $51.33 * * *$ & & $46.11 * *$ & & $24.41 * * *$ & \\
\hline \multicolumn{11}{|l|}{ Ratings } \\
\hline$\%$ Rated & 62.13 & & $29.1 * * *$ & & $73.75 * * *$ & & $87.25 * * *$ & & $25.12 * * *$ & \\
\hline$\%$ AAA Rated & 50.10 & & $16.4 * * *$ & & $58.64 * * *$ & & 56.89 & & $6.79 * *$ & \\
\hline \% Investment Grade & 61.34 & & $29.1 * * *$ & & $73.59 * * *$ & & $85.12 * * *$ & & $23.77 * * *$ & \\
\hline \multicolumn{11}{|l|}{ Type of Deal } \\
\hline$\%$ Auto Loan ABS & 43.98 & & $25.93 * * *$ & & $49.83 * * *$ & & $57.57 * * *$ & & $13.59 * * *$ & \\
\hline$\%$ Credit Card ABS & 20.32 & & $11.64 * * *$ & & $20.6^{* * *}$ & & $5.99 * * *$ & & $-14.33 * * *$ & \\
\hline$\%$ Student Loan ABS & 15.98 & & $1.06^{* * *}$ & & $5.98 * * *$ & & $12.32 * * *$ & & $-3.66^{*}$ & \\
\hline$\%$ Equipment Loan ABS & 6.11 & & $1.06 * * *$ & & $13.29 * * *$ & & 11.89 & & $5.78 * * *$ & \\
\hline$\%$ Asset ABS & 10.65 & & $54.5^{* * *}$ & & $6.48 * * *$ & & $9.41 * *$ & & -1.24 & \\
\hline$\%$ Small Business ABS & 2.96 & & 5.82 & & 3.82 & & 2.82 & & -0.14 & \\
\hline \multicolumn{11}{|l|}{ TALF } \\
\hline$\%$ TALF-Funded & 0.59 & & 1.59 & & 23.59 & & 0 & & & \\
\hline
\end{tabular}


crisis. Specifically, deals with larger safe tranches and less complexity are being issued. This is likely due to the increased uncertainty in the market, which causes investors to demand safer securities.

In the final interval of the sample, some of the changes begin to reverse direction. The number of tranches per deal increases, the percent of callable tranches increases, and the percent of private placements decreases. Additionally, fewer tranches have a credit rating and a smaller fraction of those that are rated are AAA or investment grade. As market conditions improve and uncertainty decreases, investors are more willing to purchase riskier tranches. However, tranches have not reverted to their pre-crisis structure. There remains significantly more highly-rated, larger tranches in the market.

Similar univariate analysis on ABS tranches is shown in Panel B of Table 4. Again there is a decrease in the issuance of tranches during and after the crisis, although issuance continues to increase since its initial drop in late 2008. When the crisis first begins, there is a significant increase in coupons on both fixed and variable rate tranches. There is a large drop in the percent of callable tranches and an increase in private placements. Initially, there is also an increase in the number of tranches per deal. This is likely due to the fact that there is a corresponding increase in the proportion of asset ABS relative to other asset classes. Asset ABS generally have more tranches per deal than other ABS classes. As in the case with the CMBS tranches, these initial trends begin to reverse in the third time interval.

Overall, ABS have fewer tranches per deal, a significantly larger share of rated tranches, and more private placements after the crisis relative to before the crisis. Additionally, tranches and deals are significantly smaller and are more likely to be fixed rate securities. These results are consistent with, albeit not as strong as, the results on CMBS that suggest a shift toward 
larger, safer tranches. This supports the idea that ambiguity was an issue during the crisis and issuers shifted to simpler deal structures to encourage the participation of ambiguity averse investors. There is also an increase in $\mathrm{ABS}$ backed by auto and equipment loans and a decrease in those backed by credit card receivables and student loans.

\subsection{Assessing the Channels through which TALF Operates}

\subsubsection{TALF Funding and Tranche Structure}

As shown in the previous section, the structure of securitization tranches was significantly affected during the financial crisis as a result of increased ambiguity and, to a lesser extent, increased risk. To assess the role that TALF played in mitigating these issues, I look at the difference in the structure of securitization tranches funded by TALF versus those that were TALF-eligible but did not participate in the program. The program can be divided into two groups - legacy CMBS and newly issued ABS. Since legacy CMBS were issued before the crisis, their structure is exogenous. On the other hand, the ABS tranches were being issued when the crisis and, in most cases, TALF were already underway. Here the structure of the tranches is endogenous.

I first look at the structure of deals that had at least one tranche funded by TALF relative to those that did not. Figure 12 shows the percentage of the total dollar value of securitization issuance by rating for these two groups. To be included in the 'No TALF' category, a deal has to have at least one TALF-eligible tranche but not actually participate in the program. CMBS that were TALF-funded have a smaller percentage of AAA-rated tranches. This suggests that CMBS that participated in the program are more risky. 


\section{Figure 12. Deal Composition and TALF Funding}

This figure shows the percentage of the total dollar value of securitization issuance by rating for deals that had at least one tranche funded by TALF versus those that did not. The 'No TALF' group includes only those deals which have at least one TALF-eligible tranche, but still did not participate. NR refers to tranches that are not rated.

\section{Panel A. CMBS Deal Structure}

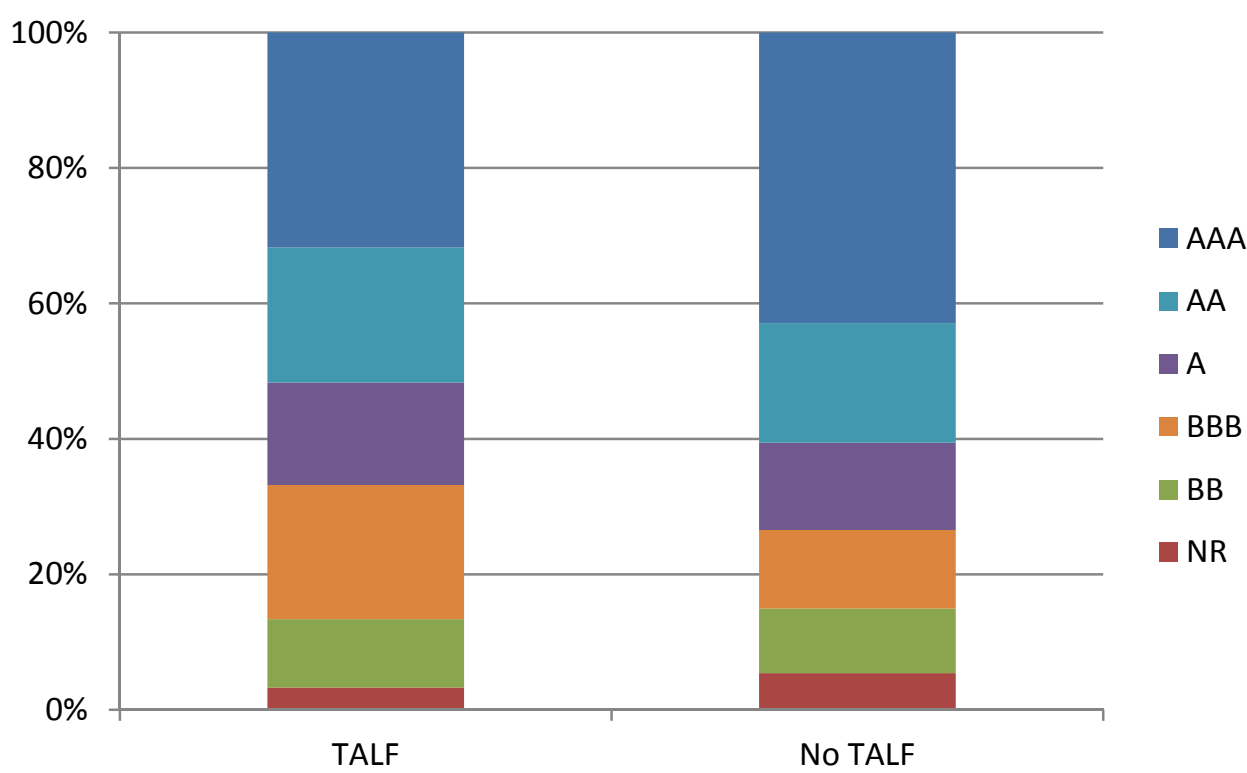

\section{Panel B. ABS Deal Structure}

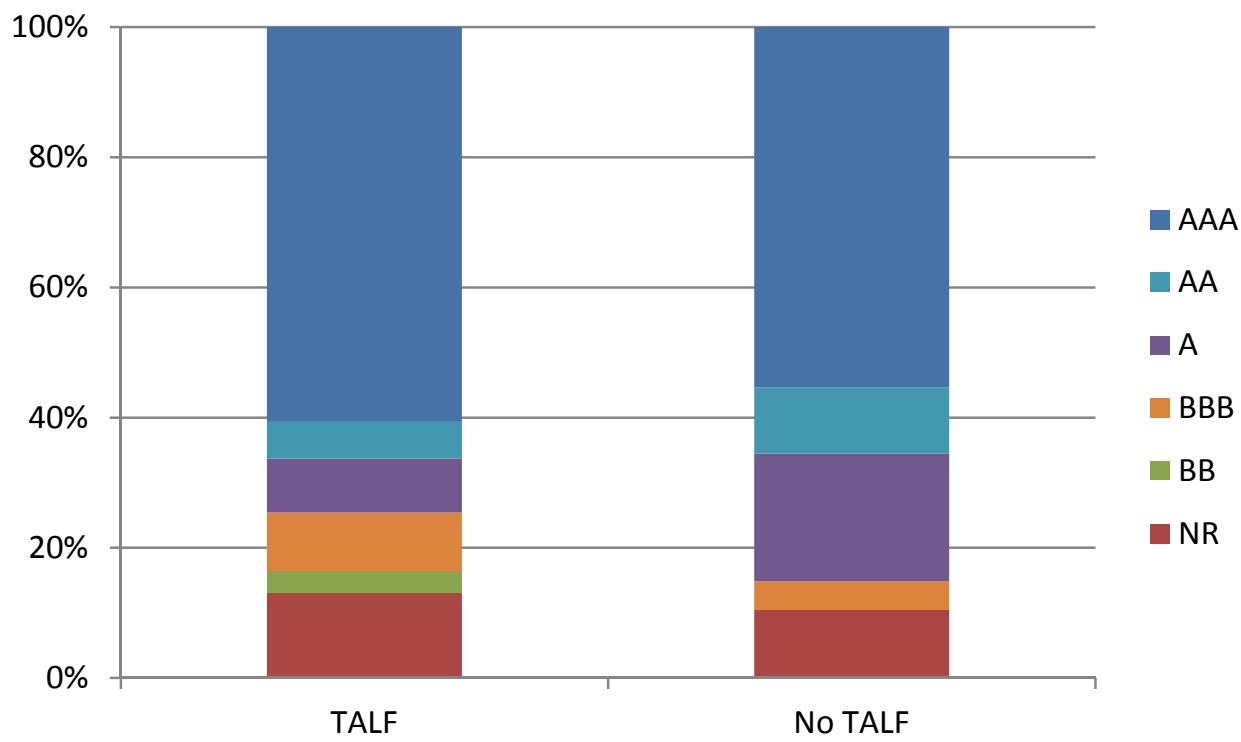


ABS deals that were involved in TALF have a slightly larger percentage of AAA-rated tranches. Additionally, they have a larger proportion of not rated or junk rated tranches. TALFfunded deals have a larger dispersion across ratings, while those deals not funded by TALF are more concentrated in the AAA- and A-rated groups. This suggests that TALF-funded tranches come from more complex deals and therefore may be more ambiguous to investors. Additionally, the underlying collateral is more risky. As a result, investors may purchase these securities using TALF loans to reduce their exposure given their increased uncertainty over the potential payoffs of these securities.

To examine the differences between tranches funded by TALF and those not in more detail, I run probit models on all TALF-eligible CMBS tranches. To be eligible, tranches had to be AAA-rated and issued before 2009. The results of these regressions are shown in Table 5 . Tranches that were funded at least partially by TALF are larger and more likely to have a fixed rate than those tranches that were not. Additionally, their fixed rate coupon is higher, they are less likely to be private placements, and the underlying collateral has both a shorter life and a lower coupon. Given that the collateral has a lower coupon but the tranche itself has a higher coupon, these tranches are likely more subordinated than those not funded by TALF. This is consistent with the hypothesis that TALF enabled investors to buy potentially riskier or more ambiguous securities than they would have otherwise. Lastly, legacy CMBS tranches that are funded by TALF are a larger percentage of the entire deal than those that are not. This also could suggest that these tranches are more ambiguous since there is a larger range of possible outcomes with a larger tranche. Investors were more willing to participate in these more ambiguous tranches given the nonrecourse protection provided by TALF. Overall, the tranches funded by the legacy CMBS TALF program were larger, both in dollar value and in percent of the entire 


\section{Table 5. Multivariate Analysis of TALF Funding and Tranche Structure}

This table presents the results of multivariate probit regressions in which the dependent variable is whether or not the tranche was funded by TALF. The sample consists of all TALF-eligible, AAA-rated tranches. Original Tranche Value is the dollar value of the tranche at origination. Amount Outstanding is the dollar value of the tranche outstanding as of June 2012. WAL is the weighted-average life of the underlying collateral at origination in years. Duration is the expected life of the tranche in years. Fixed is a dummy variable equal to 1 if the tranche has a fixed rate. Coupon is the coupon rate paid to holders of fixed rate tranches. WAC is the weighted-average coupon of the underlying collateral. Percent Deal is Original Tranche Value divided by Original Deal Value. Tranches is the total number of tranches in the deal. Callable is a dummy variable equal to 1 if the tranche is callable. Private is a dummy variable equal to 1 if the tranche was a private placement. Standard errors are reported in parentheses. ***, ** and * indicate p-values of $1 \%, 5 \%$, and $10 \%$, respectively.

\begin{tabular}{|c|c|c|c|c|c|c|}
\hline & \multicolumn{2}{|c|}{ Full Sample } & \multicolumn{2}{|c|}{ Legacy CMBS Only } & \multicolumn{2}{|c|}{ ABS Only } \\
\hline & (1) & (2) & (3) & (4) & (5) & (6) \\
\hline Intercept & $\begin{array}{l}-21.659 \\
(257.5)\end{array}$ & $\begin{array}{l}-22.959 \\
(257.4)\end{array}$ & $\begin{array}{l}-10.674 \\
(156.3)\end{array}$ & $\begin{array}{c}-13.545 \\
(156)\end{array}$ & $\begin{array}{c}-10.186^{* * *} \\
(2.8)\end{array}$ & $\begin{array}{c}-10.231^{* *} \\
(4.158)\end{array}$ \\
\hline Original Tranche Value & $\begin{array}{c}0.577 * * * \\
(0.09)\end{array}$ & $\begin{array}{c}0.574 * * * \\
(0.099)\end{array}$ & $\begin{array}{c}0.421 * * * \\
(0.106)\end{array}$ & $\begin{array}{c}0.439 * * * \\
(0.115)\end{array}$ & $\begin{array}{c}0.895^{* * *} \\
(0.153)\end{array}$ & $\begin{array}{c}0.883^{* * *} \\
(0.214)\end{array}$ \\
\hline Amount Outstanding & $\begin{array}{l}-0.001 \\
(0.015)\end{array}$ & $\begin{array}{c}0.013 \\
(0.015)\end{array}$ & $\begin{array}{c}0.007 \\
(0.022)\end{array}$ & $\begin{array}{c}0.011 \\
(0.022)\end{array}$ & $\begin{array}{l}-0.022 \\
(0.018)\end{array}$ & $\begin{array}{l}0.0538^{*} \\
(0.028)\end{array}$ \\
\hline$W A L$ & $\begin{array}{c}-0.296^{* * *} \\
(0.034)\end{array}$ & $\begin{array}{c}-0.364^{* * *} \\
(0.038)\end{array}$ & $\begin{array}{c}-0.412^{* * *} \\
(0.041)\end{array}$ & $\begin{array}{c}-0.444 * * * \\
(0.044)\end{array}$ & $\begin{array}{c}-0.443 * * * \\
(0.134)\end{array}$ & $\begin{array}{c}-0.712 * * * \\
(0.198)\end{array}$ \\
\hline Duration & $\begin{array}{c}0.021 * \\
(0.011)\end{array}$ & $\begin{array}{c}0.039^{* * *} \\
(0.012)\end{array}$ & $\begin{array}{c}0.011 \\
(0.013)\end{array}$ & $\begin{array}{c}0.021 \\
(0.014)\end{array}$ & $\begin{array}{c}0.061 * \\
(0.034)\end{array}$ & $\begin{array}{l}0.0467 \\
(0.055)\end{array}$ \\
\hline Fixed & $\begin{array}{c}0.301 * * * \\
(0.107)\end{array}$ & $\begin{array}{c}0.304 * * * \\
(0.109)\end{array}$ & $\begin{array}{c}0.498^{* * *} \\
(0.15)\end{array}$ & $\begin{array}{c}0.527 * * * \\
(0.164)\end{array}$ & $\begin{array}{c}-2.052 * * * \\
(0.472)\end{array}$ & $\begin{array}{c}-1.466^{* * * *} \\
(0.565)\end{array}$ \\
\hline Coupon & $\begin{array}{c}0.286^{* * *} \\
(0.059)\end{array}$ & $\begin{array}{c}0.305 * * * \\
(0.066)\end{array}$ & $\begin{array}{c}0.605^{* * *} \\
(0.205)\end{array}$ & $\begin{array}{c}0.746^{* * *} \\
(0.258)\end{array}$ & $\begin{array}{c}0.247 * * * \\
(0.075)\end{array}$ & $\begin{array}{c}0.04 \\
(0.091)\end{array}$ \\
\hline$W A C$ & $\begin{array}{c}-0.0581 \\
(0.036)\end{array}$ & $\begin{array}{l}-0.064 \\
(0.041)\end{array}$ & $\begin{array}{c}-1.0215^{* * *} \\
(0.248)\end{array}$ & $\begin{array}{c}-0.825^{* *} \\
(0.332)\end{array}$ & & \\
\hline Percent Deal & $\begin{array}{l}0.011^{*} \\
(0.006)\end{array}$ & $\begin{array}{l}0.016^{* *} \\
(0.007)\end{array}$ & $\begin{array}{c}0.035^{* * *} \\
(0.008)\end{array}$ & $\begin{array}{c}0.035^{* * *} \\
(0.009)\end{array}$ & $\begin{array}{c}-0.0369^{* * *} \\
(0.009)\end{array}$ & $\begin{array}{c}-0.033 * * * \\
(0.011)\end{array}$ \\
\hline Tranches & $\begin{array}{l}-0.009 \\
(0.011)\end{array}$ & $\begin{array}{l}-0.01 \\
(0.011)\end{array}$ & $\begin{array}{l}-0.007 \\
(0.013)\end{array}$ & $\begin{array}{l}-0.006 \\
(0.013)\end{array}$ & $\begin{array}{c}-0.242 * * * \\
(0.084)\end{array}$ & $\begin{array}{l}-0.3^{* *} \\
(0.122)\end{array}$ \\
\hline Callable & $\begin{array}{c}4.564 \\
(31.895)\end{array}$ & $\begin{array}{c}4.55 \\
(30.969)\end{array}$ & $\begin{array}{c}6.318 \\
(156.3)\end{array}$ & $\begin{array}{l}6.257 \\
(156)\end{array}$ & $\begin{array}{c}-2.135^{* *} \\
(0.862)\end{array}$ & $\begin{array}{c}-2.809 * * * \\
(0.965)\end{array}$ \\
\hline Private & $\begin{array}{c}-0.462 * * \\
(0.232)\end{array}$ & $\begin{array}{c}-0.495^{* *} \\
(0.246)\end{array}$ & $\begin{array}{c}-1.861 * * * \\
(0.591)\end{array}$ & $\begin{array}{c}-1.731 * * * \\
(0.607)\end{array}$ & $\begin{array}{l}0.591 * * \\
(0.241)\end{array}$ & $\begin{array}{c}1.596^{* * *} \\
(0.405)\end{array}$ \\
\hline $\begin{array}{l}\text { Asset Class Fixed Effect } \\
\text { Time Fixed Effect }\end{array}$ & $\begin{array}{l}\text { Yes } \\
\text { No }\end{array}$ & $\begin{array}{l}\text { Yes } \\
\text { Yes }\end{array}$ & No & Yes & $\begin{array}{l}\text { Yes } \\
\text { No }\end{array}$ & $\begin{array}{l}\text { Yes } \\
\text { Yes }\end{array}$ \\
\hline Obs. & 1145 & 1145 & 1024 & 1024 & 230 & 230 \\
\hline
\end{tabular}


deal, and had higher coupons despite having lower coupon collateral.

Table 5 also shows the results of the probit regressions for newly issued ABS. As with CMBS, tranches that were funded by TALF are larger, have higher coupons, and have shorter duration collateral. However, they are less likely to have a fixed rate, less likely to be callable, and more likely to be private placements. TALF-funded ABS tranches are a smaller percentage of the entire deal and are part of deals with fewer total tranches. This implies that these deals have a few, large tranches, as opposed to the unfunded tranches, which are a large portion of deals with many tranches. Therefore, the TALF-funded tranches have a higher degree of subordination and are less complex. This should make them safer and more attractive to investors, contrasting the idea that TALF is used for risker, more ambiguous tranches that need to induce participation using the nonrecourse feature of TALF loans. However, we saw in Table 4 that ABS tranches in general were larger and deals had fewer tranches while TALF was operational, but tranches became smaller and deals had more tranches after the program ended. Originators may have chosen to create larger tranches with more subordination because it was more likely that these securities would be accepted into TALF and would therefore be easier to sell to investors. However, once the program ended, they moved back toward the pre-crisis structure. Unfortunately, it is not possible to say whether this is due to the end of TALF or the end of the crisis.

The third channel suggests that TALF induced participation by new investors such as hedge funds by providing them with a significant amount of leverage that they were unable to get in the private market. Investors only had to put up the haircut, which encouraged them to purchase ABS despite the relatively low coupons on the tranches themselves. If these investors were seeking higher returns through leverage, it would seem that they would gravitate toward 
securitization tranches with higher coupons. This is indeed the case with CMBS tranches. However, after controlling for time fixed effects, the ABS tranches funded by TALF did not have a significantly different coupon from those not funded by TALF.

\subsubsection{TALF Participation, Tranche Structure, and Loan Performance}

As discussed in the previous section, legacy CMBS that were funded by TALF were larger, both in dollar value and fraction of the entire deal, and had higher coupons despite having lower coupon collateral, suggesting greater subordination and therefore greater risk. However, I am interested in whether these funded tranches are actually more risky in terms of the default likelihood of the underlying collateral, or if they are simply more ambiguous due to their structure. To test this, I add deal-level delinquency variables to the probit regressions on legacy CMBS. Specifically, WALTV is the weighted-average loan-to-value ratio of the underlying collateral. $D S C R$ is the weighted-average debt-service coverage ratio of the underlying collateral. Loans is the total number of loans remaining in the collateral pool. Losses is the percentage of cumulative losses on the underlying collateral. Foreclosure is the percentage of loans in the collateral pool that are in foreclosure. $R E O$ is the percentage of loans in the collateral pool that are bank-owned. Additionally, I break the sample into several groups based on whether the tranche applied to TALF and was accepted, whether it applied and was rejected, or whether it did not apply using acceptance and rejection data from the Federal Reserve.

Results of this analysis are shown in Table 6. Specification (2) is similar to specification (4) of Table 5 with the additional of the delinquency variables. All of the coefficient signs and significant variables are the same as in the initial regression. Additionally, CMBS tranches 


\section{Table 6. Multivariate Analysis of TALF Participation, Tranche Structure, and Loan Performance}

This table presents the results of multivariate probit regressions on the relationship between TALF application and acceptance and tranche structure and performance. The sample is TALF-eligible legacy CMBS tranches. In specification (1), the dependent variable is equal to 1 if the tranche applied for TALF funding and 0 otherwise. In specification (2), the dependent variable is equal to 1 if the tranche was accepted into TALF and 0 otherwise. In specification (3), the dependent variable is equal to 1 if the tranche was accepted into TALF and 0 if it was rejected. In specification (4), the dependent variable is equal to 1 if the tranche was rejected from TALF and 0 if the tranche did not apply for TALF funding. Original Tranche Value is the dollar value of the tranche at origination. Amount Outstanding is the dollar value of the tranche outstanding as of June 2012. WAL is the weighted-average life of the underlying collateral at origination in years. Duration is the expected life of the tranche in years. Fixed is a dummy variable equal to 1 if the tranche has a fixed rate. Coupon is the coupon rate paid to holders of fixed rate tranches. WAC is the weighted-average coupon of the underlying collateral. Percent Deal is Original Tranche Value divided by Original Deal Value. Tranches is the total number of tranches in the deal. Private is a dummy variable equal to 1 if the tranche was a private placement. WALTV is the weightedaverage loan-to-value ratio of the underlying collateral. DSCR is the weighted-average debt-service coverage ratio of the underlying collateral. Loans is the total number of loans remaining in the collateral pool. Losses is the percentage of cumulative losses on the underlying collateral. Foreclosure is the percentage of loans in the collateral pool that are in foreclosure. REO is the percentage of loans in the collateral pool that are bank owned. Standard errors are reported in parentheses. $* * *, * *$ and $*$ indicate pvalues of $1 \%, 5 \%$, and $10 \%$, respectively. 
Table 6 (cont.)

\begin{tabular}{|c|c|c|c|c|}
\hline & $\begin{array}{l}\text { Applied vs. Didn't } \\
\text { Apply }\end{array}$ & $\begin{array}{l}\text { Accepted vs. Rejected } \\
\text { and Didn't Apply }\end{array}$ & $\begin{array}{l}\text { Accepted vs. } \\
\text { Rejected }\end{array}$ & $\begin{array}{l}\text { Rejected vs. Didn't } \\
\text { Apply }\end{array}$ \\
\hline & $(1)$ & $(2)$ & $(3)$ & $(4)$ \\
\hline$\overline{\text { Intercept }}$ & $\begin{array}{l}-7.536^{* *} \\
(3.281)\end{array}$ & $\begin{array}{l}-8.453^{* *} \\
(3.415)\end{array}$ & $\begin{array}{c}3.459 \\
(11.498)\end{array}$ & $\begin{array}{l}-7.281 \\
(6.947)\end{array}$ \\
\hline Original Tranche Value & $\begin{array}{l}0.407 * * * \\
(0.119)\end{array}$ & $\begin{array}{l}0.424 * * * \\
(0.126)\end{array}$ & $\begin{array}{l}3.829^{* *} \\
(1.845)\end{array}$ & $\begin{array}{c}-3.791 * * \\
(1.536)\end{array}$ \\
\hline Amount Outstanding & $\begin{array}{c}0.018 \\
(0.024)\end{array}$ & $\begin{array}{c}0.013 \\
(0.024)\end{array}$ & $\begin{array}{l}-4.54 * * \\
(1.901)\end{array}$ & $\begin{array}{l}4.27 * * * \\
(1.576)\end{array}$ \\
\hline$W A L$ & $\begin{array}{c}-0.415^{* * *} \\
(0.042)\end{array}$ & $\begin{array}{c}-0.454^{* * *} \\
(0.045)\end{array}$ & $\begin{array}{l}-0.083 \\
(0.189)\end{array}$ & $\begin{array}{c}-0.334^{* * *} \\
(0.11)\end{array}$ \\
\hline Duration & $\begin{array}{c}0.01 \\
(0.014)\end{array}$ & $\begin{array}{c}0.019 \\
(0.014)\end{array}$ & $\begin{array}{l}0.025 \\
(0.04)\end{array}$ & $\begin{array}{c}-0.0218 \\
(0.028)\end{array}$ \\
\hline Fixed & $\begin{array}{c}0.556 * * * \\
(0.161)\end{array}$ & $\begin{array}{c}0.631 * * * \\
(0.175)\end{array}$ & $\begin{array}{c}0.945^{*} \\
(0.572)\end{array}$ & $\begin{array}{c}0.44^{*} \\
(0.238)\end{array}$ \\
\hline Coupon & $\begin{array}{l}0.76^{* * *} \\
(0.266)\end{array}$ & $\begin{array}{c}1.056^{* * *} \\
(0.294)\end{array}$ & $\begin{array}{c}2.905^{* * *} \\
(1.096)\end{array}$ & $\begin{array}{c}0.039 \\
(0.164)\end{array}$ \\
\hline$W A C$ & $\begin{array}{c}-0.7973^{* *} \\
(0.331)\end{array}$ & $\begin{array}{c}-0.999 * * * \\
(0.352)\end{array}$ & $\begin{array}{c}-1.9169 \\
(1.18)\end{array}$ & $\begin{array}{l}-0.141 \\
(0.688)\end{array}$ \\
\hline Percent Deal & $\begin{array}{c}0.037 * * * \\
(0.009)\end{array}$ & $\begin{array}{c}0.037 * * * \\
(0.009)\end{array}$ & $\begin{array}{c}0.05 \\
(0.035)\end{array}$ & $\begin{array}{c}0.011 \\
(0.017)\end{array}$ \\
\hline Tranches & $\begin{array}{l}-0.001 \\
(0.013)\end{array}$ & $\begin{array}{l}-0.006 \\
(0.013)\end{array}$ & $\begin{array}{l}-0.045 \\
(0.043)\end{array}$ & $\begin{array}{c}0.011 \\
(0.027)\end{array}$ \\
\hline Private & $\begin{array}{c}-1.884^{* * *} \\
(0.708)\end{array}$ & $\begin{array}{c}-1.713 * * \\
(0.731)\end{array}$ & $\begin{array}{l}-6.157 \\
(301.5)\end{array}$ & $\begin{array}{l}-4.706 \\
(230.6)\end{array}$ \\
\hline WALTV & $\begin{array}{c}0.007 \\
(0.006)\end{array}$ & $\begin{array}{r}-0.0002 \\
(0.006)\end{array}$ & $\begin{array}{l}-0.021 \\
(0.017)\end{array}$ & $\begin{array}{l}0.025^{* *} \\
(0.011)\end{array}$ \\
\hline$D S C R$ & $\begin{array}{c}0.09 \\
(0.166)\end{array}$ & $\begin{array}{c}0.214 \\
(0.161)\end{array}$ & $\begin{array}{c}3.065^{*} \\
(1.784)\end{array}$ & $\begin{array}{l}-1.057 \\
(1.048)\end{array}$ \\
\hline Loans & $\begin{array}{c}0.001 \\
(0.001)\end{array}$ & $\begin{array}{c}0.001 \\
(0.001)\end{array}$ & $\begin{array}{r}-0.0001 \\
(0.003)\end{array}$ & $\begin{array}{l}-0.0005 \\
(0.002)\end{array}$ \\
\hline Losses & $\begin{array}{c}0.067^{*} \\
(0.037)\end{array}$ & $\begin{array}{l}0.098^{* *} \\
(0.039)\end{array}$ & $\begin{array}{c}0.201^{*} \\
(0.113)\end{array}$ & $\begin{array}{c}0.012 \\
(0.086)\end{array}$ \\
\hline Foreclosure & $\begin{array}{c}0.019 \\
(0.016)\end{array}$ & $\begin{array}{c}0.015 \\
(0.018)\end{array}$ & $\begin{array}{c}0.004 \\
(0.043)\end{array}$ & $\begin{array}{c}0.014 \\
(0.026)\end{array}$ \\
\hline$R E O$ & $\begin{array}{c}0.003 \\
(0.018)\end{array}$ & $\begin{array}{c}0.018 \\
(0.019)\end{array}$ & $\begin{array}{c}0.121^{*} \\
(0.065)\end{array}$ & $\begin{array}{l}-0.051 \\
(0.039)\end{array}$ \\
\hline Time Fixed Effect & Yes & Yes & Yes & Yes \\
\hline Obs. & 995 & 995 & 207 & 814 \\
\hline
\end{tabular}


funded by TALF belong to deals with a higher percentage of losses than non-funded tranches. This does not mean there were necessarily losses on the TALF-funded tranche, just that there were losses on the collateral underlying the tranche. This suggests that tranches that participated in the program may be riskier. However, there is no difference in loan-to-value ratios, debtservice coverage ratios, or the percentages of properties that are in foreclosure or are bankowned, implying that these two groups of securities have similar risk profiles. Additionally, even after accounting for delinquency variables, the role of tranche structure, in terms of size and percent of the entire deal, remain highly significant. Therefore, even though TALF-funded tranches are somewhat riskier, there are additional factors beyond risk, including ambiguity and leverage, which determine participation in the program as well.

It is interesting to see that the accepted tranches come from deals with higher losses and higher percentages of bank-owned properties relative to rejected tranches. It is unclear exactly how the Federal Reserve chose which tranches would be accepted into the program, but intuitively it seems like they would reject the riskier tranches to protect themselves from potential losses. Consistent with that hypothesis, Campbell, Covitz, Nelson, and Pence (2011) show that accepted tranches have lower yields than rejected tranches. However, despite higher losses, I find that accepted tranches have higher debt-service coverage ratios, which suggests these tranches are more likely to be repaid. Therefore, it is inconclusive whether rejected tranches are in fact riskier than accepted tranches or not. The data also show that rejected tranches are smaller tranches with lower coupons.

\subsection{Security-Level vs. Market-Level Effects}

The three channels through which TALF can operate also have different implications on the reach of TALF's effect. In particular, if TALF serves to reduce risk, it will only have a 
security-level benefit on the particular ABS that is being funded. Even if two ABS have similar risk profiles, only the one being funded by TALF will have lower risk as a result of the nonrecourse provision. On the contrary, if TALF is increasing participation through leverage, this will benefit all ABS in the market. Even unfunded securities will be more attractive to investors since the market as a whole is more liquid.

The effect of the ambiguity channel lies somewhere in between. On one hand, the specific security being funded by TALF will benefit from lower ambiguity given the threshold on losses the investor faces. However, the program as a whole gives the market a signal about the quality of the eligible securities. The fact that the Federal Reserve is willing to offer these nonrecourse loans has positive implications about the value of the securities. This is especially true among newly issued ABS, which initially did not have to go through any additional screening process - as long as they were AAA-rated, they qualified for the program. Unlike the case with risk, the mere fact that a security is eligible for the program reduces its ambiguity since it signals to investors that the worst-case outcome they should consider is a loss in the amount of the haircut. ${ }^{25}$ Therefore, TALF has market-level benefits of reducing ambiguity for all eligible securities, not just security-level benefits for those directly funded in the program. However, the effect on a funded security will be stronger than the effect on a non-funded security since TALF funding provides a guaranteed maximum loss, while it is still possible for a non-funded security to lose more.

Several papers in the TALF literature look at the impact of TALF on yields at the security-level. Ashcraft, Garleanu, and Pedersen (2010) show that there is little effect on yield spreads when a security is accepted into TALF and a significant but temporary increase in yield

\footnotetext{
${ }^{25}$ This is assuming ambiguity is severe enough that the worst-case loss considered by investors is worse than the loss of the haircut. If not, the introduction of TALF loans does not reduce ambiguity.
} 
spreads upon rejection. The effect of rejection was largest in the beginning of the program when liquidity constraints were more binding. Likewise, Campbell, Covitz, Nelson, and Pence (2011) find little impact on pricing when a security was accepted to or rejected from TALF. However, when looking at market-level responses to TALF, they find that announcements about the program do have a significant impact on market spreads.

This evidence implies that the market-level impact of TALF was more significant than the security-level impact. The fact that issuance of securities not funded by TALF began to increase around the same time TALF began further supports the role of the market-level effect. As shown in Table 3, there is a significant portion of ABS tranches issued during the time of TALF that did not actually participate in the program. This suggests that TALF benefited the entire securitization market, not just the securities it directly funded. Therefore, TALF is mostly effective by reducing of ambiguity and increasing in participation through the provision of leverage. 


\section{CHAPTER 10}

\section{CONCLUSION}

This dissertation studies the impact of ambiguity securitization markets both theoretically and empirically. I first present a model of financial intermediation in which securitization markets can freeze or at least suffer a significant decrease in volume when investors are ambiguity averse. In cases where ambiguity is high, the probability of the state with ambiguity occurring is high, or expected payoffs are low, securitization is significantly reduced when the state in which investors face ambiguity is realized. However, when ambiguity is mild or the returns to securitization are high, banks will opt to originate more loans. This may force banks to sell their loans at fire sale prices when the state with ambiguity is realized given that the banks' debt constraint is now binding. Therefore, the presence of ambiguity can explain both market freezes and fire sales. The potential for ambiguity aversion among investors also causes a decrease in the number of loans that banks are willing to undertake in all cases. As a result, there are both financial and real economic consequences to ambiguity in securitization markets. Additionally, the presence of ambiguity averse investors can help explain both the timing and duration of the freeze in securitization markets seen during the 2008 financial crisis in a way that existing theories cannot.

Measures which reduce ambiguity, either by reducing the worst-case outcome considered by investors or by reducing the probability that the state in which ambiguity is present occurs, can ameliorate conditions in both the real economy and in the securitization markets. By reducing ambiguity ex ante, more loans will be undertaken by the bank, since there will be better 
prospects for selling those loans as securities. Ambiguity can also be reduced ex post once the state with ambiguity is realized. Improving the worst-case outcome considered by ambiguity averse investors can encourage banks to securitize their loans and revive trading in securitization markets. This can have the added benefit of freeing up capital with which banks can originate more new loans, in turn stimulating the real economy as well. Given the nature of ambiguity, small changes in the level of ambiguity can have large impacts on both origination and securitization outcomes.

Using the theoretical model as motivation, the empirical analyses of this dissertation examine the effects of the 2008 financial crisis on the structure of securitization tranches. During the crisis, securitization deals have fewer, larger tranches relative to their structure both before and after the crisis. In the CMBS market, there are significantly fewer AAA-rated tranches, indicative of the increased risk in mortgage-related markets. However, the ABS market has an increase in highly-rated tranches during the crisis. This is consistent with the result of Anderson (2012), which suggests that issuers will create a larger safe tranche during times of increased ambiguity to induce more investors to participate.

The Federal Reserve created a program called TALF to provide nonrecourse loans to investors in highly-rated securitization tranches during the crisis. I find evidence that TALFfunded legacy CMBS tranches are larger and more subordinated than TALF-eligible tranches that did not participate in the program, suggesting they have higher ambiguity. Additionally, they have higher losses, suggesting higher risk, and higher coupons, suggesting an increase in levered investors. In the ABS market, there is mixed evidence on the reduction of ambiguity, but limited support for the role of leverage. Overall, there is moderate support for each of the three channels through which TALF could support the market - reducing risk, reducing ambiguity, and 
inducing investor participation through leverage. However, the market-level impacts of TALF suggest that reducing ambiguity and increasing leverage were the primary factors that made TALF so effective in restarting the securitization markets. 


\section{APPENDIX}

Proof of Proposition 1. The maximization problem faced by the bank at time 0 , given in equation (14), can be restated with the following Lagrangian equation

$$
\begin{aligned}
L=(1+i)(1 & -\alpha) N\left(\widehat{V}-(1-\alpha) N \gamma \sigma^{2}\right)+\alpha N \widehat{V}-N-r D+\lambda_{1}\left[E_{0}+D-N\right] \\
& +\lambda_{2}\left[E_{0}+D-N+(1-\alpha) N\left(\widehat{V}-(1-\alpha) N \gamma \sigma^{2}\right)\right. \\
& -(1+r) D]
\end{aligned}
$$

where $\lambda_{1}$ and $\lambda_{2}$ are the Lagrangian multipliers corresponding to the budget constraint and the riskless debt constraint, respectively.. Solving this equation yields the following Kuhn-Tucker first-order conditions:

$$
\begin{array}{r}
(1+i)(1-\alpha) \widehat{V}-2(1+i)(1-\alpha)^{2} N \gamma \sigma^{2}+\alpha \widehat{V}-1-\lambda_{1} \\
+\lambda_{2}\left[-1+(1-\alpha) \widehat{V}-2(1-\alpha)^{2} N \gamma \sigma^{2}\right]=0 \\
-(1+i) N \widehat{V}+2(1+i)(1-\alpha) N^{2} \gamma \sigma^{2}+N \widehat{V}+\lambda_{2}\left[-N \widehat{V}+2(1-\alpha) N^{2} \gamma \sigma^{2}\right]=0 \\
-r+\lambda_{1}+\lambda_{2}(1-(1+r))=0 \\
\lambda_{1}\left[E_{0}+D-N\right]=0 \\
\lambda_{2}\left[E_{0}+D-N+(1-\alpha) N\left(\widehat{V}-(1-\alpha) N \gamma \sigma^{2}\right)-(1+r) D\right]=0
\end{array}
$$

The solution has 4 possible cases.

(i) Neither constraint is binding

From (A.3),

$$
\alpha=1-\frac{i \widehat{V}}{2(1+i) N \gamma \sigma^{2}}
$$


Plugging (A.7) into (A.2), given that $\lambda_{1}=0$ and $\lambda_{2}=0$ from (A.5) and (A.6), respectively, yields $\widehat{V}=1$. If $\widehat{V} \geq 1, N$ should be maximized, which contradicts constraint 1 not binding. If $\widehat{V}<1, N=0$ at the optimum. Therefore, $D_{N A}=0$, and $\alpha_{N A}=1$.

(ii) Constraint 1 binds, constraint 2 does not

From (A.5),

$$
N=E_{0}+D
$$

From (A.3),

$$
\alpha=1-\frac{i \widehat{V}}{2(1+i) N \gamma \sigma^{2}}
$$

Equation (A.4) yields the following Lagrangian multiplier

$$
\lambda_{1}=r
$$

Plugging (A.9) and (A.10) into (A.2) yields $\widehat{V}=1+r$. When $\widehat{V}>(1+r), N$ should be maximized, which contradicts constraint 2 not binding. Therefore, this case is only applicable when $\widehat{V} \leq(1+r)$. Here, any combination of $N$ and $\alpha \in[\underline{\alpha}, 1]$ satisfying (A.9) will be optimal.

\section{Constraint 2 binds, constraint 1 does not}

This case is not feasible. If constraint 1 is slack, the optimal choice of $D$ is 0 since there is no reason to take on costly deposits when the bank has remaining equity. Since constraint 1 is not binding, $E_{0}-N>0$. Therefore, to satisfy (A.6), we need $(1-\alpha) N(\widehat{V}-$ $\left.(1-\alpha) N \gamma \sigma^{2}\right)<0$. Since price is always positive, this requires $\alpha>1$, which is not 
feasible given that $\alpha$ is a fraction bounded above by 1 . Therefore, constraint 2 cannot bind before constraint 1 .

(iv) Both constraints bind

From (A.5),

$$
N=E_{0}+D
$$

From (A.6),

$$
\alpha=1-\frac{\widehat{V}-\sqrt{\widehat{V}^{2}-4 \gamma \sigma^{2}(1+r)\left(N-E_{0}\right)}}{2 N \gamma \sigma^{2}}
$$

Equations (A.3) and (A.4), respectively, yield the following expressions for the Lagrangian multipliers

$$
\begin{gathered}
\lambda_{2}=\frac{2(1+i)(1-\alpha) N \gamma \sigma^{2}-i \widehat{V}}{\widehat{V}-2(1-\alpha) N \gamma \sigma^{2}} \\
\lambda_{1}=r\left(1+\lambda_{2}\right)
\end{gathered}
$$

Plugging (A.13) and (A.14) into (A.2) yields

$$
\alpha=1-\frac{\widehat{V}(\widehat{V}+(i-1)(1+r))}{2 N \gamma \sigma^{2}(\widehat{V}+i(1+r))}
$$

From (A.12), (A.15), and (A.11), the bank's optimal origination and borrowing decisions can be determined, as follows, provided $\alpha \geq \underline{\alpha}$.

$$
\begin{gathered}
N=E_{0}+\frac{\widehat{V}^{2}(\widehat{V}+i(1+r))^{2}-(\widehat{V}(1+r))^{2}}{4 \gamma \sigma^{2}(1+r)(\widehat{V}+i(1+r))^{2}} \\
D=\frac{\widehat{V}^{2}(\widehat{V}+i(1+r))^{2}-(\widehat{V}(1+r))^{2}}{4 \gamma \sigma^{2}(1+r)(\widehat{V}+i(1+r))^{2}}
\end{gathered}
$$

If $\alpha$ is limited by $\underline{\alpha}$, the optimal $N$ is determined by setting (A.12) equal to $\underline{\alpha}$. This yields 


$$
N(\underline{\alpha})=\frac{(1-\underline{\alpha}) \hat{V}-(1+r)+\sqrt{(-(1-\underline{\alpha}) \hat{V}+(1+r))^{2}-4 \gamma \sigma^{2}(1-\underline{\alpha})^{2}(1+r) E_{0}}}{2(1-\underline{\alpha}) \gamma \sigma^{2}}
$$

The more loans the bank originates, the more it must sell to meet its debt constraint. Therefore, when retention is at its minimum $\underline{\alpha}$, origination is at its maximum. That is, $N(\underline{\alpha})$, as defined in (A.18), is greater than $N$, as defined in (A.16) when $\alpha>\underline{\alpha}$.

When $\widehat{V}>(1+r)$, the optimal solution is always case $(i v)$. This is the case I focus on since it is logical that the return on the risky loans is greater than the return on riskless debt. However, this is not necessarily the case. If $\widehat{V}<1$, the expected return to creating a new loan is less than the cost and the bank will opt not to originate any loans. The trivial solution of $N=0, D=0$, and $\alpha=1$ will prevail for any model parameters. This is case $(i)$. When $1 \leq \hat{V} \leq(1+r)$, both case (ii) and case (iv) are possible.

The threshold between case (ii) and case (iv) when $1 \leq \hat{V} \leq(1+r)$ is determined by plugging (A.9) and $\underline{\alpha}$ into constraint 2 . This gives the threshold

$$
V^{*}=\frac{i(1+i)(1+r)-(1+i) \sqrt{(i(1+r))^{2}-4 \gamma \sigma^{2}(1+i)(1-\underline{\alpha})^{2}(1+r) E_{0}}}{i(2+1)(1-\underline{\alpha})}
$$

When $\widehat{V}>V^{*}$, loans are more valuable so the bank will originate more. This will require more deposits, which will lead the bank's debt constraint to bind. This is case (iv). On the other hand, when $\widehat{V} \leq V^{*}$, the bank originates fewer loans and the debt constraint will not bind. This is case (ii). 
Proof of Proposition 2. The maximization problem faced by the bank at time 0 , given in equation (15), can be restated with the following Lagrangian equation

$$
\begin{aligned}
L=\theta[(1+i)( & \left.\left.1-\alpha_{H}\right) N\left(\hat{V}-\left(1-\alpha_{H}\right) N \gamma \sigma^{2}\right)+\alpha_{H} N \hat{V}\right] \\
& +(1-\theta)\left[(1+i)\left(1-\alpha_{L}\right) N\left(\underline{V}-\left(1-\alpha_{L}\right) N \gamma \sigma^{2}\right)+\alpha_{L} N \hat{V}\right]-N-r D \\
& +\lambda_{1}\left[E_{0}+D-N\right] \\
& +\lambda_{2}\left[E_{0}+D-N+\left(1-\alpha_{H}\right) N\left(\hat{V}-\left(1-\alpha_{H}\right) N \gamma \sigma^{2}\right)-(1+r) D\right] \\
& +\lambda_{3}\left[E_{0}+D-N+\left(1-\alpha_{L}\right) N\left(\underline{V}-\left(1-\alpha_{L}\right) N \gamma \sigma^{2}\right)\right. \\
& -(1+r) D]
\end{aligned}
$$

where $\lambda_{1}, \lambda_{2}$, and $\lambda_{3}$ are the Lagrangian multipliers corresponding to the budget constraint, the riskless debt constraint in state $H$, and the riskless debt constrain in state $L$, respectively. Solving this equation yields the following Kuhn-Tucker first-order conditions:

$$
\begin{aligned}
& \theta\left[(1+i)\left(1-\alpha_{H}\right) \hat{V}-2(1+i)\left(1-\alpha_{H}\right)^{2} N \gamma \sigma^{2}+\alpha_{H} \hat{V}\right] \\
&+(1-\theta)\left[(1+i)\left(1-\alpha_{L}\right) \underline{V}-2(1+i)\left(1-\alpha_{L}\right)^{2} N \gamma \sigma^{2}+\alpha_{L} \widehat{V}\right]-1-\lambda_{1} \\
&+\lambda_{2}\left[-1+\left(1-\alpha_{H}\right) \hat{V}-2\left(1-\alpha_{H}\right)^{2} N \gamma \sigma^{2}\right] \\
&+\lambda_{3}\left[-1+\left(1-\alpha_{L}\right) \hat{V}-2\left(1-\alpha_{L}\right)^{2} N \gamma \sigma^{2}\right]=0 \\
& \theta\left[-(1+i) N \hat{V}+2(1+i)\left(1-\alpha_{H}\right) N^{2} \gamma \sigma^{2}+N \hat{V}+\lambda_{2}\left[-N \widehat{V}+2\left(1-\alpha_{H}\right) N^{2} \gamma \sigma^{2}\right]\right]=0 \\
&(1-\theta)\left[-(1+i) N \underline{V}+2(1+i)\left(1-\alpha_{L}\right) N^{2} \gamma \sigma^{2}+N \hat{V}+\lambda_{3}\left[-N \underline{V}+2\left(1-\alpha_{L}\right) N^{2} \gamma \sigma^{2}\right]\right]=0 \\
& \lambda_{1}\left[E_{0}+D-N\right]=0 \\
& \lambda_{2}\left[E_{0}+D-N+\left(1-\alpha_{H}\right) N\left(\hat{V}-\left(1-\alpha_{H}\right) N \gamma \sigma^{2}\right)-(1+r) D\right]=0 \\
& \lambda_{3}\left[E_{0}+D-N+\left(1-\alpha_{L}\right) N\left(\underline{V}-\left(1-\alpha_{L}\right) N \gamma \sigma^{2}\right)-(1+r) D\right]=0
\end{aligned}
$$

The solution has 8 possible cases, some of which are not feasible. 
(i) None of the constraints are binding

From (A.22),

$$
\alpha_{H}=1-\frac{i \widehat{V}}{2(1+i) N \gamma \sigma^{2}}
$$

From (A.23),

$$
\alpha_{L}=1-\frac{(1+i) \underline{V}-\hat{V}}{2(1+i) N \gamma \sigma^{2}}
$$

Plugging (A.28) and (A.29) into (A.21), given that $\lambda_{1}=\lambda_{2}=\lambda_{3}=0$ from (A.25), (A.26), and (A.27), respectively, yields $\widehat{V}=1$. If $\widehat{V} \geq 1, N$ should be maximized, which contradicts constraint 3 not binding. If $\widehat{V}<1, N=0$ at the optimum. Therefore, $D=0, \alpha_{H}=1$, and $\alpha_{L}=1$

(ii) Constraint 2 binds, constraints 1 and 3 do not

This case is not feasible. If constraint 1 is slack, the optimal choice of $D$ is 0 since there is no reason to take on costly deposits when the bank has remaining equity. Therefore, when constraint 2 is binding, we have

$$
E_{0}-N+\left(1-\alpha_{H}\right) N\left(\widehat{V}-\left(1-\alpha_{H}\right) N \gamma \sigma^{2}\right)=0
$$

Since constraint 1 is not binding, $E_{0}-N>0$. Therefore, to satisfy (A.26), we need $\left(1-\alpha_{H}\right) N\left(\widehat{V}-\left(1-\alpha_{H}\right) N \gamma \sigma^{2}\right)<0$. Since price is always positive, this requires $\alpha_{H}>1$, which is not feasible given that $\alpha_{H}$ is a fraction bounded above by 1 . Therefore, constraint 2 cannot bind before constraint 1 .

(iii) Constraint 3 binds, constraints 1 and 2 do not 
By the same logic as shown in case $(i i)$, this case is not feasible.

(iv) Constraint 1 binds, constraints 2 and 3 do not

From (A.25),

$$
N=E_{0}+D
$$

From (A.22),

$$
\alpha_{H}=1-\frac{i \widehat{V}}{2(1+i) N \gamma \sigma^{2}}
$$

From (A.23),

$$
\alpha_{L}=1-\frac{(1+i) \underline{V}-\widehat{V}}{2(1+i) N \gamma \sigma^{2}}
$$

Equation (A.24) yields the following Lagrangian multiplier

$$
\lambda_{1}=r
$$

Plugging (A.32) and (A.33) into (A.21) yields $\widehat{V}=1+r$. When $\widehat{V}>(1+r), N$ should be maximized, which contradicts constraints 2 or 3 not binding. Therefore, this case is only applicable when $\widehat{V} \leq(1+r)$. Here, any combination of $N$ and $\left(\alpha_{H}, \alpha_{L}\right) \in[\underline{\alpha}, 1]$ satisfying (A.32) and (A.33) will be optimal.

(v) Constraints 2 and 3 bind, constraint 1 does not By the same logic as shown in case $(i i)$, this case is not feasible.

(vi) Constraints 1 and 2 bind, constraint 3 does not 
From (A.25),

$$
N=E_{0}+D
$$

From (A.26),

$$
\alpha_{H}=1-\frac{\widehat{V}-\sqrt{\hat{V}^{2}-4 \gamma \sigma^{2}\left(N-E_{0}+r D\right)}}{2 N \gamma \sigma^{2}}
$$

From (A.23),

$$
\alpha_{L}=1-\frac{(1+i) \underline{V}-\hat{V}}{2(1+i) N \gamma \sigma^{2}}
$$

Equations (A.22) and (A.24), respectively, yield the following expressions for the Lagrangian multipliers

$$
\begin{gathered}
\lambda_{2}=\frac{\theta\left[2(1+i)\left(1-\alpha_{L}\right) N \gamma \sigma^{2}-i \widehat{V}\right]}{\widehat{V}-2\left(1-\alpha_{L}\right) N \gamma \sigma^{2}} \\
\lambda_{1}=r\left(1+\lambda_{2}\right)
\end{gathered}
$$

Plugging (A.37), (A.38), and (A.39) into (A.21) yields

$$
\alpha_{H}=1-\frac{\widehat{V}(\widehat{V}+(1+r)(1-(1+i) \theta))-\theta(1+r) \widehat{V}}{2 N \gamma \sigma^{2}(\widehat{V}+(1+r)(1-(1+i) \theta))}
$$

From (A.35), (A.36), and (A.40), the bank's optimal origination and borrowing decisions can be determined, as follows, provided $\alpha \geq \underline{\alpha}$.

$$
N=E_{0}+\frac{\widehat{V}^{2}(\widehat{V}+(1+r)(1-(1+i) \theta))^{2}-(\theta(1+r) \widehat{V})^{2}}{4 \gamma \sigma^{2}(1+r)(\widehat{V}+(1+r)(1-(1+i) \theta))^{2}}
$$

Given that constraint 1 and 2 bind, but constraint 3 does not, this requires

$$
(1+r) D=\left(1-\alpha_{H}\right) N\left(\widehat{V}-\left(1-\alpha_{H}\right) N \gamma \sigma^{2}\right)<\left(1-\alpha_{L}\right) N\left(\hat{V}-\left(1-\alpha_{L}\right) N \gamma \sigma^{2}\right)
$$

Plugging (A.36), (A.37), and (A.41) into (A.42) yields 


$$
\widehat{V}^{2}-\frac{\theta^{2}(1+r)^{2} \widehat{V}^{2}}{(\widehat{V}+(1+r)(1-(1+i) \theta))^{2}}<\underline{V}^{2}-\frac{\widehat{V}^{2}}{(1+i)^{2}}
$$

This inequality does not hold for any parameter values, meaning case (vi) is not feasible. The debt constraint in state $L$ always binds before the debt constraint in state $H$.

(vii) Constraints 1 and 3 bind, constraint 2 does not

From (A.25),

$$
N=E_{0}+D
$$

From (A.22),

$$
\alpha_{H}=1-\frac{i \widehat{V}}{2(1+i) N \gamma \sigma^{2}}
$$

From (A.27),

$$
\alpha_{L}=1-\frac{\underline{V}-\sqrt{\underline{V}^{2}-4 \gamma \sigma^{2}\left(N-E_{0}+r D\right)}}{2 N \gamma \sigma^{2}}
$$

Equations (A.23) and (A.24), respectively, yield the following expressions for the Lagrangian multipliers

$$
\begin{gathered}
\lambda_{3}=\frac{(1-\theta)\left[2(1+i)\left(1-\alpha_{L}\right) N \gamma \sigma^{2}+\widehat{V}-(1+i) \underline{V}\right]}{\underline{V}-2\left(1-\alpha_{L}\right) N \gamma \sigma^{2}} \\
\lambda_{1}=r\left(1+\lambda_{3}\right)
\end{gathered}
$$

Plugging (A.45), (A.47), and (A.48) into (A.21) yields

$$
\alpha_{L}=1-\frac{V}{(\widehat{V}+(1+r)(1-(1+i)(1-\theta)))-(1-\theta)(1+r) \widehat{V}}
$$

From (A.44), (A.46), and (A.49), the bank's optimal origination and borrowing decisions can be determined, as follows, provided $\alpha \geq \underline{\alpha}$. 


$$
\begin{gathered}
N=E_{0}+\frac{\underline{V}^{2}(\widehat{V}+(1+r)(1-(1+i)(1-\theta)))^{2}-((1-\theta)(1+r) \widehat{V})^{2}}{4 \gamma \sigma^{2}(1+r)(\widehat{V}+(1+r)(1-(1+i)(1-\theta)))^{2}} \\
D=\frac{\underline{V}^{2}(\widehat{V}+(1+r)(1-(1+i)(1-\theta)))^{2}-((1-\theta)(1+r) \widehat{V})^{2}}{4 \gamma \sigma^{2}(1+r)(\widehat{V}+(1+r)(1-(1+i)(1-\theta)))^{2}}
\end{gathered}
$$

(viii) All constraints bind

From (A.25),

$$
N=E_{0}+D
$$

From (A.26),

$$
\alpha_{H}=1-\frac{\widehat{V}-\sqrt{\hat{V}^{2}-4 \gamma \sigma^{2}\left(N-E_{0}+r D\right)}}{2 N \gamma \sigma^{2}}
$$

From (A.27),

$$
\alpha_{L}=1-\frac{V-\sqrt{\underline{V}^{2}-4 \gamma \sigma^{2}\left(N-E_{0}+r D\right)}}{2 N \gamma \sigma^{2}}
$$

Equations (A.22), (A.23), and (A.24), respectively, yield the following expressions for the Lagrangian multipliers

$$
\begin{gathered}
\lambda_{2}=\frac{\theta\left[2(1+i)\left(1-\alpha_{H}\right) N \gamma \sigma^{2}-i \widehat{V}\right]}{\widehat{V}-2\left(1-\alpha_{H}\right) N \gamma \sigma^{2}} \\
\lambda_{3}=\frac{(1-\theta)\left[2(1+i)\left(1-\alpha_{L}\right) N \gamma \sigma^{2}+\hat{V}-(1+i) \underline{V}\right]}{\underline{V}-2\left(1-\alpha_{L}\right) N \gamma \sigma^{2}} \\
\lambda_{1}=r\left(1+\lambda_{2}+\lambda_{3}\right)
\end{gathered}
$$

Plugging (A.52), (A.54), (A.55), (A.56), and (A.57) into (A.21) yields 


$$
\alpha_{H}=1-\frac{\widehat{V}}{2 N \gamma \sigma^{2}}-\frac{\theta(1+r) \widehat{V}}{2 N \gamma \sigma^{2}\left[\widehat{V}+i(1+r)-\frac{(1-\theta)(1+r) \widehat{V}}{\sqrt{\underline{V}^{2}-4 \gamma \sigma^{2}(1+r)\left(N-E_{0}\right)}}\right]}
$$

Setting (A.53) and (A.58) equal yields the bank's optimal origination decision.

When $\hat{V}>(1+r)$, the bank's optimal solution falls in either case (vii) or case (viii). Plugging $\alpha_{H}$ from case (vii), as defined by (A.45), into constraint 2 shows that, for the constraint to be slack, the following condition is required.

$$
N<E_{0}+\frac{2 i \widehat{V}^{2}+i^{2} \widehat{V}^{2}}{4(1+i)^{2}(1+r) \gamma \sigma^{2}}
$$

Setting (A.59) equal to (A.50) yields the following threshold on $\underline{V}$.

$$
\underline{V}^{*}=\hat{V} \sqrt{\frac{((1-\theta)(1+r)(1+i))^{2}+\left(2 i+i^{2}\right)(\hat{V}+i(1+r))^{2}}{(1+i)^{2}(\hat{V}+i(1+r))^{2}}}
$$

Therefore, when $\underline{V}<\underline{V}^{*}$, ambiguity is high, origination is low, and constraint 2 does not bind. However, when $\underline{V} \geq \underline{V}^{*}$, constraint 2 will bind as the bank is taking on more deposits to fund more loans in this lower ambiguity setting. 
Proof of Proposition 3. When there is no risk in the market, the bank's maximization problem at time 0 , given in equation (17), can be restated with the following Lagrangian equation

$$
\begin{aligned}
L=\theta\left[(1+i)\left(1-\alpha_{H}\right) N \hat{V}+\alpha_{H} N \hat{V}\right]+(1-\theta)\left[(1+i)\left(1-\alpha_{L}\right) N \underline{V}+\alpha_{L} N \hat{V}\right]-N-r D \\
+\lambda_{1}\left[E_{0}+D-N\right]+\lambda_{2}\left[E_{0}+D-N+\left(1-\alpha_{H}\right) N \hat{V}-(1+r) D\right] \\
+\lambda_{3}\left[E_{0}+D-N+\left(1-\alpha_{L}\right) N \underline{V}-(1+r) D\right]
\end{aligned}
$$

where $\lambda_{1}, \lambda_{2}$, and $\lambda_{3}$ are the Lagrangian multipliers corresponding to the budget constraint, the riskless debt constraint in state $H$, and the riskless debt constrain in state $L$, respectively. Solving this yields the following Kuhn-Tucker first-order conditions:

$$
\begin{aligned}
\theta\left[(1+i)\left(1-\alpha_{H}\right) \hat{V}+\alpha_{H} \hat{V}\right]+(1-\theta)\left[(1+i)\left(1-\alpha_{L}\right) \underline{V}+\alpha_{L} \hat{V}\right]-1-\lambda_{1} \\
+\lambda_{2}\left[-1+\left(1-\alpha_{H}\right) \hat{V}\right]+\lambda_{3}\left[-1+\left(1-\alpha_{L}\right) \hat{V}\right]=0 \\
\theta\left[-(1+i) N \hat{V}+N \hat{V}+\lambda_{2}[-N \hat{V}]\right]=0 \\
(1-\theta)\left[-(1+i) N \underline{V}+N \hat{V}+\lambda_{3}[-N \underline{V}]\right]=0 \\
-r+\lambda_{1}+r \lambda_{2}+r \lambda_{3}=0 \\
\lambda_{1}\left[E_{0}+D-N\right]=0 \\
\lambda_{2}\left[E_{0}+D-N+\left(1-\alpha_{H}\right) N \hat{V}-(1+r) D\right]=0 \\
\lambda_{3}\left[E_{0}+D-N+\left(1-\alpha_{L}\right) N \underline{V}-(1+r) D\right]=0
\end{aligned}
$$

First note that, in state $H$, the bank will always choose $\alpha_{H}=\underline{\alpha}$. When there is no risk, the price the bank receives does not decrease with quantity. Therefore, the bank can receive the full value $\widehat{V}$ for all securities it sells and then investment the proceeds in additional loans for an even higher return. 
Also note, that as shown in the case with both risk and ambiguity, the budget constraint always binds when $\widehat{V}>1$. Therefore, $N=E_{0}+D$.

Consider the case when constraint 3 binds, in addition to constraint 1. From (A.68), we have

$$
\alpha_{L}=1-\frac{(1+r)\left(N-E_{0}\right)}{N \underline{V}}
$$

Equations (A.64) and (A.65), respectively, yield the following expressions for the Lagrangian multipliers

$$
\begin{gathered}
\lambda_{3}=\frac{(1-\theta)(\widehat{V}-(1+i) \underline{V})}{\underline{V}} \\
\lambda_{1}=r\left(1+\lambda_{3}\right)
\end{gathered}
$$

Plugging (A.69), (A.70), and (A.71) into (A.62) yields

$$
1+r-\theta(1+i-\underline{\alpha} i) \hat{V}+(1-\theta)\left(-\hat{V}+\frac{\hat{V}-(1+i) \underline{V}}{\underline{V}}(1+r)\right)=0
$$

Solving (A.72) for $\underline{V}$ gives us the threshold

$$
V^{*}=\frac{(1-\theta)(1+r) \hat{V}}{(i \theta(1-\underline{\alpha})+1) \hat{V}+(1+r)(i-\theta-i \theta)}
$$

When $\underline{V}<V^{*}$, there is severe ambiguity in the market such that the bank will opt to retain everything in state $L$. That is, $\alpha_{L}=1$. However, if $\underline{V} \geq V^{*}$, the lower price received due to ambiguity is overweighed by the benefit of securitizing and investing in additional loans. Therefore, $\alpha_{L}=\underline{\alpha}$.

The alternative case is that constraint 3 does not bind. In this case, from (A.58), we obtain

$$
\underline{V}=\frac{\hat{V}}{(1+i)}
$$


That is, if $\underline{V}<\frac{\widehat{V}}{(1+i)}$, the bank will choose $\alpha_{L}=1$ and if $\underline{V} \geq \frac{\widehat{V}}{(1+i)}$, the bank will choose $\alpha_{L}=\underline{\alpha}$. Therefore, to determine if constraint 3 binds or not, we need to compare $\frac{\widehat{V}}{(1+i)}$ and $V^{*}$. This yields the required condition for constraint 3 to bind:

$$
\widehat{V}(1+\theta i(1-\underline{\alpha}))>1+r
$$

Intuitively, this condition will always hold under reasonable parameter values given that $\theta i(1-\underline{\alpha})>0$ and the return on the risky asset, $\widehat{V}$, should be greater than the return on riskless deposits, $1+r$.

Given that constraint 3 always binds, the optimal value for origination is solved by plugging $\alpha_{L}$ into (A.69) and solving for $N$. Likewise, $D$ is obtained from $N=E_{0}+D$. Specifically, we obtain

$$
N=\left\{\begin{array}{cl}
E_{0} & \text { if } \underline{V}<V^{*} \\
\frac{(1+r) E_{0}}{1+r-\left(1-\alpha_{L}\right) \underline{V}} & \text { if } \underline{V}<V^{*}
\end{array}\right.
$$




\section{REFERENCES}

Acharya, V. P., Schnabl, P., \& Suarez, G. (2011). Securitization without risk transfer. Journal of Financial Economics, forthcoming.

Agarwal, S. J., Barrett, C., Cun, C., \& De Nardi, M. (2010). The asset-backed securities markets, the crisis, and TALF. Federal Reserve Bank of Chicago Economic Perspectives, 34(4), 101-115.

Allen, F., \& Gale, D. (1994). Limited market participation and volatility of asset prices. The American Economic Review, 84(4), 933-955.

Anderson, A. G. (2012). Ambiguity in securitization markets. Working paper, Cornell University.

Ashcraft, A., Garleanu, N., \& Pedersen, L. H. (2010). Two monetary tools: Interest rates and haircuts. NBER Macroeconomics Annual, 25, 143-180.

Ashcraft, A., Malz, A., \& Pozsar, Z. (2012). The Federal Reserves's term asset-backed securities loan facility. Federal Reserve Bank of New York Economic Policy Review, 18(3), 29-66.

Badertscher, B. A., Banks, J. J., \& Easton, P. D. (2010). A convenient scapegoat: Fair value accounting by commercial banks during the financial crisis. Working paper, Notre Dame University.

Bhansali, V., \& Wise, M. B. (2009). How valuable are the TALF puts? Journal of Fixed Income, 19(2), 71-75.

Board of Governors of the Federal Reserve System. (2008, November 25). Press Release. Retrieved January 19, 2012, from Board of Governors of the Federal Reserve System: http://www.federalreserve.gov/newsevents/press/monetary/20081125a.htm

Board of Governors of the Federal Reserve System. (2011). Term Asset-Backed Securities Loan Facility (TALF). Retrieved January 19, 2012, from Board of Governors of the Federal Reserve System: http://www.federalreserve.gov/newsevents/reform_talf.htm

Board of Governors of the Federal Reserve System, \& U.S. Department of the Treasury. (2009, March 3). Joint Press Release. Retrieved January 19, 2012, from Board of Governors of the Federal Reserve System: 
http://www.federalreserve.gov/newsevents/press/monetary/20090303a.htm

Calomiris, C. W., \& Mason, J. R. (2004). Credit card securitization and regulatory arbitrage. Journal of Financial Services Research, 26(1), 5-27.

Campbell, S., Covitz, D., Nelson, W., \& Pence, K. (2011). Securitization markets and central banking: An evaluation of the Term Asset-Backed Securities Loan Facility. Journal of Monetary Economics, 58(5), 518-531.

Cao, H., Wang, T., \& Zhang, H. H. (2005). Model uncertainty, limited market participation and asset prices. Review of Financial Studies, 18, 1219-1251.

Coval, J., \& Stafford, E. (2007). Asset fire sales (and purchases) in equity markets. Journal of Financial Economics, 86(2), 479-512.

Coval, J., Jurek, J., \& Stafford, E. (2009). The economics of structured finance. Journal of Economic Perspectives, 23, 3-26.

Dang, T. V., Gorton, G., \& Holmstrom, B. (2010). Financial crises and the optimality of debt for liquidity provision. Working paper, Yale University.

DeMarzo, P. (2005). The pooling and tranching of securities: A model of informed intermediation. Review of Financial Studies, 18(1), 1-35.

DeMarzo, P., \& Duffie, D. (1990). A liquidity-based model of security design. Econometrica, 67(1), 65-99.

Demiroglu, C., \& James, C. (2012). How important is having skin in the game? Originatorsponsor affiliation and losses on mortgage-backed securities. Review of Financial Studies, forthcoming.

Diamond, D., \& Rajan, R. (2010). Fear of fire sales, illiquidity seeking and credit freezes. Working paper, University of Chicago.

Easley, D., \& O'Hara, M. (2009). Ambiguity and nonparticipation: The role of regulation. Review of Financial Studies, 22(5), 1817-1843.

Easley, D., \& O'Hara, M. (2010). Liquidity and valuation in an uncertain world. Journal of 
Financial Economics, 97, 1-11.

Ellsberg, D. (1961). Risk, ambiguity, and the Savage axioms. Quarterly Journal of Economics, $75,643-669$.

Epstein, L. G., \& Schneider, M. (2007). Learning under ambiguity. Review of Economic Studies, 74, 1275-1303.

Erel, I., Nadauld, T., \& Stulz, R. M. (2011). Why did U.S. banks invest in highly-rated securitization tranches? Working paper, Ohio State University.

Garlappi, L., Uppal, R., \& Wang, T. (2007). Portfolio selection with parameter and model uncertainty: A multi-prior approach. Review of Financial Studies, 20(1), 41-81.

Gennaioli, N., Shleifer, A., \& Vishny, R. (2011). A model of shadow banking. Working paper, Harvard University.

Gennaioli, N., Shleifer, A., \& Vishny, R. (2012). Neglected risks, financial innovation, and financial fragility. Journal of Financial Economics, 104, 452-468.

Gilboa, I., \& Schmeidler, D. (1989). Maxmin expected utility with non-unique prior. Journal of Mathematical Economics, 18(2), 141-153.

Guidolin, M., \& Rinaldi, F. (2009). A simple model of trading and pricing risky assets under ambiguity: Any lessons for policy-makers? Working paper, Federal Reserve Bank of St. Louis.

Guidolin, M., \& Rinaldi, F. (2010). Ambiguity in asset pricing and portfolio choice: A review of the literature. Working paper, Federal Reserve Bank of St. Louis.

Jiang, W., Nelson, A., \& Vytlacil, E. (2012). Securitization and loan performance: A contrast of ex ante and ex post relations in the mortgage market. Working paper, Columbia University.

Knight, F. (1921). Risk, Ambiguity, and Profit. Boston, MA: Houghton Mifflin.

Leitner, Y. (2011). Why do markets freeze? Federal Reserve Bank of Philadelphia Business Review, Q2, 12-19. 
Loutskina, E. (2011). The role of securitization in bank liquidity and funding management. Journal of Financial Economics, 100, 663-684.

Nadauld, T., \& Sherlund, S. M. (2009). The role of the securitization process in the expansion of subprime credit. Working paper, Brigham Young University and Federal Reserve Board of Governors.

Nelson, W. R. (2011, March 4). Term Asset-Backed Securities Loan Facility, Testimony before the Congressional Oversight Panel for the Troubled Asset Relief Program. Retrieved from Board of Governors of the Federal Reserve System: http://www.federalreserve.gov/newsevents/testimony/nelson20110304a.htm

Pagano, M., \& Volpin, P. (2010). Securitization, transparency, and liquidity. Working paper, London Business School.

Riddiough, T. J. (1997). Optimal design and governance of asset-backed securities. Journal of Financial Intermediation, 6, 121-152.

Sack, B. P. (2010, June). Reflections on the TALF and the Federal Reserve's role as liquidity provider. New York Association for Business Economics, New York, NY.

Savage, L. J. (1954). The Foundations of Statistics. New York, NY: John Wiley \& Sons.

Schmeidler, D. (1989). Subjective probability and expected utility without additivity. Econometrica, 57, 571-587.

Shin, H. S. (2009). Securitisation and financial stability. The Economic Journal, 119(March), 309-332.

Shleifer, A., \& Vishny, R. W. (2010). Asset fire sales and credit easing. American Economic Review: Papers and Proceedings, 100(2), 46-50.

Shleifer, A., \& Vishny, R. W. (2010). Unstable banking. Journal of Financial Economics, 97, 306-318.

Tirole, J. (2011). Illiquidity and all its friends. Journal of Economic Literature, 49(2), 287-325.

Uhlig, H. (2010). A model of a systemic bank run. Journal of Monetary Economics, 57, 78-96. 
von Neumann, J., \& Morgenstern, O. (1947). Theory of Games and Economic Behavior. Princeton, NJ: Princeton University Press.

Wilson, L. (2011). Toxic asset subsidies and the early redemption of TALF loans. Working paper, University of Louisiana at Lafayette.

Xu, M. (2012, July 25). Losses on US cash flow CLO tranches are infrequent. Moody's CLO Interest, pp. 4-6. 